\title{
Predictive factors of brachial plexus neuropathy in wrestling athletes: A prospective longitudinal study
}

Deena M. Dillard

West Virginia University

Follow this and additional works at: https://researchrepository.wvu.edu/etd

\section{Recommended Citation}

Dillard, Deena M., "Predictive factors of brachial plexus neuropathy in wrestling athletes: A prospective longitudinal study" (2006). Graduate Theses, Dissertations, and Problem Reports. 2451.

https://researchrepository.wvu.edu/etd/2451

This Thesis is protected by copyright and/or related rights. It has been brought to you by the The Research Repository @ WVU with permission from the rights-holder(s). You are free to use this Thesis in any way that is permitted by the copyright and related rights legislation that applies to your use. For other uses you must obtain permission from the rights-holder(s) directly, unless additional rights are indicated by a Creative Commons license in the record and/ or on the work itself. This Thesis has been accepted for inclusion in WVU Graduate Theses, Dissertations, and Problem Reports collection by an authorized administrator of The Research Repository @ WVU. For more information, please contact researchrepository@mail.wvu.edu. 
Predictive Factors of Brachial Plexus Neuropathy in Wrestling Athletes: A Prospective Longitudinal Study.

Deena M. Dillard, ATC

Thesis submitted to the School of Physical Education at West Virginia University in partial fulfillment of the requirements for the degree of

Master of Science

In

Physical Education

(Athletic Training)

Michelle A. Sandrey, Ph.D., ATC, Chair Mathew Lively, DO

Sam Zizzi, Ed.D.

School of Physical Education

Morgantown, West Virginia

2006

Key Words: brachial plexus neuropathy, wrestling, neck muscle strength 


\begin{abstract}
PREDICITVE FACTORS OF BRACHIAL PLEXUS NEUROPATHY IN WRESTLING ATHLETES.
\end{abstract}

\author{
Deena M. Dillard
}

Context: Brachial plexus neuropathies are prevalent within wrestling. Objective: The purpose was to examine possible predisposing factors to brachial plexus neuropathy. Design: This study was a prospective longitudinal study. Setting: An athletic training room at an Eastern Wrestling League University (EWL). Patients and Other Participants: Twenty-three collegiate wrestlers ranging in age from $19.83 \pm 1.62$ years volunteered to participate. Interventions: Neck strength, Head-neck segment, Head-neck length, and neck girth were measured. Previous history and number of years of wrestling were measured using a questionnaire. Main Outcome Measures: Neck strength and previous history may predispose wrestlers to brachial plexus neuropathy. Results: There was a main effect for neck strength in the directions of right and left lateral flexion for Time. All other analyses were not significant. Conclusion: Trends indicate that a larger sample size may allow effects to be noted. Further research is necessary to examine these possible effects. 


\section{ACKNOWLEDGMENTS}

First, and foremost, I would like to thank my family and the love of my life. Without your encouragement, never-ending optimism, and patience, I would not have completed this with any of my sanity left. I will always remember your words of encouragement. There are not enough words to describe how much you mean to me. Suffice it to say, I love you all very much and can never thank you enough for your support.

Without the support of the wrestling team and coaching staff, I would not have been able to do this study at all. I thank the wrestlers for their patience in reporting injuries, and participating in neck strength measurements before each dual match. I must also thank them for their patience in participating in this study over such a long time period. I would also like to thank the wrestling coaches for making every day interesting. I will always remember my two years of work with them.

I would like to thank Dr. Sandrey for enabling me to do a study that I was not only required to do, but also interested in as well. I thank her for her careful editing and insightful ideas. Her door was always open and she was always willing to talk about my questions.

I must thank Kevin Kotsko, Med, ATC for all of his support and mentoring throughout my two years at West Virginia University. Without his help, this study may have never been. I have never met a harder working individual. He constantly strives to learn more and pushed me to do the same. He has taught me more in my two years here than he realizes. Thank you for everything!

Amy Hile MS, ATC has made this study an enjoyable experience. She has been at West Virginia University for only one year however; within that year she has helped me retain my sanity. She was always there for me when I needed someone to talk to, thank you.

As with most students, I am indebted to Dr. Zizzi and his infinite wisdom of statistics and SPSS. Although SPSS and I formed a good relationship, without Dr. Zizzi, this would not have happened. Thank you for your patience and ability to explain complicated statistics in "English."

I must also thank Dr. Matt Lively. Without your support and incredible insight, this study would not be what it is today. I thank you for your help in developing the initial idea and for pushing me to finish the study when the going got tough.

I would like to thank the entire athletic training staff and students. The staff was willing to help me in all aspects, whether it was job hunting or athletic training issues. The students helped me to become a more proficient athletic trainer through my experiences as an $\mathrm{ACI}$. 
Finally, I must thank my roommates, Kyla, Tim, and Nate. Without the three of you to talk to and vent to, this past two years would have been incredibly tough. The three of you were instrumental in my ability to continue this task. Thank you for everything. 


\section{TABLE OF CONTENTS}

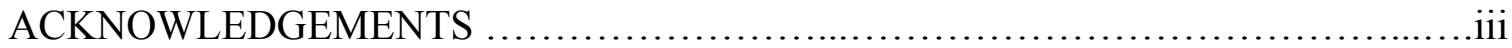

LIST OF TABLES …....................................................................

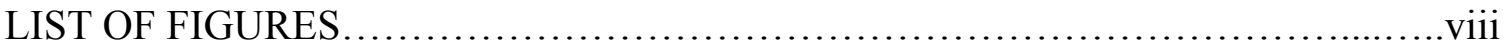

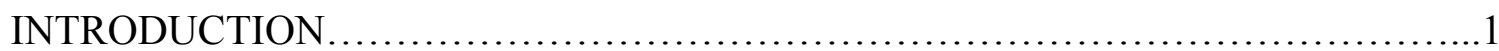

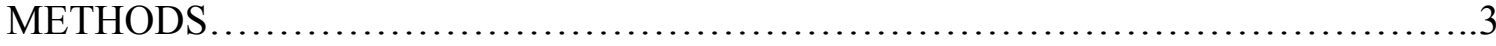

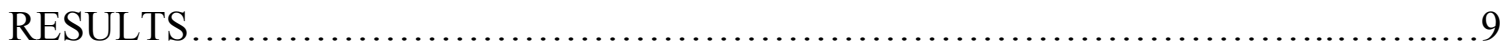

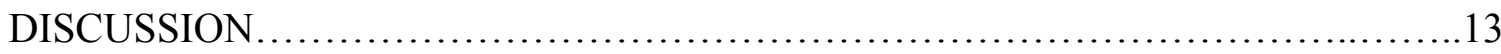

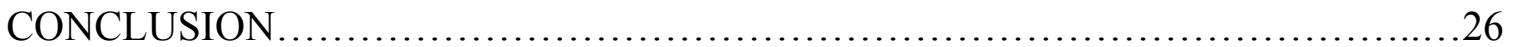

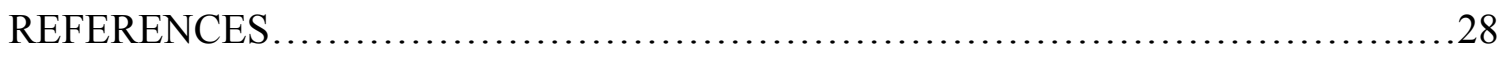

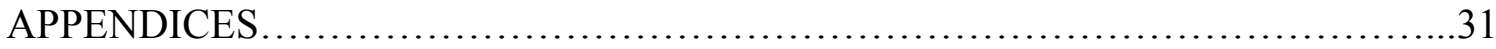

APPENDIX A. THE PROBLEM................................................32

APPENDIX B. LITERATURE REVIEW ...................................40

APPENDIX C. ADDITIONAL METHODS....................................71

APPENDIX D. ADDITIONAL RESULTS....................................90

APPENDIX E. RECOMMENDATIONS FOR FUTURE RESEARCH.........112

ADDITIONAL REFERENCES..................................................113 


\section{LIST OF TABLES}

Table

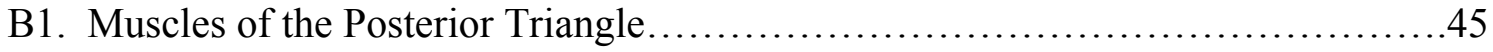

B2. Prevertebral Muscles................................................46

B3. Intrinsic Back Muscles...............................................47

B4. Nerves of the Brachial Plexus............................................49

B5. Muscles and Motions of the Occipitoatlantal and Atlantoaxial Joints.............53

B6. Muscles of Rotation at the Atlantoaxial Joint................................54

C1. Informed Consent................................................. 71

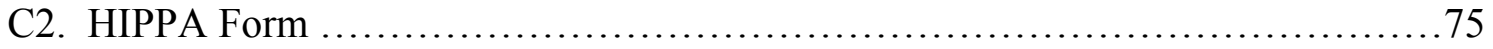

C3. Pre-Screening Questionnaire............................................ 77

C4. Neck Muscle Strength Procedure.......................................79

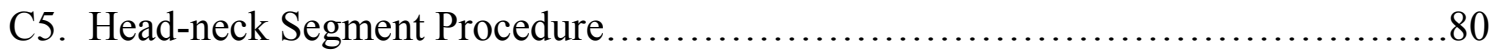

C6. Head-neck Length Procedure........................................... 81

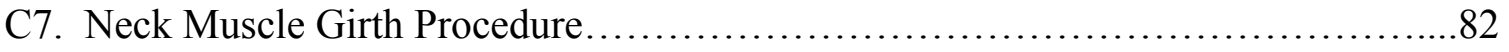

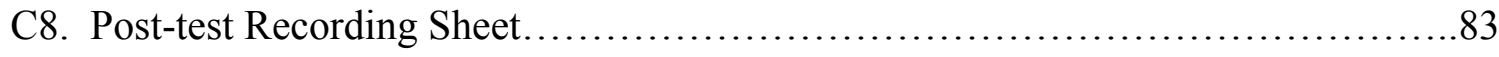

C9. Pre-Dual Match Neck Muscle Strength Sheet...................................84

C10.Injury Recording Worksheet........................................... 86

D1. Subject Demographic Means.........................................90

D2. Hand Dominance Frequencies....................................... 90

D3. Head-Neck Segment, Head-Neck Length \& Neck Girth Means...................91

D4. Means Between Injured and Non-Injured Wrestlers.........................91 
D5. Pre-Test Head-Neck Segment Frequencies.....................................92

D6. Post-Test Head-Neck Segment Frequencies.......................................93

D7. Pre-Test Head-Neck Length Frequencies........................................99

D8. Post-Test Head-Neck Length Frequencies....................................94

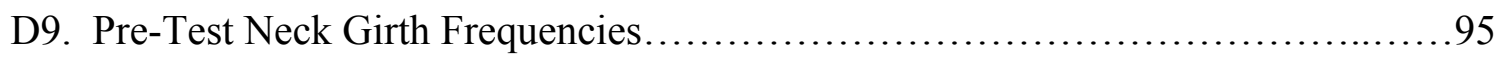

D10.Post-Test Neck Girth Frequencies......................................... 95

D11.Neck Strength Means........................................................ 96

D12.Pre-Test Neck Strength Frequencies - Forward Flexion...........................96

D13.Post-Test Neck Strength Frequencies - Forward Flexion..........................97

D14.Pre-Test Neck Strength Frequencies - Extension.................................98

D15.Post-Test Neck Strength Frequencies - Extension................................99

D16.Pre-Test Neck Strength Frequencies - Left Lateral Flexion.......................100

D17.Post-Test Neck Strength Frequencies - Left Lateral Flexion........................101

D18.Pre-Test Neck Strength Frequencies - Right Lateral Flexion....................102

D19.Post-Test Neck Strength Frequencies - Right Lateral Flexion......................103

D20.Two-Way Repeated-Measures ANOVA Results for Entire Sample.................104

D21.Two-Way Repeated-Measures ANOVA Results for the Starters..................104

D22.Independent t-test Results................................................ 105

D23.Crosstabulation Results (Previous History * Occurrence) ........................105

D24.Crosstabulation Results (Previous History * Occurrence this Season)..............105 


\section{LIST OF FIGURES}

Figure

B1. The Brachial Plexus................................................ 49

B2. Mechanism of Injury for a Brachial Plexus Neuropathy........................57

B3. Torg Ratio AB/D ..................................................6 60

C1. Neck Muscle Strength Procedure............................................ 88

D1. Neck Strength Measurements in the Direction of Forward Flexion................106

D2. Neck Strength Measurements in the Direction of Extension......................107

D3. Neck Strength Measurements in the Direction of Left Lateral Flexion.............108

D4. Neck Strength Measurements in the Direction of Right Lateral Flexion............109

D5. Pre-Dual Match Neck Strength Measurements of a Wrestler Experiencing

Multiple BPN Incidents.................................................110

D6. Pre-Dual Match Neck Strength Measurements of a Wrestler that did not Experience

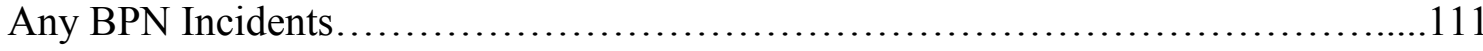




\section{INTRODUCTION}

Cervical spine injuries have often been the focus of research in football athletes. ${ }^{1-11}$ The specific etiology, epidemiology, diagnosis and management procedures have been documented. ${ }^{1-13}$ Of cervical spine injuries, brachial plexus neuropathies are common, non fatal, and occur quite frequently in football. ${ }^{1-11}$ As many as $50 \%$ to $65 \%$ of football players will suffer from brachial plexus neurapraxia at some point during their career. ${ }^{\text {Cramer, Shannon, Page }}$ Wrestling athletes experience this same injury many times throughout any given season. Usually, football athletes experience brachial plexus neuropathies in one single, more significant incident whereas wrestlers, based on observation, experience a greater number of less severe incidents within a shorter time span.

Wrestlers are exposed to a multitude of injuries within the collegiate setting. The majority of these injuries affect the musculoskeletal system, including the extremities as well as the spine. Severe injuries are evident in wrestling due to the nature of the sport. However, most cervical injuries involve cervical discs as well as the brachial plexus, which tend to occur more frequently and lead to chronic syndromes. Collegiate wrestlers experience disc herniations, which, in some cases can lead to cervical fusions. In addition, medical disqualifications and playing time absences due to this injury are becoming more prevalent. Wrestling athletes experience numerous episodes of brachial plexus neuropathies (BPN) throughout any given season. The initial occurrence of a brachial plexus neuropathy is bewildering to the athlete due to the previously unknown experience of numbness and paraesthesia. Whether resulting from multiple recurrences, anatomic or functional deficits, or due to inappropriate treatment and rehabilitation techniques, a more severe pathology may result. Unfortunately, the vast majority 
of the literature regarding brachial plexus neuropathies involves football athletes rather than wrestling athletes.

The literature also lacks information regarding predisposing factors of brachial plexus injury. The Torg ratio, a measurement of the ratio of the midsagittal diameter of the spinal canal to the vertebral body diameter, referring to the narrowing of the cervical spinal canal, is the most studied predictive factor for brachial plexus neuropathy. However, it has been documented that athletes with a smaller Torg ratio did not necessarily exhibit a higher injury rate compared to those athletes with a larger ratio. Degenerative changes may also play a role in leading to injury. These changes may narrow the spinal canal enabling compression of the nerve root during a hyperextension injury mechanism. Anthropometric measurements, on the other hand, have not been evaluated as extensively as anatomical variables. Tierney et al ${ }^{14}$ has proposed that headneck segment, head-neck length, and neck girth may be variables to consider in concussions. With wrestling being a sport that involves considerable neck movement, these variables need to be considered as possible predisposing factors in brachial plexus neuropathies. In addition, neck strength may also have an influence on the incidence of brachial plexus neuropathy. Increased neck strength may allow the muscles to absorb external loads applied to the neck to keep from becoming injured whereas decreased strength may allow for increased susceptibility to injury. "The ability of the myotendon unit to absorb external loads and minimize excessive joint movement" is defined as dynamic joint stabilization. ${ }^{14}$ The two primary stabilizers of the head and neck are the sternocleidomastoid and the trapezius. It is these muscles that must react in response to or before external forces are applied to decrease the resulting acceleration.

It is not known whether, or how, a change in muscle strength over time may affect the neck muscles' response to external forces. Several studies have examined neck strength, 
however, these studies have only examined neck strength at one time point. ${ }^{17-25}$ The roles of these factors in the predictability of brachial plexus neuropathy have yet to be examined therefore; it now becomes essential to examine possible factors that predispose wrestling athletes to brachial plexus neuropathies. The lack of literature regarding predisposing factors including injury history, anthropometric measurements, and strength changes over time make it imperative to conduct this study. The primary purpose of this study is to examine anthropometric measurements (head-neck segment, head-neck length, neck muscle girth), neck muscle strength, number of total years wrestling, and past history of burners in the occurrence of brachial plexus neuropathies within the sport of wrestling. The secondary purpose of this study is to provide documentation of the mechanism, incidence, and prevalence of brachial plexus neuropathies within the sport of wrestling.

\section{METHODS}

This study is a prospective, descriptive longitudinal study. Originally, a logistic regression was utilized to determine the probability of cervical burners or stingers based on the existence of specific predisposing factors. Independent variables were past history, head-neck segment, head-neck length, neck strength, neck muscle girth, and the number of years in wrestling participation. Past history exists on two levels, yes or no. Head-neck segment, headneck length, neck strength, neck muscle girth, and the number of years in wrestling participation are all objective measurements and were ratio level data. The dependant variable was brachial plexus neuropathy as assessed by a certified athletic trainer.

Subjects

This study started with 25 subjects, however two were excluded due to neck injury incurred prior to pre-test data collection. Therefore, a total of 23 Division I collegiate wrestlers 
from the Eastern Wrestling League (EWL) participated in this study. Nine subjects were freshman (39.1\%), six were sophomores (26.1\%), four were juniors $(17.4 \%)$, one was a senior (4.3\%), and three were fifth year seniors $(13.0 \%)$. The mean age was $19.83 \pm 1.62$ years. The age range for the subject population was 18-23 years of age.

Potential participants were presented with an informed consent form. There was not any inclusion criteria, and the only exclusion criteria was a previous history of neck surgery or neck pathology other than brachial plexus neuropathy. The Institutional Review Board (IRB) for the Protection of Human Subjects at West Virginia University approved this study. Instrumentation

Weight measurements were taken on an industrial sized digital scale; Panther (Mettler, Toledo, $\mathrm{OH}$ ). The scale is accurate to the $0.11 \mathrm{~b}$ and is calibrated yearly by Kanawha Scales \& Systems (Fairmont, WV) as per manufactures and NCAA specifications. This procedure requires the technician to empty the scale platform and then press enter on the digital scale. Test weights are then placed on the scale platform in increments of 50lbs (beginning with $50 \mathrm{lbs}$ and ending with 5001bs). The weight value is entered one at a time and the procedure is repeated until $5001 \mathrm{bs}$ is on the scale.

The Lafayette Manual Muscle Test System Model 01163 is a handheld device used for quantifying isometric muscle strength. The unit can measure from 0 to 300 pounds (136.1 kilograms) or 0 to 50 pounds (22.6 kilograms) depending on the setting (high or low threshold) utilized. This system has the ability to eliminate errors due to nonperpendicular forces. Peak force, time to reach peak force, and total test time are displayed on the LCD display and may be saved to be analyzed at a later time. The inter-tester reliability has been found to be moderate (ICC 0.5274 for both single observations as well as for the average of two measurements) with a 
standard deviation of $2.1 \mathrm{~kg}$. The intra-tester reliability has been found to be excellent (ICC 0.863 ) with a standard deviation varying from $1.038 \mathrm{~kg}$ to $1.0266 \mathrm{~kg} .{ }^{15}$ Test-retest reliability has been recorded between .81 and $.87 .^{16}$

A standard measuring tape in centimeters was utilized to measure both neck muscle girth and head-neck segment length. Neck muscle girth was measured just above the thyroid cartilage, in front of the athlete. Head-neck length was measured behind the athlete from the center tip of the spine of the $7^{\text {th }}$ cervical vertebrae to the top of the head.

Procedures

Subjects were contacted and asked to attend a meeting where they were provided with an informed consent form (Table C1) and a Pre-Screening Questionnaire (Table C2). The informed consent form was explained and the study was described to the potential subjects, so as to understand their rights as Human subjects and to make an informed decision with regard to participation in this project. Any questions from the potential subject pool was answered and explained. The potential subjects were then asked to fill out the Pre-Screening Questionnaire as truthfully and completely as possible. The principle investigator then reviewed the forms for completeness as well as to determine whether the subjects fit the inclusion criteria rather than the exclusion criteria. The potential subjects that fit the inclusion criteria were contacted and asked to schedule a time to perform the pre-screening testing.

The pre-screening testing took approximately twenty minutes and consisted of baseline manual muscle testing with the Lafayette Manual Muscle Test System, head-neck length, neck muscle girth, and head-neck segment measurement. Evaluation of an injury when it occurred was performed to determine the severity and exact diagnosis of the injury throughout the season. The primary researcher administered and supervised all testing sessions. Once the wrestling 
season was over, the subjects then scheduled a time to perform their post-test. The post-test was performed to the exact specifications as the pre-test, and was completed within the week. A prescreening questionnaire was completed at the beginning of the study. Questions regarding the subject's past history of injury to the head and neck as well as questions pertaining to wrestling were covered. Neck strength, neck muscle girth, head-neck length, and head-neck segment were assessed during the Pre-test as well as at the Post-test. Those competing in the dual match had their neck strength measured two days prior to all dual matches. Subjects contacted included freshman, sophomores, juniors, seniors, and fifth year seniors. Neck Muscle Strength

Before beginning the manual muscle test, every subject was oriented to the Lafayette Manual Muscle Test System and given a preliminary session of one trial. They were given instruction as to body placement and how to stop testing, should the need arise. A two-minute rest period was given before the subject began testing. The subject was tested once so that fatigue and the possibility of a learning effect did not occur. The subjects were then instructed to sit up straight with their back flat against the chair they were seated in, with their arms crossed in front of their chest and their fingertips touching their acromions. The patient's head was positioned in neutral. Straps were crisscrossed across the subject's chest so that compensation with their shoulders did not occur. The subjects were then instructed to apply maximum force (Table C3, Figure C1) to the Lafayette Manual Muscle Test System for a total of 6 seconds. The athlete was instructed to gradually build-up to maximal force for a duration of 2 seconds and then hold the maximal effort for a duration of 4 seconds (Table C3). This test was completed in forward flexion, extension, and both right and left lateral flexion. The test was performed once in each direction. The subjects were given 30 seconds of rest between each test. Two nights 
prior to any dual match the subjects performed neck strength testing. The results were recorded on the appropriate sheets (Table C7, C8).

Force may be measured utilizing either a make or break test. During a make test, the examiner holds the dynamometer stationary while the subject applies maximal force against the dynamometer. During a break test, the subject will attempt to remain stationary while the examiner applies maximal force until the subject gives from their start position. Research has shown that the reliability of both a make and a break test are similar therefore, this project utilized a make test.

It was not likely at any point during the test that the subjects should feel any pain. However, they were instructed that if they do feel pain or any neurological symptoms and need to stop testing they were to raise their hand or verbally indicate that testing needed to be stopped. Testing ceased immediately and the subject was evaluated and treated for injury. The subject was then rescheduled to be tested at another point in time.

Head-Neck Segment

Head-neck segment (Table C4) was measured by weighing the subjects on an industrial sized digital scale (Panther; Mettler, Toledo, Ohio) in pounds and then converting the measure to kilograms $(\mathrm{kg}) .{ }^{14}$ This gave the Body mass, which was then multiplied by the gender specific head-neck segment $($ male $=8.26 \%$; female $=8.20 \%)$ to total body mass percentage to determine head-neck segment mass in $\mathrm{kg}$. These measurements were recorded on the appropriate sheets (Table $\mathrm{C} 2$ and $\mathrm{C} 3$ ). 
Head-Neck Segment Length

Head-neck segment length (Table C5) was determined by measuring from the spinous process of the $7^{\text {th }}$ cervical vertebrae to the top of the head. ${ }^{14}$ These measurements were recorded on the appropriate sheets.

\section{Neck Muscle Girth}

Neck muscle girth (Table C6) was measured just above the thyroid cartilage and was the circumference around the neck. ${ }^{14}$ These measurements were recorded on the appropriate sheets. Injury Recording

Recording of the prevalence, incidence, and mechanism of burners or stingers was documented throughout the season by the athletic trainers that were assigned to the sport. Each incidence was documented utilizing the injury worksheet in Table C9.

Statistical analysis

Descriptive analysis consisted of means and standard deviations for all participants for the age, number of years wrestling, head-neck segment, head-neck length, neck girth, previous history of brachial plexus neuropathy, and neck strength in the directions of flexion, extension, left lateral flexion, and right lateral flexion.

Because there was not enough power to run a Logistic Regression, individual analyses looking for a relationship between each independent variable and the dependant variable were performed. The relationship between previous history and the dependant variable was calculated using a Chi-square. The individual relationship between head-neck segment, head-neck length, the number of years wrestling (neck strength) and the dependant variable were calculated utilizing independent $\mathrm{t}$-tests. The $\mathrm{P}$ value for each of the individual $\mathrm{t}$-tests was set at $\mathrm{P} \leq .05$. 
The relationship between neck strength for all directions and the dependant variable (brachial plexus neuropathy) was examined descriptively with a repeated measures visual analysis through the use of a line graph as well as through the use of Two-Way RepeatedMeasures ANOVAs. Five separate Two-Way Repeated-Measures ANOVA's were performed for the entire sample $(n=23)$. They were a $2 \times 2$ factorial utilizing time (Pre- and Post-test) and the occurrence of injury (yes or no). Four separate Two-Way Repeated-Measures ANOVA's were then performed for the starters $(n=9)$. They were a $2 \times 9$ factorial utilizing the occurrence of injury (yes or no) and pre-dual match measurements; which were taken across seven different time points prior to each dual match throughout the $2005-2006$ wrestling season as well as preand post-testing. The $\mathrm{P}$-value was set at $\mathrm{P}<.05$.

\section{RESULTS}

Demographic Information

Subjects have been wrestling for $12.93 \pm 4.21$ years (Table D1). Twenty-six and one tenth percent $(n=6)$ of the subjects presented with at least one brachial plexus neuropathy throughout the 2005-2006 wrestling season, while $73.9 \%(n=17)$ did not have any brachial plexus neuropathies throughout the 2005-2006 wrestling season. Out of the six subjects that experienced brachial plexus neuropathies, $4.3 \%(n=1)$ experienced one occurrence, $8.7 \%(n=2)$ experienced two occurrences, $4.3 \%(n=1)$ experienced 10 occurrences, and $4.3 \%(n=1)$ experienced 11 occurrences. Four and three tenths percent $(n=1)$ experienced 23 brachial plexus neuropathies throughout the 2005-2006 wrestling season. Of the six subjects that experienced brachial plexus neuropathies, $21.7 \%(n=5)$ experienced the brachial plexus neuropathy on the right side while only $4.3 \%(n=1)$ experienced their BPN on the left side (Table D2). Eighty- 
seven percent $(\mathrm{n}=20)$ of the subject population was categorized as right hand dominant whereas $13.0 \%(n=3)$ indicated that they are left hand dominant. Forty-seven and eight tenths percent $(n=11)$ of the subjects indicated that they had previously experienced a brachial plexus neuropathy. Of these eleven subjects, $30.4 \%(\mathrm{n}=7)$ reported experiencing between one and three previous episodes of brachial plexus neuropathy, $8.7 \%(\mathrm{n}=2)$ reported experiencing between four and seven episodes, and $8.7 \%(\mathrm{n}=2)$ reported experiencing eight or more brachial plexus neuropathies.

The means for Head-neck segment, head-neck length, and neck girth for pre- and posttest as well as for the entire sample, the injured sample, and the non-injured sample may be found in Table D3. For a comparison of means between the injured sample and the non-injured sample refer to Table D4. Frequencies for head-neck segment, head-neck length, and neck girth pre- and post-test and for the entire sample, the injured sample, and the non-injured sample may be found in Tables D5-D10. For neck strength means refer to Table D11. For neck strength measurement frequencies refer to Tables D12- D19.

\section{Neck Strength and Neck Girth}

Five Two-Way Repeated-Measures ANOVAs utilizing all 23 subjects were performed for each direction of neck strength measurements as well as for neck girth to examine the main effects and interactions between neck strength and the occurrence of brachial plexus neuropathy as well as the main effects and interactions between neck girth and the occurrence of brachial plexus neuropathy. The Repeated-Measures ANOVA was a 2x2 factorial utilizing time (pre- and post-test) and the occurrence of brachial plexus neuropathy (yes or no) (Table D20). There was a main effect for Time for neck strength in the direction of left lateral flexion $\left(\mathrm{F}_{(1,22)}\right)=13.318, \mathrm{P}=$ 
$0.001, \mathrm{ES}=0.388, \beta=0.935$ ) however, there was no significant main effect for Occurrence $\left(\mathrm{F}_{(1,22)}=.522, \mathrm{P}=0 . .478, \mathrm{ES}=0.024, \beta=0.106\right)$ and there was no significant interaction between Time and Occurrence $\left(\mathrm{F}_{(1,22)}=1.069, \mathrm{P}=0.313, \mathrm{ES}=0.048, \beta=0.167\right)$. There was also a main effect for neck strength in the direction of right lateral flexion for Time $\left(\mathrm{F}_{(1,22)}=12.938, \mathrm{P}=\right.$ $0.002, E S=0.381, \beta=0.929)$ however, there was no significant main effect for Occurrence $\left(F_{(1,22)}=0.068, P=0.797, E S=0.033, \beta=0.057\right)$ and there was no significant interaction between Time and Occurrence $\left(\mathrm{F}_{(1,22)}=0.039, \mathrm{P}=0.845, \mathrm{ES}=0.002, \beta=0.054\right)$. There were no significant main effects or interactions for neck strength in the direction of forward flexion for Time $\left(\mathrm{F}_{(1,22)}=\right.$ 4.142, $\mathrm{P}=0.055, \mathrm{ES}=0.165, \beta=0.493)$ or Occurrence $\left(\mathrm{F}_{(1,22)}=0.224, \mathrm{P}=0.641, \mathrm{ES}=0.011, \beta=\right.$ $0.074)$ and there was no significant interaction between Time and Occurrence $\left(\mathrm{F}_{(1,22)}=1.252, \mathrm{P}=\right.$ $0.276, \mathrm{ES}=0.056, \beta=0.188)$. There were no significant main effects or interactions for neck strength in the direction of extension for Time $\left(\mathrm{F}_{(1,22)}=2.377, \mathrm{P}=0.138, \mathrm{ES}=0.102, \beta=0.313\right)$ or Occurrence $\left(\mathrm{F}_{(1,22)}=1.673, \mathrm{P}=0.210, \mathrm{ES}=0.074, \beta=0.235\right)$ and there was no significant interaction between Time and Occurrence $\left(\mathrm{F}_{(1,22)}=.239, \mathrm{P}=0.630, \mathrm{ES}=0.011, \beta=0 . .075\right)$. There were no significant main effects or interactions for neck girth for Time $\left(\mathrm{F}_{(1,22)}=0.017, \mathrm{P}=0.898\right.$, $\mathrm{ES}=0.001, \beta=0.052)$ or Occurrence $\left(\mathrm{F}_{(1,22)}=0.837, \mathrm{P}=0.371, \mathrm{ES}=0.038, \beta=0.141\right)$ and there was no significant interaction between Time and Occurrence $\left(\mathrm{F}_{(1,22)}=0.219, \mathrm{P}=0.645\right.$, ES= $0.010, \beta=0.073)$.

Four Two-Way Repeated-Measures ANOVAs were performed for the starters $(\mathrm{n}=9)$ for each direction of neck strength to examine the interaction between Time (measurements taken at 9 time points throughout the season) and Occurrence of brachial plexus neuropathy (yes or no) (Table D21). These Repeated-Measures ANOVAs were a 2x9 factorial. For neck strength in the direction of forward flexion, there was no significant main effect for Time $\left(\mathrm{F}_{(1,8)}=1.306, \mathrm{P}=\right.$ 
$0.269, \mathrm{ES}=0.207, \beta=0.517)$ or Occurrence $\left(\mathrm{F}_{(1,8)}=4.104, \mathrm{P}=0.099, \mathrm{ES}=0.451, \beta=0.376\right)$ and there was no significant interaction between Time and Occurrence $\left(\mathrm{F}_{(1,8)}=1.273, \mathrm{P}=0.285\right.$, ES= $0.203, \beta=0.504)$. For neck strength in the direction of extension, there was no significant main effect for Time $\left(\mathrm{F}_{(1,8)}=1.108, \mathrm{P}=0.378, \mathrm{ES}=0.181, \beta=0.440\right)$ or Occurrence $\left(\mathrm{F}_{(1,8)}=1.555, \mathrm{P}=\right.$ $0.268, \mathrm{ES}=0.237, \beta=0.175)$ and there was no significant interaction between Time and Occurrence $\left(\mathrm{F}_{(1,8)}=1.472, \mathrm{P}=0.198, \mathrm{ES}=0.227, \beta=0.577\right)$. For neck strength in the direction of left lateral flexion, there was no significant main effect for Time $\left(\mathrm{F}_{(1,8)}=1.928, \mathrm{P}=0.082\right.$, ES= $0.278, \beta=0.720)$ or Occurrence $\left(\mathrm{F}_{(1,8)}=2.806, \mathrm{P}=0.155, \mathrm{ES}=0.359, \beta=0.276\right)$ and there was no significant interaction between Time and Occurrence $\left(\mathrm{F}_{(1,8)}=0.992, \mathrm{P}=0.457, \mathrm{ES}=0.165, \beta=\right.$ 0.394). For neck strength in the direction of right lateral flexion, there was no significant main effect for Time $\left(\mathrm{F}_{(1,8)}=2.095, \mathrm{P}=0.059, \mathrm{ES}=0.295, \beta=0.763\right)$ or Occurrence $\left(\mathrm{F}_{(1,8)}=3.013, \mathrm{P}=\right.$ $0.143, \mathrm{ES}=0.376, \beta=0.293)$ and there was no significant interaction between Time and Occurrence $\left(\mathrm{F}_{(1,8)}=0.493, \mathrm{P}=0.854, \mathrm{ES}=0.090, \beta=0.198\right)$. Although there were no significant main effects or interactions the effect sizes for these analyses were moderate to good (>.10).

Number of years Wrestling, Head-Neck Segment, and Head-Neck Length Independent $\mathrm{t}$-tests $(\mathrm{n}=23)$ were performed for each of the above variables with the occurrence of brachial plexus neuropathy (yes or no) (Table D22). There was no statistically significant relationship between the number of years wrestling and occurrence of injury ( $\mathrm{t}=1.432$, $\mathrm{P}=0.167, \mathrm{~d}=0.74)$. There was no statistically significant relationship between head-neck segment pre-test and occurrence of injury $(\mathrm{t}=0.739, \mathrm{P}=0.468, \mathrm{~d}=0.39)$. There was no statistically significant relationship between head-neck segment post-test and occurrence of injury ( $t=0.801, P=0.432, d=0.42$ ). There was no statistically significant relationship between 
head-neck length pre-test and occurrence of injury $(t=0.846, P=0.407, d=0.33)$. There was no statistically significant relationship between head-neck length post-test and occurrence of injury $(\mathrm{t}=0.985, \mathrm{P}=0.336, \mathrm{~d}=0.38)$. There are moderate to large effect sizes for number of years wrestling, head-neck segment, and head-neck length.

Previous History of Brachial Plexus Neuropathy

A crosstabulation was performed to examine the previous history of brachial plexus neuropathy and the occurrence of a brachial plexus neuropathy during the 2005-2006 wrestling season $\left(\chi_{22}^{2}=1.155, \mathrm{P}=0.283, \mathrm{CC}=0.359\right)$. As indicated by the crosstabulation performed with this sample $(n=23)$, those wrestlers that had a previous history of brachial plexus neuropathies experienced a brachial plexus neuropathy during the 2005-2006 wrestling season at a percentage of $66.7 \%$ as compared to those that did have a previous history but did not experience a brachial plexus neuropathy this season (Table D23). A second crosstabulation was performed to examine the previous history of brachial plexus neuropathy and the number of brachial plexus neuropathies experienced throughout the 2005-2006 wrestling season. Of the six subjects that experienced brachial plexus neuropathies throughout the season, $66.7 \%(n=4)$ indicated that they had a previous history of brachial plexus neuropathy and $50 \%(n=3)$ experienced ten or more brachial plexus neuropathies within the 2005-2006 wrestling season (Table D24).

\section{DISCUSSION}

The first hypothesis stated that past medical history and neck muscle strength would be the strongest predictors of brachial plexus neuropathies in wrestlers while the total number of years that the wrestler has participated in wrestling would be the weakest predictor of brachial plexus neuropathies in wrestlers. Unfortunately, a logistic regression could not be performed 
due to a low power level. Rather, individual analyses of independent variables were performed using statistical analysis or line graphs.

Neck Strength

The first hypothesis dealing with neck strength stated that athletes that have had brachial plexus neuropathies would have significantly decreased neck strength compared to athletes that have not had brachial plexus neuropathies. This hypothesis was not statistically substantiated however, a trend indicating that wrestlers that did not experience brachial plexus neuropathies had increased neck strength was noted upon visual analyses utilizing a line graph. Wrestlers that experienced brachial plexus neuropathies during the season demonstrated noticeably decreased neck strength measurements as compared to those wrestlers that did not experience brachial plexus neuropathies.

The fourth hypothesis dealing with neck strength stated that athletes that have had brachial plexus neuropathies would have significantly decreased neck strength in the direction of lateral flexion in the dominant arm as compared to lateral flexion in the non-dominant arm compared to athletes that have not had brachial plexus neuropathies. A slight increase in neck strength toward the direction of the non-dominant arm was noted however; this increase was not large enough to be substantiated statistically or visually. There was a main effect for Time for neck strength in both the direction of left lateral flexion $\left(\mathrm{F}_{(1,22)}=13.318, \mathrm{P}=0.001, \mathrm{ES}=0.388, \beta=\right.$ $0.935)$ as well as right lateral flexion $\left(\mathrm{F}_{(1,22)}=12.938, \mathrm{P}=0.002, \mathrm{ES}=0.381, \beta=0.929\right)$. These main effects indicate that there is a significant difference between pre-testing and post-testing for both left and right lateral flexion individually. Weakness of the musculature utilized to support the cervical spine during lateral flexion may result in muscular imbalance resulting in injury to an athlete. ${ }^{17,18}$ When, compared against one another, there is no statistical significance. 
The second hypotheses stated that athletes that have had brachial plexus neuropathies would have significantly decreased neck strength compared to athletes that have not had brachial plexus neuropathies for the directions of forward flexion. The results of the study indicated a small difference in average neck strength between wrestlers that experienced at least one incident of brachial plexus neuropathy $(21.38 \pm 2.05 \mathrm{~kg})$ and wrestlers that did not experience any incidents of brachial plexus neuropathy $(22.49 \pm 3.29 \mathrm{~kg})$. Although there was a difference, the difference was not statistically significant; therefore, the hypothesis was not substantiated by the results. The third hypotheses stated that athletes that have had brachial plexus neuropathies would have significantly decreased neck strength compared to athletes that have not had brachial plexus neuropathies for the directions of extension. The results of the study indicated a small difference in average neck strength between wrestlers that experienced at least one incident of brachial plexus neuropathy $(30.70 \pm 5.43 \mathrm{~kg})$ and wrestlers that did not experience any incidents of brachial plexus neuropathy $(26.88 \pm 6.45 \mathrm{~kg})$. Although there was a difference, the difference was not statistically significant; therefore, the hypothesis was not statistically substantiated. Although the results were not statistically significant a trend indicating that, over time, strength was increased in those athletes that had not experienced brachial plexus neuropathies as compared to those that did was noted.

The first hypothesis examining pre- and post-test measurements for neck strength stated that there would be a difference between pre- and post-test measurements of neck strength. This was examined as four different statistical analyses; one for each direction, forward flexion, extension, left lateral flexion, and right lateral flexion. The results of the study indicated that there was a small difference in average neck strength in the direction of left lateral flexion between pre-test measurements $(21.30 \pm 3.57 \mathrm{~kg})$ and post-test measurements $(24.92 \pm 2.75 \mathrm{~kg})$. 
This difference was statistically significant, as demonstrated through examination using a twoway repeated-measures ANOVA therefore, the hypothesis was substantiated by the results and the hypothesis was accepted. The results of the study indicate that there was a small difference in average neck strength in the direction of right lateral flexion pre-test measurements $(21.63 \pm$ $4.08 \mathrm{~kg})$ and post-test measurements $(25.19 \pm 3.45 \mathrm{~kg})$. Once again, this difference was documented as statistically significant through the use of two-way repeated-measures ANOVA therefore; the hypothesis was statistically substantiated by the results and was accepted. Neck strength in both right lateral flexion and left lateral flexion was statistically significant between pre-test and post-test measurements. As demonstrated through the use of visual analysis, neck strength increased over time. The results of the study indicated that there was a small difference in average neck strength in the direction of forward flexion pre-test measurements $(22.20 \pm 3.01$ $\mathrm{kg})$ and post-test measurements $(24.03 \pm 3.53 \mathrm{~kg})$. Although there was a difference, the difference was not statistically significant; therefore, the hypothesis was not statistically substantiated by the results. The results of the study indicated that there was a small difference in average neck strength in the direction of extension pre-test measurements $(27.88 \pm 6.32 \mathrm{~kg})$ and post-test measurements $(31.17 \pm 5.98 \mathrm{~kg})$. Although there was a difference, the difference was not statistically significant; therefore, the hypothesis was not statistically substantiated by the results.

In this study, there was a significant main effect in the strength measurements of right and left lateral flexion for all wrestlers. It was noted that $75 \%$ of the subjects had a strength deficiency toward their dominant side however; there was no difference in the means to indicate whether the right or left side was stronger. Chiu ${ }^{21}$ demonstrated that lateral flexion to the right side (dominant in his patients) is $11 \%$ stronger than lateral flexion to the left side (non-dominant 
side) in men. He hypothesized that this could be due to hand dominance. This particular information is of clinical importance when considering the mechanism of injury. An athlete that presents with injury resulting from a mechanism associated with lateral flexion should be asked whether his dominant or non-dominant side is affected. Using Chiu's ${ }^{21}$ study one may hypothesize that the non-dominant side will be injured more often than the dominant side. The results of this study demonstrated that brachial plexus neuropathy occurred on the dominant side in five out of six wrestlers. Also, in the vast majority of the sample, neck strength in lateral flexion was decreased toward the dominant side. Although this trend is not supported statistically, it does have clinical implications. Based on observation, wrestlers typically reach for their opponent with the dominant arm. This arm is utilized to "control the head" of the opponent and is left open to a compression mechanism of injury, as was the case in this study.

Ylinen et al. ${ }^{22}$ demonstrated that the extensor muscles of the neck are substantially stronger than the flexors. And Suryanarayana ${ }^{20}$ substantiated this finding. This demonstrates the postural role of the extensor musculature as well as the "obvious muscle mass difference between posterior and anterior muscles of the cervical spine., ${ }^{20}$ The extensor muscles were found to be stronger than the flexors in this study as well. The nature of wrestling calls for resistance of flexion. The extensors are continually working to keep the neck from going into flexion and are much stronger than the flexor muscles as a result. Visual analysis indicated that the neck strength of wrestlers that did not experience any brachial plexus neuropathy incidents throughout the wrestling season was stronger than those that did experience incidents of brachial plexus neuropathy.

Clinically, there may be implications to increase neck strength in an attempt to prevent the occurrence of brachial plexus neuropathy. Ylinen ${ }^{22,23}$ repeatedly demonstrated that neck 
strength values were significantly correlated with neck pain. In one study, Ylinen ${ }^{23}$ documented that neck strength measures were significantly decreased in subjects with chronic neck pain. $\mathrm{Chiu}^{18}$ documented the same finding; noting decreased neck strength and endurance in subjects with neck pain. Ylinen's ${ }^{23}$ decrease in strength was documented as being confined to the neck rather than an overall weakness due to comparable grip strength measurements between subjects that did not have chronic neck pain and those that did. Wrestlers that have experienced a brachial plexus neuropathy reported pain and general muscle soreness following the injury. Based on Ylinen's ${ }^{23}$ findings, this may lead to decreased neck strength and an increased susceptibility to injury. Another study by Ylinen ${ }^{22}$ documents that after an eight-week training period, isometric strength increased while pain decreased thereby, further substantiating a relationship between neck strength and perceived pain.

Due to the small effect sizes and a small sample size, the impact that decreased neck strength may have on the occurrence of brachial plexus neuropathy was unable to be seen. While there is some controversy in the literature regarding measurement technique, the technique utilized in this study is widely accepted as an accurate measurement technique. Garces et al. ${ }^{19}$ documented that while the prone position provides significantly stronger neck strength measurements, the sitting position is more frequently utilized due to subject comfort. Suryanarayana ${ }^{20}$ noted that the standing position could also involve participation of extrinsic musculature as well as body segments such as the feet, arms, and trunk due to the difficulty in proper stabilization. The seated position offers representation of the posture in which the cervical muscles can be isolated. Also, the seated position enables the examiner to measure isometric neck strength in the neutral position, the position at which the highest and most 
effective electrical activity may be seen. ${ }^{19}$ This study utilized the seated position to accomplish accurate testing of neck strength.

\section{Anthropometric Measurements}

The first hypothesis examining pre- and post-test measurements stated that there would be a difference between pre- and post-test measurements of head-neck segment. The results of the study indicated that there was a small difference in average head-neck segment between pretest measurements $(6.16 \pm 1.10 \mathrm{~kg})$ and post-test measurements $(6.33 \pm 1.02 \mathrm{~kg})$ for head-neck segment. Although there was a difference, the difference was not statistically significant in terms of power; therefore, the hypothesis was not statistically substantiated by the results. The pre-test means for wrestlers that did experience a brachial plexus neuropathy was $6.44 \pm 0.75$ as compared to $6.05 \pm 1.02$ for those wrestlers that did not experience a brachial plexus neuropathy.

The second hypothesis stated that there would be a difference between pre- and post-test measurements of neck muscle girth. The results of the study indicated that there was a small difference in average neck girth pre-test measurements $(39.59 \pm 2.20 \mathrm{~cm})$ and post-test measurements $(39.67 \pm 2.52 \mathrm{~cm})$ for neck girth. Although there was a difference, the difference was not statistically significant; therefore, the hypothesis was not statistically substantiated by the results in terms of power.

The third hypothesis stated that there would be a difference between pre- and post-test measurements of head-neck length. The results of the study indicated that there was a small difference in average head-neck length pre-test measurements $(31.07 \pm 2.57 \mathrm{~cm})$ and post-test measurements $(30.85 \pm 2.61 \mathrm{~cm})$ for head-neck length. Although there was a small difference, the difference was not statistically significant; therefore, the hypothesis was not statistically substantiated by the results. 
Head-neck segment: The hypothesis dealing with head-neck segment stated that athletes that have had a brachial plexus neuropathy would have a larger head-neck segment than those athletes that have not. The results of the study indicated a very minimal difference in average head-neck segment between wrestlers that experienced at least one incident of brachial plexus neuropathy $(6.44 \pm 0.75 \mathrm{~kg})$ and wrestlers that did not experience any incidents of brachial plexus neuropathy $(6.05 \pm 1.20 \mathrm{~kg})$. Not surprisingly, this difference was not statistically significant $(\mathrm{P}=0.47)$; therefore, the hypothesis was not substantiated by the results. However, there was a large effect size demonstrating that the data did show something $(\mathrm{d}=0.39$ for pre-test and $\mathrm{d}=0.42$ for post-test) and that with a larger sample size, the data might have indicated statistical significance. This trend is demonstrated again in the post-test measurements $(6.62 \pm$ 0.74 for wrestlers injured by BPN and $6.23 \pm 1.10$ for those that did not). This data demonstrates the possibility that wrestlers that have a larger head-neck segment may be more susceptible to experiencing brachial plexus neuropathies.

Dynamic joint stabilization is defined as "the ability of the myotendon unit to absorb external loads and minimize excessive joint movement." ${ }^{14}$ The two primary stabilizers of the head and neck are the sternocleidomastoid and the trapezius. It is these muscles that must react in response to or before external forces are applied to decrease the resulting acceleration. Tierney et al. ${ }^{14}$ documented that greater head-neck segment angular acceleration was present in females due to decreased levels of strength, neck girth, and head mass, therefore resulting in decreased head-neck stiffness as compared with males. The same may be hypothesized for injured athletes. Decreased neck strength may lead to greater head-neck accelerative forces. Because there were no noticeable trends, the dynamic stabilization of the neck may depend more heavily on the musculature rather than head-neck segment. Tierney et al. ${ }^{14}$ further states that 
females should perform head-neck segment resistance training to increase strength as well as neck girth. However, Mansell et al. ${ }^{24}$ documented that while resistance training increased strength and neck girth, there was not any decrease in head-neck segment acceleration upon force application. This suggests that the neuromuscular plasticity necessary to increase dynamic restraint and decrease head acceleration was not evident. The resistance training utilized in the Mansell et al. ${ }^{24}$ article was an isotonic program therefore, it may be suggested that neck muscle training that elicits feed-forward as well as feedback motor control may train the dynamic stabilizers for increased protection as well as increased performance.

Head-neck length: The hypothesis dealing with head-neck length stated that athletes that have had a brachial plexus neuropathy would have a significantly longer head-neck length than those athletes that have not. The results of the study indicated a minimal difference in average length between wrestlers that experienced at least one incident of brachial plexus neuropathy $(31.83 \pm 3.96 \mathrm{~cm})$ and wrestlers that did not experience any incidents of brachial plexus neuropathy $(30.79 \pm 1.97 \mathrm{~cm})$. This minimal difference was not statistically significant $(\mathrm{p}=$ 0.41); therefore, the hypothesis was not substantiated by the results. However, there was a moderate effect size demonstrating that the data did show something $(d=0.33$ for pre-test and $d=$ 0.38 for post-test) and that, with a larger sample size, the data may have demonstrated statistical significance. It was hypothesized that a greater head-neck length may have an increased probability of injury due to greater accelerative forces. The difference between pre-test means for wrestlers injured by brachial plexus neuropathy versus those that were not demonstrate that this may be a possibility. The post-test means further substantiate this hypothesis $(31.75 \pm 4.07$ for wrestlers injured by BPN and $30.53 \pm 1.94$ for those that were not). 
Neck girth: The hypothesis dealing with neck girth stated that athletes that have had a brachial plexus neuropathy would have a significantly smaller neck muscle girth than athletes that have not had a brachial plexus neuropathy. The results of the study indicated that there was a very minimal difference in average neck girth between wrestlers that experienced at least one incident of brachial plexus neuropathy $(40.42 \pm 2.35 \mathrm{~cm})$ and wrestlers that did not experience any incidents of brachial plexus neuropathy $(39.29 \pm 2.14 \mathrm{~cm})$. Not surprisingly, this minimal difference was not statistically significant $(p=0.29)$; therefore, the hypothesis was not substantiated by the results. Tierney et al. ${ }^{14}$ noted that increased girth and contraction of the stabilizing musculature increases the ability to resist external forces once applied. As discussed previously, it has been hypothesized that a small neck that is unable to dissipate force may be more prone to injury. ${ }^{10,11,25}$ This effect may be significant in a larger sample.

\section{Total Number of Years Wrestling}

The hypothesis for the total number of years that a wrestler has been wrestling stated that athletes that have had brachial plexus neuropathies would have been wrestling significantly longer than athletes that have not had a brachial plexus neuropathy. The results of the study indicated that there was a small difference in average years between wrestlers that experienced at least one incident of brachial plexus neuropathy $(15.00 \pm 3.03$ years $)$ and wrestlers that did not experience any incidents of brachial plexus neuropathy $(12.21 \pm 4.39$ years). Although there was a difference, the difference was not statistically significant $(\mathrm{p}=0.17)$; therefore, the hypothesis was not substantiated by the results. However, there was a large effect size $(\mathrm{d}=0.74)$ indicating that the data may demonstrate statistical significance with a larger sample size. Thus the hypothesis that wrestlers that have been wrestling for a longer period of time are more 
susceptible to brachial plexus neuropathy may be substantiated by the results with a larger sample size. This may be due to the development of degenerative changes over time.

The longer that a wrestler has been wrestling, the longer the amount of time that greater forces have been applied to the neck. These degenerative changes can cause a small slippage of the vertebrae, leading to decreased foraminal openings and disc herniations. The instability that may result from brachial plexus injuries is due to deficits in neck strength and range-of-motion that can be found post-injury. ${ }^{17}$ MRIs and X-Rays are necessary when there is any suspicion of chronic burner syndrome due to the implication that degenerative changes may have on the cervical spine. Although diagnostic testing was not obtained for subjects, one subject did have an MRI prior to the start of this study that indicated degenerative changes. This same subject reported twenty-three separate incidents of brachial plexus neuropathy within the 2005-2006 wrestling season.

\section{Previous History}

The hypothesis dealing with previous history of brachial plexus neuropathies stated that athletes that have a brachial plexus neuropathy during the season would have had a previous history of brachial plexus neuropathy as compared to athletes that do not have a previous medical history of brachial plexus neuropathy. Fifty percent $(n=3)$ of the wrestlers that did experience a brachial plexus neuropathy during the season experienced ten or more brachial plexus neuropathies. Of the six subjects that experienced brachial plexus neuropathies throughout the season, $66.7 \%(\mathrm{n}=4)$ indicated that they had a previous history of brachial plexus neuropathy. Chronic burner syndrome deals with the reoccurrence of brachial plexus neuropathies. The incidence of this syndrome may be as high as $57 \%{ }^{3,26}$ Levitz et al. ${ }^{13}$ examined this syndrome and found that the mechanism of extension in combination with 
ipsilateral-lateral deviation occurred in athletes with chronic burner syndrome. ${ }^{27}$ Sallis et al. ${ }^{4}$ reported an $87 \%$ recurrence rate of brachial plexus neuropathies, further demonstrating the high recurrence rate associated with this injury. ${ }^{28}$ The results of this study substantiate this information and seem to lend credence to the idea that an athlete that has had a brachial plexus neuropathy is more likely to experience another brachial plexus neuropathy than an athlete that has never experienced one. This is substantiated by previous literature. The relative risk of a player having a reoccurrence of injury was twice the risk of an athlete experiencing an initial stinger. ${ }^{1,2}$ Meyer et al. ${ }^{5}$ found that there was a relative risk of reoccurrence three times that of experiencing an initial stinger. ${ }^{27}$

Incidence, Prevalence \& Mechanism

This study demonstrated that six wrestlers out of twenty-three experienced brachial plexus neuropathies. These six reported a total number of forty-nine incidents throughout the 2005-2006 wrestling season. This is a staggering number. Meyer et al. ${ }^{5}$ reported a yearly stinger incidence of $3.7 \%$ as well as a stinger prevalence of $15 \%$. Within the sport of wrestling there is a $20 \%$ chance of sustaining a neck injury with a $50 \%$ risk of reoccurrence. ${ }^{12}$ This study supports this finding due to the result that $83.3 \%(n=5)$ of the wrestlers that did experience a BPN did have at least one reoccurrence of brachial plexus neuropathy at some point during the season.

It has been documented that the incidence of injury is at three times more likely during matches than during practice. This study found all of the reported brachial plexus neuropathies to occur during practice. 
The literature also documents that take-down maneuvers accounted for the majority of these injuries. ${ }^{32,33}$ The subjects that reported brachial plexus neuropathies did report that injury occurred while attempting to take-down an opponent. The distributions of C5 and C6 are documented as being the most commonly injured during brachial plexus neuropathies. ${ }^{3}$ This finding held true in this study as well. Nerve root compression may occur with cervical spine extension in combination with ipsilateral-lateral flexion. ${ }^{9,11,13,34}$ This specific mechanism has been shown to be more predominant in a more mature population due to degenerative changes that may influence foraminal height to compress the cervical nerve roots. ${ }^{3,10,11,25,26,27,35}$ All of the wrestlers that experienced a brachial plexus neuropathy reported this mechanism, further substantiating the literature. It should be noted that a study of this nature has not been performed prior to this study. Therefore, direct comparisons to similar studies cannot be made instead inferences were made.

\section{Clinical Relevance}

Many studies have documented statistical significance between neck strength and pain, although this study is unable to demonstrate statistical significance between neck strength and occurrence of brachial plexus neuropathy, there are trends showing decreased neck strength overall in wrestlers that have experienced incidents of BPN. Wrestlers that experienced an incident of BPN during the season demonstrated decreased neck strength over time. Refer to Figures D1-D4. Ylinen et al. ${ }^{36}$ noted that many wrestling maneuvers impose loading on the neck. This increases the risk of injuries. A strong neck has been assumed to be pivotal in the prevention of trauma. Tierney et al. ${ }^{14}$ and Mansell et al. ${ }^{24}$ noted that although neck strength increased, head-neck segment acceleration did not decrease. Mansell et al. ${ }^{24}$ then discussed the 
possibility that the type of neck strength program may affect head-neck segment stabilization. Ylinen et al. ${ }^{36}$ noted that neck strength increases inherently in the sport of wrestling, although this was not statistically evident in this study, there was an increase noted utilizing line graphs for visual analysis. Often, wrestlers experience neck pain assumed to be related to muscle stiffness arising from a tough training session. Mansell et al. ${ }^{24}$ proposed the use of feed-forward and feedback motor control to increase dynamic stabilization rather than isotonic training. Feedforward and feedback motor control in conjunction with isometric or isotonic, both have been demonstrated to increase neck strength as well as neck girth, may yield greater results in decreasing injury susceptibility.

Previous history of BPN has also been noted to increase brachial plexus neuropathy susceptibility. Although the results of this study were not statistically significant, the previous literature may be substantiated clinically. It is not possible to change an athlete's prior history however, the knowledge that increased neck strength may aid in the prevention of BPN incidents may decrease the number of recurrences of brachial plexus neuropathies. This and the decrease of head-neck segment acceleration may decrease the athlete's susceptibility to injury.

\section{CONCLUSION}

The only main effects that were significant were for neck strength in right lateral flexion and left lateral flexion between pre- and post-test measurements. All other main effects and interactions were not statistically significant for any other strength measurement or for neck girth measurements. Anthropometric measurements consisting of head-neck segment, head-neck length, and neck girth also were not statistically significant. Pre-Test/Post-Test measurements for strength as well as all anthropometric measurements were not statistically significant. 
However, based on visual analysis utilizing line graphs, there was a difference noted between the nine time points for neck strength measurements between starting wrestlers that sustained a brachial plexus neuropathy and those that did not. Despite a lack of statistical significance, trends indicating that increased neck strength may prevent the occurrence of brachial plexus neuropathy were noted. Further research should be conducted to include larger sample sizes to appropriately examine the predictability of these variables on the occurrence of brachial plexus neuropathies. 


\section{REFERENCES}

1. Castro FP Jr. Stingers, cervical cord neurapraxia, and stenosis. Clin Sports Med. 2003;22(3):483-92.

2. Castro FP Jr, Ricciardi J, Brunet ME, Busch MT, Whitecloud TS 3rd. Stingers, the Torg ratio, and the cervical spine. Am J Sports Med. 1997;25(5):603-8.

3. Stracciolini A. Cervical burners in the athlete. Pediatr Case Rev. 2003;3(4):181-8.

4. Sallis RE, Jones K, Knopp W. Burners: offensive strategy in an underreported injury. Phys Sportsmed. 1992;20:47-55.

5. Meyer SA, Schulte KR, Callaghan JJ, Albright JP, Powell JW, Crowley ET, el-Khoury GY. Cervical spinal stenosis and stingers in collegiate football players. Am J Sports Med. 1994;22(2):158-66.

6. Torg JS. Cervical spinal stenosis with cord neurapraxia: evaluations and decisions regarding participation in athletics. Curr Sports Med Rep. 2002;1(1):43-6.

7. Torg JS. Cervical spinal stenosis with cord neurapraxia and transient quadriplegia. Sports Med. 1995;20(6):429-34.

8. Torg JS, Ramsey-Emrhein JA. Management guidelines for participation in collision activities with congenital, developmental, or postinjury lesions involving the cervical spine. Clin J Sport Med. 1997;7(4):273-91.

9. Weinberg J, Rokito S, Silber JS. Etiology, treatment, and prevention of athletic "stingers". Clin Sports Med. 2003;22(3):493-500, viii.

10. Koffler KM, Kelly JD 4th. Neurovascular trauma in athletes. Orthop Clin North Amer. 2002;33(3):523-34.

11. Kelly JD 4th, Aliquo D, Sitler MR, Odgers C, Moyer RA. Association of burners with cervical canal and foraminal stenosis. Am J Sports Med. 2000;28(2):214-7.

12. Ylinen JJ, Julin M, Rezasoltani A, Virtapohja H, Kautiainen H, Karila T, Malkia E. Effect of training in Greco-Roman wrestling on neck strength at the elite level. J Strength Cond Res. 2003; 17(4):755-9.

13. Levitz CL, Reilly PJ, Torg JS. The pathomechanics of chronic, recurrent cervical nerve root neurapraxia. The chronic burner syndrome. Am J Sports Med. 1997;25(1):73-6.

14. Tierney R, Sitler M, Swanik CB, Swanik K, Higgins M, Torg J. Gender differences in headneck segment dynamic stabilization during head acceleration. Med Sci Sports Exerc. 2005:272-79. 
15. Smith JR, Willard SJ, Giffin T, Jordan NL, Kinsella N, Roche D. The reliability of manual muscle testing and hand-held dynamometry in testing the hip extensor strength of healthy subjects. Physiotherapy unit, Chelsea \& Westminster Hospital NHS Trust, London.

16. Nicholas JA, Marino MW, and Gleim GW. Characterization of a strength measurement device. Institute of Sports Medicine and Athletic Trauma, Lenox Hill Hospital, New York, NY.

17. Cramer CR. A reconditioning program to lower the recurrence rate of brachial plexus neurapraxia in collegiate football players. J Athl Train. 1999;34(4):390-96.

18. Vernon HT, Aker P, Aramenko M, Battershill D, Alepin A, Penner T. Evaluation of neck muscle strength with a modified sphygmomanometer dynamometer: reliability and validity. $J$ Manipulative Physiol Ther. 1992;15(6):343-9.

19. Garces GL, Medina D, Milutinovic L, Garavote P, Guerado E. Normative database of isometric cervical strength in a healthy population. Med Sci Sports Exerc. 2002;34(3):464-70.

20. Suryanarayana L, Kumar S. Quantification of isometric cervical strength at different ranges of flexion and extension. Clin Biomech. 2005;20(2):138-44.

21. Chiu TT, Sing KL. Evaluation of cervical range of motion and isometric neck muscle strength: reliability and validity. Clin Rehabil. 2002;16(8):851-8.

22. Ylinen $\mathrm{J}$ and Ruuska $\mathrm{J}$. Clinical use of neck isometric strength measurement in rehabilitation. Arch Phys Med Rehabil. 1994; 75: 465-469.

23. Ylinen J, Salo P, Nykanen M, Kautianinen H, and Hakkinen A. Decreased isometric neck strength in women with chronic neck pain and the repeatability of neck strength measurements. Arch Phys Med Rehabil. 2004; 85: 1303-1307.

24. Mansell J, Tierney RT, Sitler MR, Swanik KA, Stearne D. Resistance training and head-neck segment dynamic stabilization in male and female collegiate soccer players. $J$ Athl Train. 2005;40(4):310-319.

25. Torg JS, Pavlov H. Cervical spinal stenosis with cord neurapraxia and transient quadriplegia. Clin Sports Med. 1987;6(1):115-33.

26. Page S, Guy JA. Neurapraxia, "stingers," and spinal stenosis in athletes. South Med J. 2004;97(8):766-9.

27. Cantu RC. Stingers, transient quadriplegia, and cervical spinal stenosis: return to play criteria. Med Sci Sports Exerc. 1997;29(7 Suppl):S233-5. 
28. Kuhlman GS, McKeag DB. The "burner": a common nerve injury in contact sports. Am Fam Physician. 1999;60(7):2035-40, 2042.

29. Leggett SH, Graves JE, Pollock ML, Shank M, Carpenter DM, Holmes B, Fulton M. Quantitative assessment and training of isometric cervical extension strength. Am J Sports Med. 1991;19(6):653-9.

30. Jordan A, Mehlsen J, Bulow PM, Ostergaard K, Danneskiold-Samsoe B. Maximal isometric strength of the cervical musculature in 100 healthy volunteers. Spine. 1999;24(13):1343-8.

31. Strimpakos N, Sakellari V, Gioftsos G, Oldham J. Intratester and intertester reliability of neck isometric dynamometry. Arch Phys Med Rehabil. 2004;85(8):1309-16.

32. Cooper MT, McGee KM, Anderson DG. Epidemiology of athletic head and neck injuries. Clin Sports Med. 2003;22:427-443.

33. Krivickas LS, Wilbourn AJ. Sports and peripheral nerve injuries: report of 190 injuries evaluated in a single electromyography laboratory. Muscle Nerve. 1998;21(8):1092-4.

34. Torg JS, Naranja RJ Jr, Palov H, Galinat BJ, Warren R, Stine RA. The relationship of developmental narrowing of the cervical spinal canal to reversible and irreversible injury of the cervical spinal cord in football players. J Bone Joint Surg Am. 1996;78(9):1308-14.

35. Kim DH, Vaccaro AR, Berta SC. Acute sports-related spinal cord injury: contemporary management principles. Clin Sports Med. 2003;22(3):501-12.

36. Ylinen JJ, Julin M, Rezasoltani A, Virtapohja H, Kautiainen H, Karila T, Malkia E. Effect of training in Greco-roman wrestling on neck strength at the elite level. J Strength Cond Res. 2003;17(4):755-759. 


\section{APPENDICES}




\section{APPENDIX A}

\section{THE PROBLEM}

\section{Research Question}

Wrestlers are exposed to a multitude of injuries within the collegiate setting. The majority of these injuries affect the musculoskeletal system, including the extremities as well as the spine. Severe injuries are evident in wrestling due to the nature of the sport. However, most cervical injuries involve cervical discs as well as the brachial plexus, which tend to occur more frequently. Collegiate wrestlers experience disc herniations, which, in some cases can lead to cervical fusions and lead to chronic syndromes. Because of this, medical disqualifications and playing time absences due to this injury are becoming more prevalent. However, based on the two injuries, wrestling athletes experience more numerous episodes of brachial plexus neuropathies throughout any given season. The initial occurrence of a brachial plexus neuropathy is bewildering to the athlete due to the previously unknown experience of numbness and paraesthesia. Whether resulting from multiple recurrences, anatomic or functional deficits, or due to inappropriate treatment and rehabilitation techniques, a more severe pathology may result. Unfortunately, the vast majority of the literature regarding brachial plexus neuropathies involves football athletes rather than wrestling athletes.

As many as $50 \%$ to $65 \%$ of football players will suffer from brachial plexus neurapraxia

at some point during their career. ${ }^{17,26,55}$ Football athletes frequently experience brachial plexus neuropathies in a single, more serious incident whereas wrestlers experience a greater number of less severe incidents in a shorter time span. Furthermore, football athletes are fitted with protective equipment to aid in the prevention and reoccurrence of brachial plexus neuropathies whereas; wrestlers cannot wear the added protective equipment. 
The literature regarding brachial plexus neuropathies documents that the mechanism of injury in a brachial plexus neuropathy is one of three different mechanisms: traction, a compressive force to the ipsilateral side, or a compressive force to Erb's point. ${ }^{1,2,32,10,11}$ Neck extension-compression is a common mechanism in the more mature athletic population and may be associated with more serious pathologies. ${ }^{\text {Shannon, } 11}$ Neck extension combined with ipsilaterallateral deviation is a common mechanism within the younger athletic population. ${ }^{11}$ The compression mechanism is thought to occur as a result of impingement between the shoulder pads of football athletes or as a direct blow to Erb's point. ${ }^{10}$ However, wrestlers may experience a compression mechanism when falling or being pushed into compression by the weight of their own body in combination with the weight of their opponent. Due to the nature and positioning of the neck throughout practices and competitions neck range-of-motion and strengthening may be essential to the prevention of brachial plexus neuropathies. Because adequate documentation regarding the specific mechanism of brachial plexus neuropathies in wrestling athletes is not available, the certified athletic trainer may be limited in their prevention techniques.

Substantial research into the role that a decreased Torg ratio plays in predisposing athletes to brachial plexus neuropathies has been documented with the conclusion that a decreased Torg ratio does not predispose an athlete to an initial incident but has been shown in correlation with greater reoccurrences of injury. ${ }^{34,40,69,70}$ Unfortunately, this is the only variable that has been researched. Neck strength has been shown to increase throughout a wrestling season however, research as to the possible role of decreased neck strength in predisposing wrestling athletes to brachial plexus neuropathy has not been conducted. Reports from West Virginia University wrestlers that have experienced incidents of brachial plexus neuropathy have revealed the possible connection of decreased neck strength or perceptions of feeling weak to 
this injury. Thus far, the medical community has ruled out a decreased Torg ratio as a predisposing factor to brachial plexus neuropathies and has not provided any other replacement variables as possible predisposing factors.

After experiencing multiple incidences of brachial plexus neuropathies six wrestling athletes have undergone cervical fusions and two others have been diagnosed with multi-level disc herniations but have not undergone surgery. All of this has occurred within the past five years at West Virginia University. It now becomes essential to examine possible factors that predispose wrestling athletes to brachial plexus neuropathies. The lack of literature regarding wrestling, predisposing factors, and preventative techniques for this injury is the primary reason for this study. My observations of prevalence of this injury in working with the West Virginia University wrestling team during the 2004-2005 wrestling season has also prompted many questions as to how these athletes can prevent and recover from brachial plexus neuropathies. By examining possible risk factors, the certified athletic trainer can tailor the athlete's strength and rehabilitation programs to aid in the prevention of this type of injury. This being said, my research questions are: 1) Which variables predispose wrestling athletes to a brachial plexus neuropathy; 2) Does neck strength play an integral role in predisposing wrestling athletes to a brachial plexus neuropathy; and 3) To provide documentation of the mechanism and incidence of brachial plexus neuropathies within the sport of wrestling using a sample of convenience. Experimental Hypotheses

Logistic regression:

1. Past medical history and neck muscle strength will be the strongest predictors of brachial plexus neuropathies in wrestlers. The total number of years that the wrestler has participated in wrestling will be the weakest predictor of brachial plexus neuropathies in wrestlers. 
Neck muscle strength:

1. Athletes that have had brachial plexus neuropathies will have significantly decreased neck strength compared to athletes that have not had brachial plexus neuropathies.

2. Athletes that have had brachial plexus neuropathies will have significantly decreased neck strength compared to athletes that have not had brachial plexus neuropathies in the direction of forward flexion.

3. Athletes that have had brachial plexus neuropathies will have significantly decreased neck strength compared to athletes that have not had brachial plexus neuropathies in the direction of extension.

4. Athletes that have had brachial plexus neuropathies will have significantly decreased neck strength in the direction of lateral flexion in the dominant arm as compared to lateral flexion in the non-dominant arm compared to athletes that have not had brachial plexus neuropathies.

Head-neck segment:

5. Athletes that have had a brachial plexus neuropathy will have a larger head-neck segment than those athletes that have not.

Head-neck length:

6. Athletes that have had a brachial plexus neuropathy will have a significantly longer head-neck length than those athletes that have not.

Neck muscle girth:

7. Athletes that have had a brachial plexus neuropathy will have a significantly smaller neck muscle girth than athletes that have not had a brachial plexus neuropathy.

Total number of years wrestling:

8. Athletes that have had brachial plexus neuropathies will have been wrestling significantly longer than athletes that have not had a brachial plexus neuropathy.

Past medical history:

9. Athletes that have a brachial plexus neuropathy during the season will have had a previous medical history of brachial plexus neuropathy as compared to athletes that do not have a previous medical history of brachial plexus neuropathy. 
Pre- and post-test:

10. There will be a difference between pre- and post-test measurements of head-neck segment.

11. There will be a difference between pre- and post-test measurements of neck muscle girth.

12. There will be a difference between pre- and post-test measurements of head-neck length.

13. There will be a difference between pre- and post-test measurements of neck strength.

\section{Assumptions}

1. The subjects will complete the pre-season questionnaire as honestly and completely as possible.

2. The subjects will notify the investigators when a brachial plexus neuropathy occurs.

3. The instrument utilized to measure neck strength will be valid and reliable method of measurement.

\section{Delimitations}

1. Only West Virginia University wrestlers were used for this study, therefore, this study cannot be generalized to the population.

2. The sample size of the study is small; therefore this study cannot be generalized to the population.

\section{Operational Definitions}

1. Brachial Plexus Neuropathy - An injury that commonly occurs in football and other collision sports. The brachial plexus is compressed or a traction force is applied causing "paraesthesias, numbness, weakness of the upper extremity", and a feeling of burning pain. ${ }^{13}$

2. Cervical Cord Neurapraxia $(\mathrm{CCN})$ - "A transient disturbance in neuronal function that may be associated with motor paresis involving both arms, both legs, or all four extremities after cervical cord hyperextension, hyperflexion, or axial loading." $8,25,66$

3. Cervical Stenosis - "The least distance between the anterior margin of the column of contrast material and the nearest point on the cortical line of the overlying lamina." This is said to be stenotic when the diameter is between $13 \mathrm{~mm}$ and $15 \mathrm{~mm}$ or less in a spondylotic spine. 
4. Competitive Season - The competitive season, for use in this study, includes the time from which "official" practice begins through the last dual match prior to the NCAA tournament.

5. Contralateral - Occurring on the opposite side of the injury.

6. Epidemiology - The elements that contribute to the occurrence of a disease, illness, or injury.

7. Flexibility - The ability of a muscle to lengthen and yield to stretch forces.

8. Functional Stenosis - Considers "bony canal dimensions, cord thickness, and the cushioning potential of the cerebral spinal fluid (CSF)." " A measurement thought to be functional when the aforementioned variables are taken into account.

9. Head-Neck Length - The length from the spinous process of the $7^{\text {th }}$ cervical vertebrae to the top of the head.

10. Head-Neck Segment - Head-neck segment is measured by weighing the subjects in pounds and converting the measure to kilograms $(\mathrm{kg})$. This will give the Body mass which will then be multiplied by the gender specific head-neck segment (male $=8.26 \%$; female $=8.20 \%$ ) to total body mass percentage to determine head-neck segment mass. ${ }^{14}$

11. Incidence - Rate of occurrence or influence.

12. Ipsilateral - Occurring on the same side as an injury.

13. Neck Endurance - The ability of the cervical musculature to accomplish exercises over a prolonged period of time.

14. Neck Muscle Girth - The measurement of the circumference of the neck just above the thyroid cartilage.

15. Neck Strength - Strength of cervical musculature.

16. Osteophyte - A small, abnormal bony outgrowth.

17. Paraesthesia - A sensation of tingling or prickling on the skin.

18. Prevalence - How often a particular event occurs.

19. Magnetic Resonance Imaging (MRI) - A noninvasive diagnostic technique that produces computerized images of internal body tissues. Based on the application of radio waves.

20. Sagittal - Divides the body into right and left halves. 
21. Seddon's Criteria - Criteria used to define brachial plexus neuropathies. A grade I injury is a neurapraxia, "defined as a transient motor or sensory deficit without structural axonal disruption." "9 Grade II injuries are axonotmesis, where "axonal disruption occurs but with an intact outer supporting connective tissue known as the epineurium. The neural deficit is present for at least 2 weeks following the injury." "9 Grade III injuries persist for 1 year, with little to no clinical improvement. "The injuries correspond to Seddon's criteria of a neurotmesis, or total disruption of both axons and all supporting connective tissue." 9

22. Torg Ratio - Technique utilized to measure for Cervical Stenosis. "The ratio of the midsagittal diameter of the spinal canal to the vertebral body diameter." 1 A Torg ratio of less than 0.80 is considered to be stenotic. $1,2,13$

23. Transient Quadriparesis (Quadraplegia) - Another term for CCN. Transient Quadriparesis is less specific than $\mathrm{CCN}$ because loss of sensation may occur with or without loss of motor functioning.

24. X-Ray - Another diagnostic tool utilized mainly to detect bony abnormalities.

\section{Limitations}

1. The subjects may not have completed the pre-season questionnaire honestly and completely.

2. The subjects may not have notified the investigators when a brachial plexus neuropathy occurs.

3. All subjects did not complete the study due to injury or quitting the team.

Significance of the Study

The practical significance of this study is to provide education and information for the certified athletic trainer as well as the medical professional regarding the possible predisposing factors of brachial plexus neuropathies in wrestling athletes. The certified athletic trainer and the medical profession as a whole can begin to modify and enhance the screening process to include detection of predisposing factors, especially neck strength over time. Once identified, treatment and rehabilitation techniques can also be modified to reduce the rate of reoccurrence of brachial plexus neuropathies.

Providing documentation of the specific mechanism and incidence of brachial plexus neuropathies in the wrestling athlete may lead to a better screening process as well as more 
specific treatment and rehabilitation protocols for this injury. By enhancing the screening process, potential problems may be noted at an earlier time and preventative techniques and methods can be started prior to the occurrence of an incident. One may hypothesize that more serious pathologies and life-altering injuries may be prevented in the process. It is the basic idea of prevention that lends to the significance of this study. 


\section{APPENDIX B}

\section{LITERATURE REVIEW}

Introduction

Cervical spine injuries have often been the focus of research in football athletes ${ }^{1-11}$ as the specific etiology, epidemiology, and diagnosis and management procedures have been documented. ${ }^{1-13}$ Brachial plexus neuropathies are common and occur quite frequently in football. ${ }^{1-11}$ Characteristically, brachial plexus neuropathies in football athletes are associated with a downward displacement of the shoulder with concomitant lateral flexion of the neck towards the contralateral shoulder. ${ }^{1,9,26,28}$ Although football athletes experience more single incidents of a most serious nature some will experience what is known as the chronic burner syndrome. It is surprising then that more research concerning predisposing factors of this injury have not been considered due to the nature and possible severity of brachial plexus neuropathies.

Due to neck positioning and the dynamics of the sport, wrestling athletes experience multiple incidents of brachial plexus neuropathies within a single season. It has been hypothesized that once an initial injury has occurred, a wrestler becomes more prone to reoccurrences of this injury or to more serious pathologies. In fact, some wrestling athletes have been medically disqualified and others have gone through cervical fusions after more serious pathologies have become present. The specific mechanism of injury, incidence, and prevalence of brachial plexus neuropathies within the sport have not been documented. It is this lack of information coupled with the severity of brachial plexus neuropathies within the sport of wrestling that commands the focus for this literature review. The following topics will be discussed in the literature review: Anatomy of the Cervical Spine, Biomechanics of the Cervical Spine, Epidemiology, Etiology, Chronic Burner Syndrome, Predictive Factors, and the literature review will end with a summary. 
Anatomy

Bony anatomy: The cervical spine is made up of seven vertebrae that form eight motion segments between the base of the skull and the first thoracic vertebrae. ${ }^{19}$ Each of the cervical vertebrae is numbered from superior to inferior, $\mathrm{C} 1$ through $\mathrm{C} 7$. The motion segments are numbered $\mathrm{C} 1$ through $\mathrm{C} 8$, according to the vertebrae that lie directly inferior to it. For example, the $\mathrm{C} 1$ motion segment is between the occiput and $\mathrm{C} 1$ whereas, the $\mathrm{C} 8$ motion segment is between $\mathrm{C} 7$ and $\mathrm{T} 1 .{ }^{37}$ Due to morphologically and mechanically distinct structures, the cervical spine may be divided into two separate regions, the upper and lower cervical spine. The upper cervical spine ( $\mathrm{C} 1$ and $\mathrm{C} 2)$ is comprised of two joints, the occiputoatlantal and the atlantoaxial, and differs greatly from the lower cervical spine (C3-C7). $\mathrm{C} 1$ is known as the atlas and is a ring without a vertebral body, whereas $\mathrm{C} 2$, otherwise known as the axis, has the odontoid, an upward projection that occupies the space where C1's vertebral body would have been. ${ }^{38,39}$ The atlas can be divided into an anterior and posterior arch. The lateral sides are enlarged facet surfaces that form an articular surface with the occiput to form the occiputoatlantal joint. Because this joint does not have a vertebral body or an intervertebral disc, there is considerable flexion and extension mobility. The axis is comprised of the odontoid, or dens, as well as a bony posterior arch. The odontoid forms a synovial articulation, the atlantoaxial joint, with the posterior aspect of the anterior arch of the atlas. This allows for axial rotation of the head on the cervical spine. ${ }^{37}$ Vertebral body shape remains constant from $\mathrm{C} 3$ through $\mathrm{C} 7$ although the size increases from approximately $17 \mathrm{~mm}$ to $23 \mathrm{~mm} .{ }^{40}$ The depth of the vertebral bodies increases from $16 \mathrm{~mm}$ to $18 \mathrm{~mm}$ and height increases from approximately $11 \mathrm{~mm}$ to $13 \mathrm{~mm} .{ }^{40}$ The sagittal diameter remains fairly consistent from $\mathrm{C} 3$ through $\mathrm{C} 7$ ranging from approximately $14 \mathrm{~mm}$ to $15 \mathrm{~mm} .{ }^{1}$ 
The lower vertebrae, C2 through C7, are comprised of a cylindrical vertebral body with a posteriorly projected bony arch. This posterior projection is termed the posterior elements or the neural arch. This makes up the laminae, pedicles, the spinous process, the transverse process, and both the superior and inferior facets. The vertebral canal is enclosed anteriorly by the vertebral body and posteriorly by the neural arch. The spinal canal is considerably larger in the upper cervical spine than in the lower cervical spine. The diameter of the canal reaches adult dimensions by approximately age thirteen. ${ }^{1}$ The superior facet surfaces of the inferior vertebrae are covered with articular cartilage and connect with the articular cartilage covered inferior facets of the superior vertebrae to form the zygapophyseal joints, or the facet joints. ${ }^{37}$ The transverse processes project laterally from the pars interarticularis. These processes project anteroinferiorly and have a nerve gutter formed by two tubercles on the most lateral surface. Within the transverse process is the foramen transversarium, which houses the vertebral artery and supplies blood to the brain stem and the posterior parts of the brain. The laminae are located posteromedially from the transverse process. The spinous process projects posteriorly from the midline fusion of the laminae. These are directly palpable structures on the dorsal surface of the neck and back. The neural arch protects the spinal cord as well as provides attachment sites for the musculature of the spine. ${ }^{37}$

Soft-tissue anatomy: Each motion segment is comprised of two paired and one unpaired articulation as well as ligaments. The unpaired articulation is the intervertebral disc. It is comprised of a fluid-like central portion called the nucleus pulposus and a solid outer structure called the annulus fibrosus. One paired articulation is the facet joint mentioned above. The other paired articulation is "formed by the curved lateral surfaces of the vertebral body." ${ }^{37}$ This 
is called the uncovertebral joint. There are potential articulations due to the fact that they do not come into direct contact when the spine is in a neutral position.

The vertebral bodies are connected via the anterior longitudinal ligament (ALL) and posterior longitudinal ligaments (PLL). The ALL runs longitudinally along the anterior surface of the vertebral bodies from the base of the skull to the sacrum while the PLL runs longitudinally along the posterior surface of the vertebral bodies, residing in the anterior portion of the spinal canal. ${ }^{41}$ The ALL is continuous with the anterior fibers of the annulus fibrosus. The ligamentum flavum is located within the spinal canal, posterior to the spinal cord and is attached on the surface of adjacent laminae. The ligamentum flavum has a high concentration of elastin and may be more compliant than pure collagen ligaments. Both the interspinous and supraspinous ligaments connect the spinous processes of adjacent vertebrae. The capsular ligament surrounds the facet joints. The nuchal ligament runs posterior to the supraspinous ligament along the entire spine. ${ }^{37,41}$

In addition to the aforementioned ligaments, the occiputoatlantal and atlantoaxial joints contain structures unique to the upper cervical spine. Deep to the anterior longitudinal ligament is the broader, thinner atlantooccipital ligament, which connects the anterior arch of the atlas to the base of the skull. ${ }^{41}$ The atlantoepistophical ligament is also found in this area and connects the anterior arch of the atlas to the anterior surface of the axis. The superior tip of the odontoid is connected to the base of the skull by the apical ligament. The alar ligaments run from the posterolateral surfaces of the odontoid superolaterally to the medial surfaces of the occipital condyles. The transverse ligament of the atlas connects the medial surface of the two lateral masses of the atlas. It also constrains the odontoid process posteriorly. This comprises the horizontal portion of the cruciate ligament. The vertical portion of the cruciate ligament 
"attaches to the anterior-inferior aspect of the foramen magnum, dorsal to the apical ligament, superiorly, and to the posterior aspect of the $\mathrm{C} 2$ vertebral body, inferiorly." ${ }^{37}$ The tectorial membrane runs from the posterior surface of the vertebral body of $\mathrm{C} 2$ to the foramen magnum. Two flaval ligaments fuse on the midline and form the posterior atlantooccipital membrane in the upper cervical spine.

Muscular anatomy: Stability of the cervical spine occurs primarily at the occipitoatlantal joint with the following muscles: multifidus, interspinalis, semispinalis capitis, and the semispinalis cervicis. ${ }^{39}$ Musculature involved with the mobility of the cervical spine includes the longus capitis, rectus capitis anterior, sternocleidomastoid, recti capiti posteriores major and minor, oblique capitis superior, splenius capitis, the trapezius, rectus capitis lateralis, longus colli, the scalene muscles, rotators, semispinalis, and the erector spinae. ${ }^{39}$ The following tables show the musculature of the cervical spine as well as origin, insertion, and action. Table B1 describes the muscles of the posterior triangle, Table B2 describes the prevertebral muscles and Table B3 describes the intrinsic back muscles. 
Table B1. Muscles of the Posterior Triangle ${ }^{39,42}$

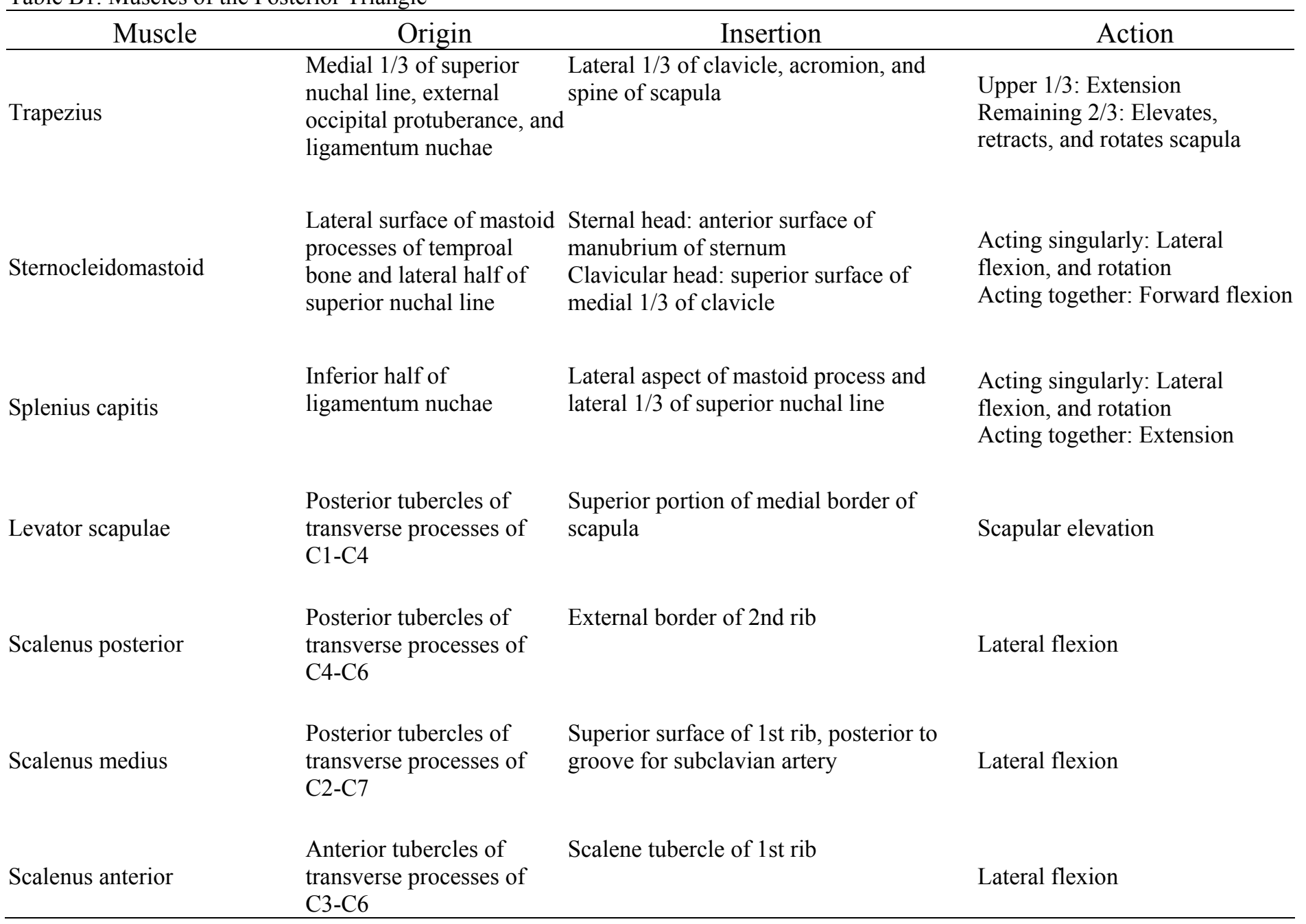


Table B2. Prevertebral Muscles 39, 42

\begin{tabular}{|c|c|c|c|}
\hline Muscle & Origin & Insertion & Action \\
\hline Longus colli & Anterior tubercle of $\mathrm{C} 1$ & $\begin{array}{l}\text { Body of } \mathrm{T} 3 \text { with attachments to } \\
\text { bodies of } \mathrm{C} 1-\mathrm{C} 3 \text { and transverse } \\
\text { processes of } \mathrm{C} 3-\mathrm{C} 6\end{array}$ & Neck flexion \\
\hline Rectus capitis anterior & $\begin{array}{l}\text { Base of skull, just anterior to } \\
\text { occipital condyle }\end{array}$ & $\begin{array}{l}\text { Anterior surface of lateral mass of } \\
\mathrm{C} 1\end{array}$ & Forward flexion \\
\hline Rectus capitis lateralis & $\begin{array}{l}\text { Jugular process of occipital } \\
\text { bone }\end{array}$ & Transverse process of $\mathrm{C} 1$ & $\begin{array}{l}\text { Forward flexion and } \\
\text { stabilization of head }\end{array}$ \\
\hline Longus capitis & Basilar part of occipital bone & & Forward flexion \\
\hline
\end{tabular}


Table B3. Intrinsic Back Muscles ${ }^{39,42}$

\begin{tabular}{|c|c|c|c|}
\hline Muscle & Origin & Insertion & Action \\
\hline Rotators & $\begin{array}{l}\text { Arise from transverse processes of } \\
\text { vertebrae }\end{array}$ & $\begin{array}{l}\text { Pass superomedially and attach to } \\
\text { junction of lamina and transverse process } \\
\text { of vertebrae of origin or into spinous } \\
\text { process above their origin, spanning one } \\
\text { to two segments }\end{array}$ & $\begin{array}{l}\text { Extension and rotation to } \\
\text { opposite side }\end{array}$ \\
\hline Semispinalis & $\begin{array}{l}\text { Arises from thoracic and cervical } \\
\text { transverse processes }\end{array}$ & $\begin{array}{l}\text { Semispinalis: thoracis, cervicis, and } \\
\text { capitis; fibers run superomedially and } \\
\text { attach to occipital bone and spinous } \\
\text { processes in thoracic and cervical regions, } \\
\text { spanning two to four segments }\end{array}$ & $\begin{array}{l}\text { Semispainalis cervicis: } \\
\text { Stabilization of cervical spine } \\
\text { Semispinalis capitis: Extension } \\
\text { and lateral flexion at } \\
\text { occipitoatlantal joint }\end{array}$ \\
\hline Erector spinae & $\begin{array}{l}\text { Arises by a broad tendon from the } \\
\text { posterior portion of the iliac crest, } \\
\text { posterior surface of the sacrum, } \\
\text { sacral and inferior lumbar spinous } \\
\text { processes, and supraspinous } \\
\text { ligament }\end{array}$ & $\begin{array}{l}\text { Iliocostalis: fibers run superiorly to angles } \\
\text { of lower ribs and cervical transverse } \\
\text { processes } \\
\text { Longissimus: fibers run superiorly to ribs } \\
\text { between tubercles and angles, to } \\
\text { transverse processes in thoracic and } \\
\text { cervical region, and to mastoid process of } \\
\text { temporal bone } \\
\text { Spinalis: fibers run superiorly to spinous } \\
\text { processes in the upper thoracic region and } \\
\text { to the skull }\end{array}$ & $\begin{array}{l}\text { Extension and rotation to same } \\
\text { side }\end{array}$ \\
\hline Multifidus & $\begin{array}{l}\text { Arises from sacrum and ilium, } \\
\text { transverse processes of T1-T3, } \\
\text { and articular processes of } \mathrm{C} 4-\mathrm{C} 7\end{array}$ & $\begin{array}{l}\text { Fibers pass superomedially to spinous } \\
\text { processes, spanning two to four segments }\end{array}$ & $\begin{array}{l}\text { Extension and rotation to } \\
\text { opposite side }\end{array}$ \\
\hline Interspinalis & $\begin{array}{l}\text { Superior surfaces of spinous } \\
\text { processes of cervical and lumbar } \\
\text { vertebrae }\end{array}$ & $\begin{array}{l}\text { Inferior surfaces of spinous processes of } \\
\text { vertebrae superior to vertebrae of origin }\end{array}$ & Stabilization of cervical spine \\
\hline
\end{tabular}

Brachial plexus anatomy: The brachial plexus (Figure B1) is comprised of the ventral rami of cervical nerves $\mathrm{C} 5$ through T1. ${ }^{10}$ The cervical nerves are formed from both a dorsal and ventral root and also yield dorsal rami, which innervates the musculature of the posterior neck as well as the skin. ${ }^{10,43}$ The ventral rami exit the intervertebral foramina and run adjacent to the subclavian artery. The brachial plexus runs deep to the sternocleidomastoid in the posterior triangle of the neck and travels "distally beneath the clavicle over the first rib en route to the 
arm." 10,43, 44 Just proximal to the clavicle, the ventral rami meet to form three trunks (Table B4). The roots of $\mathrm{C} 5$ and C6 comprise the superior trunk, C7 comprises the middle trunk, and the posterior trunk is made up of the roots of C8 and T1. Each trunk splits into an anterior and posterior division after diving beneath the clavicle. These divisions give rise to three cords: the medial, lateral, and posterior cords. The anterior division comprises both the medial and lateral cords. The posterior division comprises the posterior cord. The cords then divide to form five terminal branches that innervate the upper extremity. They are: the musculocutaneous, axillary, median, radial, and ulnar nerves. ${ }^{10,43,44}$ The cervical nerve roots, at their origin from the spinal cord, are most susceptible to injury due to a lack of protective epineurium and perineurium. These structures aid in the absorption of tensile and compressive forces. The dural dentate ligaments aid in anchoring the cervical nerve roots by creating a counter-traction force when the brachial plexus is under stress. ${ }^{9}$ Degenerative changes resulting in osteophytes, disc-space narrowing, and facet-joint hypertrophy may lead to a narrowed neuroforamen that can increase the potential of injury to this structure. Due to the "plexiform nature" of the brachial plexus it is more flexible, therefore more tolerant to tensile forces than the cervical nerve roots allowing for decreased susceptibility to injury. Overall, the more proximal nerve root-spinal complex is at greater risk for injury as a result of tensile or compressive forces than the more distal brachial plexus. $^{9}$ 
Table B4. Nerves of the Brachial Plexus ${ }^{39,42}$

\begin{tabular}{clll}
\hline Nerve Root & \multicolumn{1}{c}{ Muscles Innervated } & \multicolumn{1}{c}{ Sensation } & Reflex \\
\hline C5 & $\begin{array}{l}\text { Deltoid } \\
\text { Biceps }\end{array}$ & $\begin{array}{l}\text { Lateral Arm } \\
\text { Axillary Nerve }\end{array}$ & Biceps \\
C6 & $\begin{array}{l}\text { Wrist Extensors } \\
\text { Biceps }\end{array}$ & $\begin{array}{l}\text { Lateral Forearm } \\
\text { Musculocutaneous Nerve }\end{array}$ & Brachioradialis \\
& Wrist Flexors & Middle Finger & Triceps \\
& Finger Extensors & & \\
& Triceps & Medial Forearm & \\
& Fedial Anterior Branch Cutaneous & \\
& Finger Flexors & Nerve & \\
& Hand Intrinsics & Medial Arm \\
& & Medial Branch Cutaneous Nerve & \\
\hline
\end{tabular}

Figure B1. The Brachial Plexus ${ }^{10,11}$

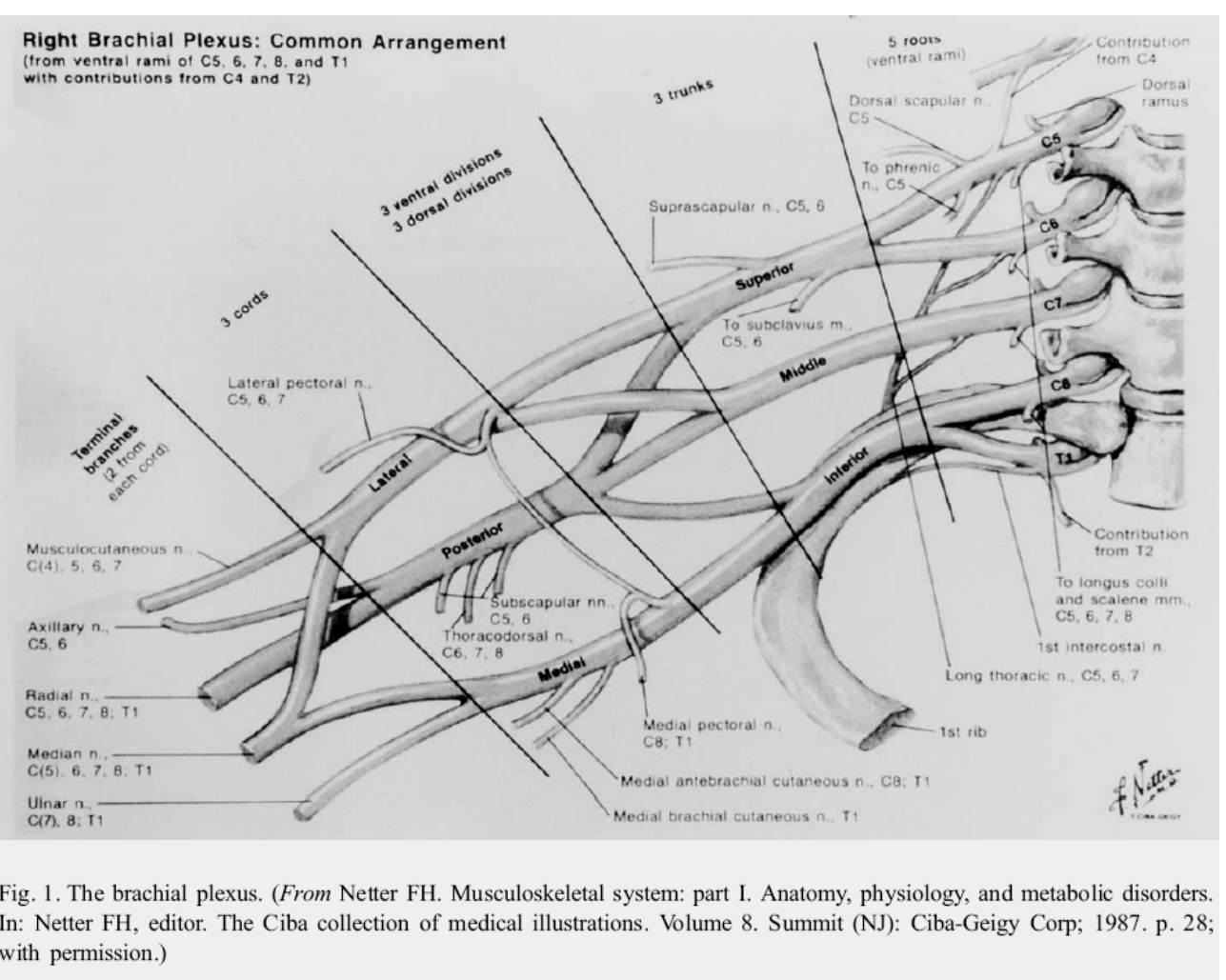

Vascular system anatomy: The axillary sheath houses the axillary artery, axillary vein, and the cords of the brachial plexus. There are three parts to the axillary artery; the first part is 
where it begins at the lateral border of the first rib where it is "continuous with the subclavian artery", the second part lies deep to the pectoralis minor, and the third portion extends between the inferolateral border of the pectoralis minor and the inferior border of the teres major where it continues distally as the brachial artery. ${ }^{45}$ The branch off of the first part of the axillary artery is the superior thoracic artery. This artery supplies part of the first and second intercostal spaces. The branches off of the second part of the axillary artery are the thoracoacromial artery and the lateral thoracic artery. The thoracoacromial artery is found at the superior border of the pectoralis minor and branches into the acromial, deltoid, pectoral, and clavicular, which run to their distributions. The lateral thoracic artery runs to the pectoral muscles. The subscapular artery comes off of the third part of the axillary artery. The subscapular artery continues inferiorly as the thoracodorsal artery, which supplies the latissimus dorsi. The circumflex scapular artery also branches off of the subscapular artery, which contributes to the anastomotic arterial network that surrounds the scapula. ${ }^{45}$

Biomechanics

The normal range-of-motion for the individual segments of the cervical spine ranges for each direction; flexion-extension may range from nine degrees to 20 degrees, one-sided lateral bending ranges from four degrees to 11 degrees, and one-sided axial rotation ranges from two degrees to seven degrees. ${ }^{46}$ The $\mathrm{C} 2-\mathrm{C} 3$ and C7-T1 motion segments have the smaller values in the range while the $\mathrm{C} 3-\mathrm{C} 4, \mathrm{C} 4-\mathrm{C} 5$, and $\mathrm{C} 5-\mathrm{C} 6$ motion segments have the higher values in the range. The upper cervical spine may approach flexion-extension values of approximately fortyfive degrees due to the lack of a vertebral body as well as the absence of an intervertebral disc. Ten degrees of one-sided lateral bending and forty-five degrees of one-sided axial rotation, with approximately forty degrees of axial rotation occurring within the atlantoaxial segment are also 
available in the upper cervical spine. ${ }^{37,47}$ However, both bony structure as well as ligamentous structures may limit the range-of-motion available to the cervical spine.

The kinematics of the lower cervical spine is largely influenced by the load-bearing role that bony structures play. ${ }^{46}$ The total bearing area of the facets is 1.2 times that of the area of the intervertebral disc in the $\mathrm{C} 2-\mathrm{C} 3$ through $\mathrm{C} 5-\mathrm{C} 6$ motion segments. It is 1.8 times that of the area of the disc in the C7-T1 segment. ${ }^{37,48}$ In addition, the articular pillars have been shown to contain a higher percentage of cortical bone than the vertebral body, thus allowing for a stiffer load path than the vertebral body. ${ }^{37,49}$

Structural limitations: The contact between the anterior portion of the foramen magnum and the apex of the odontoid process limits flexion. ${ }^{37,50}$ Bony contact between the occiput and the posterior arch of the atlas limits extension. ${ }^{37,51}$ A lock-and-key constraint to the axial rotation of the occipitoatlantal joint limits this joint to less than five degrees of rotation. ${ }^{37,47,50}$ The bony connection of the odontoid with the anterior and lateral portions of the atlas limits posterior and lateral translation of the atlas in the atlantoaxial joint. Anterior translation of the atlas is limited by the interaction between the odontoid and the transverse ligament. ${ }^{37} \mathrm{An}$ immediate loss of mechanical integrity of the motion segment may result if failure of either the transverse ligament or the odontoid is present. ${ }^{50,52,53}$ The atlantoaxial facets limit lateral bending to less than five degrees due to the cranially convex surface. The absence of intervertebral discs in both the occipitoatlantal and atlantoaxial joints means that the facets serve as the primary load-bearers during compression. ${ }^{37}$

Ligamentous limitations: The motion of the upper cervical spine is limited by additional ligamentous structures that are not found in the lower cervical spine. The transverse ligament limits anterior translation of the atlas. Werne ${ }^{50}$ suggested that the tectorial membrane limits 
forward flexion while Harris ${ }^{51}$ found extension to be limited by the tectorial membrane. ${ }^{37,39}$ The alar ligaments limit the axial rotation of the head and atlas on the axis. ${ }^{37,32,54}$ Extension of the upper cervical spine is limited by the anterior atlantoaxial ligaments while the posterior atlantoaxial ligaments limit flexion. ${ }^{39}$ The ligamentous structures of the lower cervical spine support tensile forces thereby limiting the motions causing a traction force to occur. The posterior longitudinal ligaments limit flexion as well as reinforcing the posterior portion of the annulus fibrosus. ${ }^{41}$ The anterior longitudinal ligaments limit extension as well as reinforce the anterolateral portion of the annulus fibrosus and the anterior aspect of the intervertebral disc. ${ }^{37}$, ${ }^{39,41}$ The outer fibers of the annulus fibrosus limits the distraction, translation, and rotation of the vertebral bodies. ${ }^{39}$ The ligamentum nuchae also limits forward flexion. ${ }^{39,41}$

Mobility: When movement occurs at the cervical spine the interaction of bony structures, ligamentous structures and intervertebral disc comes into play. The motions of flexion, extension, lateral flexion, and rotation are permitted in the cervical spine. ${ }^{46}$ Accompanying translations allow for greater mobility. However, translation occurs predominantly during flexion and extension. ${ }^{39}$ During flexion the anterior tilting and gliding of the superior vertebrae causes a widening of the intervertebral foramen and a separation of the spinous processes. ${ }^{39}$ The intervertebral discs influence flexion due to the anterior portion of the annulus fibrosus becoming compressed and bulging anteriorly throughout the motion while the posterior aspect becomes stretched and resists separation of the vertebral bodies. ${ }^{39}$ During extension the intervertebral foramen becomes narrowed as the spinous processes of the vertebrae move close to each other. Due to bony prominences limiting this motion, ligamentous checks are not necessary. ${ }^{39,46}$ During lateral flexion the superior vertebrae "tilts, rotates, and translates over the adjacent 
vertebrae." ${ }^{39}$ The concavity of the curve compresses the annulus fibrosus while it is stretched on the convexity of the curve at the same time. ${ }^{39,46}$

Table B5. Muscles and Motions of the Occipitoatlantal and Atlantoaxial Joints ${ }^{39}$

\begin{tabular}{lll}
\hline Extension & Flexion & Lateral Bending \\
\hline Longissimus capitis & $\begin{array}{l}\text { Anterior fibers of } \\
\text { Sternocleidomastoid }\end{array}$ & Longissimus capitis \\
$\begin{array}{l}\text { Rectus capitis posterior } \\
\text { major and minor }\end{array}$ & Longus Capitis & Rectus capitis lateralis \\
Superior oblique & Rectus capitis anterior & Splenius capitis \\
Semispinalis capitis & & Sternocleidomastoid \\
Splenius capitis & & Superior and Inferior oblique \\
Trapezius & & \\
\hline
\end{tabular}

The occipitoatlantal joint primarily permits flexion and extension although a small amount of axial rotation and lateral flexion may be possible. ${ }^{39,46}$ Only $2.5 \%$ to $5 \%$ of the total amount of rotation permitted by the cervical spine occurs at this joint. ${ }^{39}$ The atlantoaxial joint permits rotation, lateral flexion, extension, and flexion. ${ }^{46}$ Here, approximately $55 \%$ to $58 \%$ of the total rotation occurs, with the atlas pivoting approximately forty-five degrees to either side for a total of ninety degrees of motion. ${ }^{38,39}$ Table B5 describes the muscles and motions of both the Occipitoatlantal and Atlantoaxial joints while Table B6 describes the musculature related to rotation at the Atlantoaxial joint. 
Table B6. Muscles of Rotation at the Atlantoaxial Joint ${ }^{39}$

\begin{tabular}{ll}
\hline Contralateral & Ipsilateral \\
\hline Semispinalis capitis & Inferior oblique \\
Sternocleidomastoid & Longissimus capitis \\
& $\begin{array}{l}\text { Rectus capitis posterior, major } \\
\text { and minor }\end{array}$ \\
& Splenius capitis \\
\hline
\end{tabular}

The lower joints account for the remaining $40 \%$ of rotation permitted by the cervical spine. ${ }^{39}$ Below the level of $\mathrm{C} 2$, lateral flexion and rotation are coupled due to the bony configuration of the facet joints. The maximum values for both flexion and extension may be found at the C4-C5 and C5-C6 motion segments with the minimal values being recorded at the C2-C3 motion segment. ${ }^{37,39}$

Epidemiology

Cervical spine injuries can occur during a multitude of activities such as automobile accidents, gunshot wounds, falls, dives, and sports. Of these, motor vehicle accidents account for between $52 \%$ and $68 \%$ of cervical spine injuries. ${ }^{32}$ Sporting events are the fourth leading cause of spinal cord injury. ${ }^{32}$ Somewhere between $5 \%$ and $10 \%$ of the 10,000 cervical spine injuries that occur in the United States can be accounted for by sporting events. ${ }^{32,35}$

Brachial plexus neuropathies, otherwise known as burners or stingers, are a transient neurological incident that is characterized by upper extremity pain and paraesthesias unilaterally. $1,2,9,26,35,55$ Athletes experiencing this may report numbness, tingling, or burning sensations in the affected extremity. $1,2,3,6,9,13,26,27,28,32,35,55$ The neurological sensation experienced is different from a spinal cord injury as it is not bilateral and usually occurs in a circumferential rather that dermatomal pattern. ${ }^{1,3,9,28}$ Cervical nerve roots five through seven are the most 
commonly involved with this injury. ${ }^{38,40}$ This injury is common to collision as well as contact sports such as hockey, basketball, boxing, rugby, weight lifting, wrestling, and most notably football. ${ }^{3,9,13,28,35,56}$ One study revealed that stingers are the most common symptomatic upper-extremity injury. ${ }^{57}$

The literature reports that between $50 \%$ and $65 \%$ of all football players will experience a burner at least once during their career. ${ }^{1-4,17,26,27,32,35,55}$ Castro et al. ${ }^{27}$ reported a yearly stinger incidence of 7.7\% ${ }^{26}$ However, Meyer et al. ${ }^{5}$ reported a yearly stinger incidence of $3.7 \%$ as well as a stinger prevalence of $15 \%$. The relative risk of a player having a reoccurrence of injury was twice the risk of an athlete experiencing an initial stinger. ${ }^{1,2}$ Meyer et al. ${ }^{5}$ noted that there was a relative risk of reoccurrence three times that of experiencing an initial stinger. ${ }^{55}$ Within the sport of wrestling there is a $20 \%$ chance of sustaining a neck injury with a $50 \%$ risk of reoccurrence. ${ }^{12}$

Sallis et al. ${ }^{4}$ reports the percentage of incidence of this injury among the different football positions as follows: $17 \%$ offensive linemen, $18 \%$ defensive linemen, $11 \%$ offensive backs, $30 \%$ defensive backs, $5 \%$ receivers, and $2 \%$ punters.

Between the years of 1982 and 2000, wrestling accounted for the highest number of catastrophic injuries at the high school level among winter sports. ${ }^{32}$ With the incidence of injury at three times more likely during matches than during practice. Take-down maneuvers accounted for the majority of these injuries. ${ }^{32,58} \mathrm{Wu}^{59}$ documented three cases of serious injury to the cervical spine and spinal cord. He noted that the sport of wrestling may lead to serious injury to both the cervical spine and spinal cord. ${ }^{59}$ Jarrett et al. ${ }^{60}$ documented that next to spring football, wrestling recorded the highest injury rate. Requa ${ }^{58}$ noted that the injury rate in wrestling comes second only to football. Boden et al. ${ }^{61}$ documented that of his study subjects, $63 \%$ required at least one surgical procedure, usually being a cervical fusion. He also noted the 
timing and position of the athlete at the time of injury. Eighty percent of injuries occurred during a match with seventy-four percent of the wrestlers being at a disadvantage. ${ }^{61}$

\section{Etiology}

Brachial plexus neuropathies have been found to occur by one of three different mechanisms: traction, nerve root compression, or a direct blow. ${ }^{1,3,5-11,13,27,28,55}$ Seddon's criteria is utilized as a grading scale for this injury. A grade I injury is a neurapraxia which is a "transient motor or sensory deficit without structural axonal disruption." 9 A grade II injury is an axonotmesis, which includes axonal disruption although the epineurium remains intact. The neural deficit associated with this remains present for a minimum of two weeks. A grade III injury will persist for a minimum of one year with little to no improvement. ${ }^{9}$ This injury is known as a neurotmesis, a total disruption of both axons as well as all supportive connective tissue. ${ }^{9}$ Brachial plexus neuropathies usually are grade I or II type injuries. ${ }^{28}$ The distributions of C5 and C6 are most commonly injured with brachial plexus neuropathies. ${ }^{3}$ 
Figure B2. Mechanism of Injury for a Brachial Plexus Neuropathy ${ }^{10}$
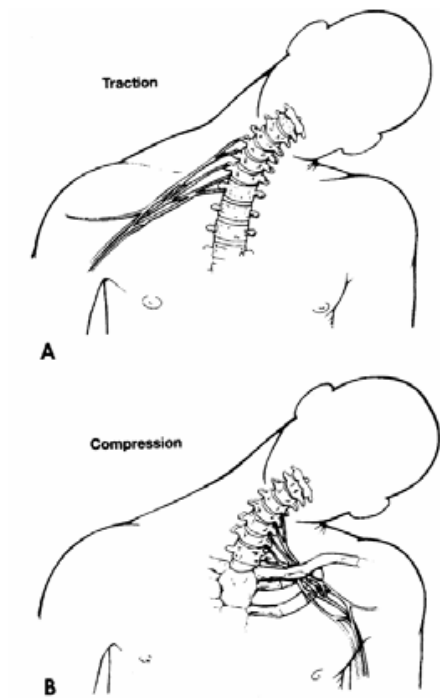

Figure B2. A) Traction injuries occur with a downward displacement of the shoulder with concomitant lateral flexion of the neck towards the contralateral shoulder.

B) Compression of the brachial plexus roots occurs with forced lateral flexion as well as cervical spine extension with ipsilateral-lateral flexion.

The most common mechanism to football players is a downward displacement of the shoulder with concomitant lateral flexion of the neck towards the contralateral shoulder (Figure B2). ${ }^{1,9,26,28}$ This is known as the traction mechanism and is associated with a block or tackle in football. ${ }^{1,3,9,26-28,32,55}$ The traction mechanism has been proposed as the mechanism for injury at the $\mathrm{C} 5$-C6 level. ${ }^{4,17,55}$ In wrestling, severe lateral flexion of the neck achieves the same mechanism as the downward displacement of the shoulder with concomitant lateral flexion of the neck in football. ${ }^{12,35}$ This occurs as a wrestler attempts to pull the opponent's leg toward him. The attacking wrestler puts their neck in flexion. ${ }^{12}$ A small neck that is unable to dissipate force is suggested to be more prone to injury, therefore a younger population presents with this particular mechanism of injury. ${ }^{10,11,63}$ Koffler $^{10}$ reported that arm position influences the injury pattern. Shoulder adduction at the time of injury places increased stress on the upper roots whereas shoulder abduction places the lower roots in a more vulnerable position. 


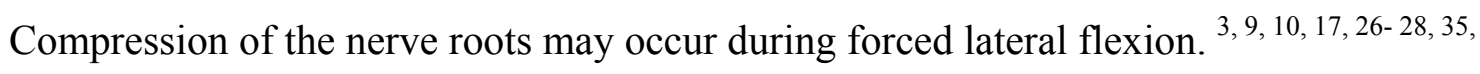
${ }^{55}$ At this time neuroforaminal narrowing occurs to cause compression of the exiting cervical nerve root. $1,9,10,26,27,32,34,35,55$ Nerve root compression may also occur with cervical spine extension in combination with ipsilateral-lateral flexion. ${ }^{9,11,13,62}$ Levitz et al. ${ }^{13}$ supports this in his study of recurrent cervical nerve root neurapraxia. This mechanism occurs in wrestling when the attacking wrestler attempts to pull the opponent's leg toward him by pulling his arms. ${ }^{62}$ During this, his head is held to the inside forcing his head into lateral flexion. In an attempt to resist this move, the opponent adds pressure to the attacking wrestler's head, further forcing it into lateral flexion. This specific mechanism has been shown to be more predominant in a more mature population due to degenerative changes that may influence foraminal height to compress the cervical nerve roots. ${ }^{3,10,11,26,27,55,63}$ These degenerative changes have been shown to lead to recurrent burner syndrome. ${ }^{3}$

Compression at Erb's point is another mechanism of injury to the brachial plexus. ${ }^{1,3,9,10,}$ 17, 28, 55 This is accomplished by a direct blow to supraclavicular region, where the brachial plexus is most superficial. ${ }^{17,55}$ This usually occurs when an opponent or an opponent's helmet drives the athlete's shoulder pad directly into the brachial plexus at this point. ${ }^{9,13}$ Chronic Burner Syndrome

Chronic burner syndrome deals with the reoccurrence of brachial plexus neuropathies. The incidence of this syndrome may be as high as $57 \% .{ }^{3,26}$ Levitz et al. ${ }^{13}$ examined this syndrome and found that the mechanism of extension in combination with ipsilateral-lateral deviation occurred in athletes with chronic burner syndrome. ${ }^{55}$ Of his study subjects, $53 \%$ had developmental narrowed cervical canals, $87 \%$ showed evidence of disk disease, and $93 \%$ had narrowing of the intervertebral foramina secondary to degenerative disk disease. ${ }^{3,13}$ These 
findings support the theory that nerve root compression due to disk degeneration leads to a greater likelihood of reoccurrence of injury. Sallis et al. ${ }^{4}$ reports an $87 \%$ recurrence rate of brachial plexus neuropathies, further demonstrating the high recurrence rate associated with this injury. ${ }^{28}$ Any time that chronic burner syndrome is suspected, the athlete should undergo diagnostic imaging to rule out the pathologies that may present with disk degeneration. Predictive Factors

The position played as well as body morphology has been identified as possible risk factors for sustaining a brachial plexus neuropathy independent of cervical stenosis. ${ }^{1,6,7}$ Position played can increase the risk of injury depending on offensive or defensive status. Offensive players have the luxury of deciding to change direction at the last second, whereas defensive players must anticipate and react to an offensive player's actions. An incorrect anticipation may lead to an unexpected collision, leaving the athlete vulnerable to injury.

Torg ratio: Torg ratio (Figure B3) is a measurement of the ratio of the midsagittal diameter of the spinal canal to the vertebral body diameter referring to the narrowing of the cervical spinal canal. ${ }^{1,2,3,6,7,25-27,35,64-67}$ The distance measured from the midpoint of the posterior aspect of the vertebral body to the nearest point on the corresponding spinolaminar line is divided by the antero-posterior width of the vertebral body, as measured through the midpoint of the corresponding vertebral body. ${ }^{3,6,7,9,25-27,40,35,55,64-68}$ 


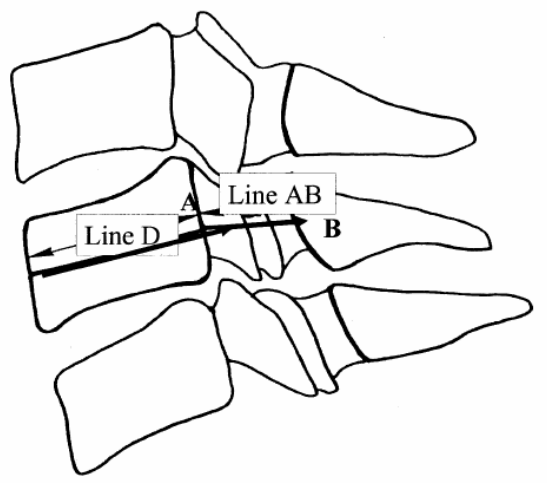

The original definition of significant cervical stenosis being 0.80 or less was based on "statistical sensitivity of the relative opening characteristic curve for the average Torg value over the entire cervical canal, not the smallest level measured." 1,2,35,40,68 An increased risk of sustaining a brachial plexus neuropathy has been correlated to a decreased Torg ratio. ${ }^{34,35}$ Evidence shows that cervical stenosis is associated with an extension compression mechanism. ${ }^{10}$ The sagittal diameter of the spinal canal is compromised by as much as $30 \%$ by the "indentation of the ligamentum flavum and laminar ligaments." ${ }^{7,26,55,65,66}$ Reoccurrence of brachial plexus neuropathies has also been associated with a decreased Torg ratio. ${ }^{13}$ Due to being a poor predictor of functional cervical stenosis, Castro et al ${ }^{2}$ redefined the Torg ratio definition of stenosis to be 0.70 or less. Functional stenosis considers "bony canal dimensions, cord thickness, and the cushioning potential of the cerebral spinal fluid (CSF)." ${ }^{1,2}$ Football players with a decreased Torg ratio have been reported to be at an increased risk of reoccurrence for brachial plexus neuropathy. Odor et al. ${ }^{69}$ reports that almost one-third of professional and amateur football players will present with a Torg ratio less than 0.8 at one or more levels anywhere from $\mathrm{C} 3$ to $\mathrm{C} 6$. This may be due to the larger mass of these athletes.

Meyer et al. ${ }^{5}$ indicated that athletes with a Torg ratio less than 0.8 are three times more likely to experience a brachial plexus neuropathy with an extension-compression type 
mechanism. ${ }^{26,55}$ Koffler et al. ${ }^{10}$ supports this theory as well. The author continues to state that the athlete with a narrow spinal canal will present with a narrow foramina as well. Foraminal stenosis may be determined by dividing the height of the intervertebral foramen by the middle vertebral height of the inferior vertebral body. Degenerative changes may lead to superior migration of the facet, buckling of the ligamentum flavum, posterior protrusion of the annulus fibrosus, and shortening of foraminal height. ${ }^{10}$ These changes along with congenital stenosis or a herniated nucleus pulposus may predispose athletes to an extension compression mechanism of brachial plexus neuropathy. As a result, root burners are most frequently observed in a more mature population. ${ }^{10}$

Cervical stenosis as determined by a decreased Torg ratio does not always predict brachial plexus neuropathies. ${ }^{38,69,70}$ Both Odor ${ }^{69}$ and Herzog ${ }^{70}$ found asymptomatic football players that had cervical stenosis. Torg ${ }^{6,7,34}$ reported the high sensitivity, low specificity, and low predictive value limits the use of the Torg ratio as a screening method. ${ }^{26,40,35,67}$ Because football players have wide vertebral bodies they will present with a lower ratio without having a narrow canal. ${ }^{35,40,63}$ This is somewhat of a false positive.

Degenerative changes: Torg ${ }^{56}$ and Pavlov ${ }^{68}$ discuss the implications of degenerative changes on the cervical spine. This is most significant in an already stenotic spine. ${ }^{25} \mathrm{~A}$ hyperextension mechanism can compress the spinal cord when the ligamentum flavum indents inwardly. ${ }^{25,64}$ The laminar ligaments undergo the same changes. ${ }^{25,64}$ This can cause the canal to decrease by up to $30 \% .{ }^{25,64}$ Degenerative changes can cause a small slippage of the vertebrae. The instability that may result from brachial plexus injuries is due to deficits in neck strength and range-of-motion that can be found post-injury. ${ }^{28}$ MRIs and X-Rays are necessary when there is 
any suspicion of chronic burner syndrome due to the implication that degenerative changes may have on the cervical spine.

Neck strength: Wrestling is one of the most demanding sports with regard to the neck. The maneuvers themselves impose significant loading upon the neck and it has been assumed that neck strength is essential to avoiding trauma. ${ }^{12,62}$ Koffler et al. ${ }^{10}$ states that high school athletes experience brachial plexus neuropathies due to decreased neck musculature. Unfortunately, this has not been studied adequately within athletics. Studies documenting any correlation between cervical muscle strength and injury are very few in number however, it has been documented that increasing cervical strength decreases the amount of neck pain perceived. 21,18, 19, 29, 30 Also, patients with neck pain have been shown to exhibit decreased cervical strength and endurance. ${ }^{71}$

Vernon et al. ${ }^{18}$ supported Chiu's ${ }^{71}$ findings that bilaterally symmetry in lateral flexion is not equal (between $6 \%$ and $8 \%$ ) and presents a problem for baseline testing in patients with unilateral pain syndromes. He also found that progressive weakness in isometric muscle strength of the cervical flexors as compared to the extensors in patient's experiencing a pain syndrome only serves to further anterior-to-posterior imbalance between this musculature. The weakness of the cervical flexors compared with that of the cervical extensors is shown in the means and standard deviations $\mathrm{kPa}$ of flexion and extension (flexion $4615 \pm 1317 \mathrm{~N}$ and extension-7927 \pm $2128 \mathrm{~N}$ ). The progressive weakness of the cervical flexors is shown in the percentage difference between trial one and trial two (10.4\%) as compared with the cervical extensors (7.0\%).

Studies have examined the motions of flexion and extension ${ }^{22,23,72,}$ however; lateral bending has not been studied. Garces et al. ${ }^{19}$ reported that cervical muscle strength for averaged flexion and extension at multiple angles and ages are $30 \%$ to $40 \%$ stronger for men than women. 
When comparing the flexor/extensor ratio there was no significant difference between men and women or between age groups ( 0.5 to 0.9 range). Mean strength was reported to be greater at $10^{\circ}$ than at $5^{\circ}$ and greater at $5^{\circ}$ than at $0^{\circ}$ in both flexion and extension in men. This finding was replicated in women as well. Although men were found to be stronger than women, the results at different angles in both genders were identical. Unfortunately, brachial plexus neuropathies occur when the head is being pushed into lateral flexion or during the extension-compression mechanism. Weakness of the musculature utilized to support the cervical spine during lateral flexion may result in muscular imbalance resulting in injury to an athlete. ${ }^{17,71}$ This hypothesis is supported by Chiu's ${ }^{71}$ study.

Chiu ${ }^{21}$ demonstrated that lateral flexion to the right side (dominant in his patients) is $11 \%$ stronger than lateral flexion to the left side (non-dominant side) in men. He hypothesized that this could be due to hand dominance. This particular information is of clinical importance when considering the mechanism of injury. An athlete that presents with injury resulting from a mechanism associated with lateral flexion should be asked whether his dominant or nondominant side is affected. Using Chiu's ${ }^{21}$ study one may hypothesize that the non-dominant side will be injured more often than the dominant side. He also noted that maximal isometric muscle strength was observed at $20^{\circ}$ of forward flexion for men and at $40^{\circ}$ of forward flexion for women. ${ }^{71}$ At $45^{\circ}$, maximal isometric muscle strength develops for both men and women. Maximal isometric muscle strength was observed at $20^{\circ}$ of extension for men and $40^{\circ}$ of extension for women. ${ }^{71}$

In another study, Ylinen et al. ${ }^{12}$ demonstrated that strength differences between elite and junior level wrestlers are not related to body size. He did note that strength in elite wrestlers is significantly higher than both junior wrestlers as well as nonsportsmen. Because strength values 
in both flexion and axial rotation were found to be elevated, he proposed that the maneuvers and specific training in wrestling does increase the strength of both cervical flexors as well as cervical rotators. ${ }^{12}$ Due to the importance of the cervical musculature in the stability of the cervical spine as well as the mobility of it, the strength of this musculature becomes essential to the reduction of injury within this sport. Again, the muscular imbalance between the cervical flexors and extensors is noted. Ylinen ${ }^{12}$ reported that senior wrestlers demonstrated a ratio of 0.74 , junior wrestlers showed a ratio of 0.65 , and nonsportsmen demonstrated a ration of 0.55 . Mean strength values for cervical extension were $462 \mathrm{~N}, 384 \mathrm{~N}$, and $275 \mathrm{~N}$ for senior wrestlers, junior wrestlers, and nonsportsmen, respectively. For flexion those values are: $346 \mathrm{~N}, 252 \mathrm{~N}$, and $153 \mathrm{~N}$, respectively. Right rotational strength values were reported to be: $33.5 \mathrm{~N}, 21.7 \mathrm{~N}$, and $12.1 \mathrm{~N}$, respectively with left rotational strength values reported at: $32.2 \mathrm{~N}, 22.0 \mathrm{~N}$, and $12.7 \mathrm{~N}$, respectively. This study demonstrates a similarity between rotational scores to the right and left instead of bilateral differences possibly due to hand dominance.

Ylinen et al. ${ }^{23}$ noted that peak isometric strength values were significantly decreased in women with chronic neck pain as compared with healthy controls. In extension healthy controls were reported to have a peak value of $187.1 \pm 39.2 \mathrm{~N}$ whereas those with chronic neck pain reported $132.1 \pm 38.5 \mathrm{~N}$. Strength values for flexion were $75.7 \pm 23.5 \mathrm{~N}$ and $53.8 \pm 18.3 \mathrm{~N}$ for healthy controls and those with chronic neck pain, respectively. Right rotational strength values were $8.0 \pm 2.4 \mathrm{~N}$ and $5.8 \pm 1.2 \mathrm{~N}$, respectively and left rotational strength values were $7.4 \pm 2.3 \mathrm{~N}$ and $6.1 \pm 1.6 \mathrm{~N}$, respectively. This supports the hypothesis that neck pain is related to muscular weakness in all directions tested. Ylinen et al. ${ }^{22}$ demonstrated once again that the extensor muscles of the neck are substantially stronger than the flexors. Prior to a neck strengthening program neck flexor isometric muscle strength was recorded at $83 \mathrm{~N}$ whereas neck extensor 
isometric muscle strength was recorded at $158 \mathrm{~N}$. After the training period the values increased to $117 \mathrm{~N}$ and $207 \mathrm{~N}$ for flexors and extensors, respectively. The authors also noted that pain decreased as strength increased. The Oswestry index was utilized to examine how neck pain and associated symptoms affected the subjects' everyday lives as compared to the life of a healthy person. These scores declined from 21 to 16 at the end of the rehabilitation program. The visual analog scale was utilized to measure pain. These scores decreased from $7.1 \mathrm{~cm}$ to $4.1 \mathrm{~cm}$ at the end of the rehabilitation program thus supporting the hypothesis that increased neck strength leads to decreased neck pain.

Suryanarayana ${ }^{20}$ also indicated that cervical extensors are stronger than cervical flexors. At neutral, $25 \%, 50 \%$, and $75 \%$ of extension the mean forces were $39.5,27.6,20.4$, and $15.4 \mathrm{~N}$ while flexion yielded $19.8,15.2,12.7$, and $5.7 \mathrm{~N}$, respectively. This demonstrates the postural role of the extensor musculature as well as the "obvious muscle mass difference between posterior and anterior muscles of the cervical spine. In contrast to Chiu's ${ }^{71}$ findings, as flexion and extension went farther from neutral the muscle strength scores decreased. Once again, males demonstrated significantly higher peak forces than females $(\mathrm{P}<0.01)$. Strimpakos ${ }^{31}$ also found that males were stronger than females in all movements. He noted that males were $42 \%$ to $58 \%$ stronger than females.

Studies seeking to standardize the method of testing cervical strength have run into discrepancies among strength values and patient positioning. Jordan et al. ${ }^{30}$ reported on the maximal isometric strength of healthy volunteers and noted that although strength values were higher than those previously reported, these values were due to the measuring system utilized as well as patient preparedness. He goes on to note that some devices prohibit extrinsic muscles 
from generating force due to the measuring setup. ${ }^{30}$ Although this is a valid concern, the input of extrinsic musculature takes away from the isolation of the cervical spine musculature.

One point does seem relatively consistent throughout the literature regarding cervical strength. Patients in a seated position show more consistent results within the study ${ }^{30}$ and patients are more comfortable in this position. Isolation of the cervical extensors may be readily accomplished because of this. ${ }^{29}$ The greatest electric activity of the spinal muscles has been shown in the seated position with the cervical spine in a neutral position as compared with maximal flexion and extension positioning of the cervical spine. ${ }^{20,29}$ Suryanarayana ${ }^{20}$ supported this view and noted that the seated position is "not only functional, but offers a representation of the postures in which we can isolate cervical muscles." Strimpakos et al. ${ }^{31}$ disagrees in stating that a standing position is more functional and allows for fewer factors necessary for control by investigators. The strength measurements for flexion, extension, and side flexion ranged from 11.2 to $27.5 \mathrm{~N}$ in the sitting position as compared to 7.7 to $16.5 \mathrm{~N}$ in the standing position. The authors stated that the increase in strength in the sitting position is caused by compensation. Extension in the sitting position yielded the highest mean strength value at $241.7 \mathrm{~N}$ whereas flexion in the standing position yielded the lowest strength value at $153.8 \mathrm{~N}$.

The type of device utilized for cervical muscle strength is yet another point of controversy within the literature. Seng et al. ${ }^{73}$ utilized a device that was fixated onto the Biodex Isokinetic Dynamometer and utilized in an isometric capacity. He reported the device to have "good repeatability with regard to all measured parameters." Suryanarayana ${ }^{20}$ also utilized an isometric device. His device consisted of an adjustable chair, sliding platform and floormounted strength measuring device. A vertical telescopic metal tube was welded to a thick plate and bolted to the floor. A counterweighted metal tube was pivoted to rotate vertically at the 
point of pivoting. ${ }^{20}$ This device was also reported to be reliable. A fixed neck strength measurement system was utilized by Ylinen ${ }^{12}$ to measure isometric muscle strength in flexion, extension, and rotation. Reliability and validity of this device was not noted. Strimpakos ${ }^{31}$ utilized a custom-made isomyometer device for his strength measurements. His device consisted of a 50-kg load cell with a double-framed stabilization system. This device was noted to have nearly excellent interexaminer and intraexaminer results. $\mathrm{Chiu}^{21}$ utilized the Multi Cervical Rehabilitation Unit to measure the isometric cervical strength in flexion, extension, left and right lateral flexion, protraction, and retraction. The validity and reliability of this device was not noted. Garces et al. ${ }^{19}$ utilized the Kin-Com computerized dynamometer in the directions of flexion and extension. This device was shown to be a reliable tool for measuring cervical strength in both flexion and extension. The MedX cervical extension machine was utilized by Leggett et al. ${ }^{29}$ and was determined to be both reliable and valid. Jordan et al. ${ }^{30}$ measured maximal isometric strength with a strain-gauge dynamometer. For both flexion and extension reliability was established. Silverman et al. ${ }^{72}$ utilized a MicroFET hand-held dynamometer. Values for interrater break testing ranged from .85 to .91 , and for isometric testing from .82 to .89. Intrarater correlation coefficients for break and isometric testing were significant with values ranging from .77 to .93 and .81 to .89 , respectively. The authors conclude that this device is reliable for both intrarater and interrater measurements. The high intraclass coefficient (.997) suggests that these measurements are reproducible in the neck pain population on repeat testing. Vernon et al. ${ }^{18}$ used a modified sphygmomanometer dynamometer (Comparative Muscle Tester) to assess isometric muscle strength. This device was found to be highly accurate with instrument-related variability or error less than $1 \%$. Nearly all measurement devices utilized were found to be both reliable and valid. 
Head-neck segment: Dynamic joint stabilization is defined as "the ability of the myotendon unit to absorb external loads and minimize excessive joint movement." ${ }^{14}$ The two primary stabilizers of the head and neck are the sternocleidomastoid and the trapezius. It is these muscles that must react in response to or before external forces are applied to decrease the resulting acceleration. Wrestlers are subjected to unexpected forces as their opponents attempt to take them down. Tierney et al. ${ }^{14}$ examined the head-neck segment by weighing subjects in pounds and then converting the measure to kilograms $(\mathrm{kg})$. This gave the Body mass which was then multiplied by the gender specific head-neck segment to total body mass percentage to determine head-neck segment mass. Head-neck segment length was determined by measuring from the spinous process of the $7^{\text {th }}$ cervical vertebrae to the top of the head. Girth was measured just above the thyroid cartilage. Unfortunately, this study sought to examine gender differences, rather than correlation to injury and the authors examined the correlation to concussions rather than neck injuries.

Head-neck length: Head-neck length can also influence the likelihood that an athlete may be injured due to acceleration forces. It may be hypothesized that a greater head-neck length may have an increased probability of injury. A longer length creates greater acceleration than a shorter length. This possible predictive factor has not been previously studied.

Neck muscle girth: Neck muscle girth may be correlated to neck muscle strength. An individual with a greater girth may have an increased muscle mass and therefore, may exhibit greater neck muscle strength. Tierney et al. ${ }^{14}$ notes that increased girth and contraction of the stabilizing musculature increases the ability to resist external forces once applied. As discussed previously, it has been hypothesized that a small neck that is unable to dissipate force may be 
more prone to injury. ${ }^{10,11,63}$ This may be evident in the lower weight classes such as $125 \mathrm{lb}$. and 133lb., where the wrestlers are generally smaller than those in other weight classes.

\section{Summary}

In conclusion, brachial plexus injuries are debilitating injuries and have been shown to have a high reoccurrence rate. The biomechanics and anatomical structures of the cervical spine lend this area a considerable amount of mobility and stability. These structures are the only preventative measures available to prevent wrestling athletes from incurring a brachial plexus neuropathy.

This injury is frequently noted within the sport of football. The specific mechanism of injury within football, as well as the prevalence of injury has been well documented. Studies dealing with wrestling athletes and brachial plexus neuropathies have attempted to explain the mechanism of injury, however these studies are few in comparison to the sport of football. Studies documenting the predictive factors of brachial plexus neuropathies have centered on the Torg ratio. The Torg ratio has been found to have a low predictive value of injury to the brachial plexus. Unfortunately, limited information regarding other predictive factors has not been substantiated with regard to correlation with brachial plexus neuropathies.

Neck strength has been examined with regard to chronic neck pain. It has been noted that increased neck strength yields a decrease in the perception of neck pain. The muscular imbalance between the cervical flexors and extensors has been well documented and has been shown to have some correlation to neck pain. A small head-neck segment and head-neck length have been reported to decrease the acceleration of the head once external forces are applied. Neck muscle girth and its correlation to neck muscle strength as well as the acceleration of the head once external forces are applied has not been thoroughly researched. 
Brachial plexus neuropathies occur frequently in athletic events, namely football and wrestling. Although there is a plethora of documentation regarding the incidence, prevalence, and mechanism of injury to football players, information regarding wrestlers is sparse.

Furthermore, research has centered on one predictive factor: the Torg ratio, which has been shown to have a low predictive value for this injury. 
APPENDIX C

ADDITIONAL METHODS

Table C1. Consent Form

CONSENT AND INFORMATION FORM

\section{PREDICITVE FACTORS OF BRACHIAL PLEXUS NEUROPATHY IN WRESTLING ATHLETES.}

\section{Introduction}

$\mathrm{I}$, , have been invited to participate in this research study, which has been explained to me by Deena Dillard, ATC. She is conducting this research under the supervision of Michelle A. Sandrey, PhD, ATC to fulfill the requirements for a master's thesis in Athletic Training in the School of Physical Education at West Virginia University.

\section{Purpose of the Study}

The purpose of this study is to examine the possible predictive factors of burner or stingers in wrestling athletes. The secondary purpose is to provide documentation of the incidence, prevalence, and mechanism of this injury within the sport of wrestling during a competitive season.

\section{Description of Procedures}

This study will take place in the Shell Athletic Training Room in the West Virginia University Shell building as well as at various locations prior to dual meets.

Orientation Procedures

At an orientation meeting the purpose of this study will be explained to me. I will be given an informed consent form explaining my rights as a research subject as well as a prescreening questionnaire. If I am one of the eligible subjects, I will be contacted by the principal investigator and will schedule a time for my baseline testing. I will be asked for my full cooperation and to work to the best of my ability. My involvement in this research study will initially take twenty minutes for a baseline testing session. This will be followed by evaluation of injury when and if it occurs. Additionally, I will be subject to repeated testing of neck strength two nights prior to dual matches. This additional testing will take approximately ten minutes. I may be subject to a post MRI or X-Ray if I experience multiple incidents of brachial plexus neuropathies. A final twenty minutes of a posttest will conclude my participation.

$11 / 03 / 05$

Version Date
Page 1 of 4

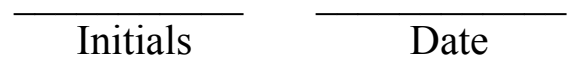




\section{PREDICITVE FACTORS OF BRACHIAL PLEXUS NEUROPATHY IN WRESTLING ATHLETES.}

\section{Interventions}

Head-neck segment, head-neck length, neck muscle girth, and the pre-screening questionnaire will be conducted prior to testing at the start of the season. Head-neck segment, head-neck length, and neck muscle girth will be repeated at the conclusion of the wrestling season along with neck strength. The procedure for testing neck strength will be repeated the night prior to dual matches. Injury recording of burners or stingers will take place throughout the season.

I will notify the principal investigator, should I experience a brachial plexus neuropathy.

I will be tested utilizing the Lafayette Manual Muscle Test System. Testing will be administered and supervised by the principal investigator at the Shell Athletic Training Room in the Shell Building. Prior to testing, the device and procedure will be explained to my satisfaction.

I will then be instructed to sit up straight with my arms crossed in front of my chest with my fingertips touching the opposite top of my shoulders. I will be instructed to sit up straight with my back flat against the chair that I am seated in. Straps will be crisscrossed across my chest so that compensation with my shoulders does not occur. I will then be instructed to apply maximum force to the Lafayette Manual Muscle Test System for a total of 6 seconds. I will be instructed to gradually build-up to maximal force for a duration of 2 seconds and then hold the maximal effort for a duration of 4 seconds. This test will be completed by tilting my head forward to my chin, backward, and from side to side. I will be given one warm-up test before testing begins. The test will be run once in each direction. I will be given 30 seconds of rest between each test.

It is not likely at any point during the test that I should feel any pain. However, I will be instructed that if I do feel pain or any neurological symptoms such as tingling, burning, or numbness and need to stop testing I am to raise my hand or verbally indicate that I need testing to be stopped. Testing will cease immediately and I will be evaluated and treated for injury.

Head-neck segment will be measured by first weighing me on a scale. My weight in pounds will then be converted into kilograms $(\mathrm{kg})$. This will give the body mass which will then be multiplied by the gender specific head-neck segment $($ male $=8.26 \%$; female $=8.20 \%$ ) to total body mass percentage to determine head-neck segment mass. Head-neck segment length will be determined by measuring my neck from behind from the center tip of my spine at the $7^{\text {th }}$ cervical vertebrae to the top of my head. Neck muscle girth will be measured in front just above my Adam's apple by measuring the distance in centimeters around my neck. Both Head-neck segment and neck muscle girth will be measured with a standard measuring tape.

Following each test, the principle investigator will record the results of the manual muscle test. Once all results have been recorded, my testing session will be completed. At this time, I will be asked by the principal investigator for any questions or comments that I may have.

$\frac{11 / 03 / 05}{\text { Version }} \quad$ Page 2 of 4

Version Date 


\section{PREDICITVE FACTORS OF BRACHIAL PLEXUS NEUROPATHY IN WRESTLING ATHLETES.}

The data from my testing sessions will be averaged with the data from the rest of the subjects for analysis.

\section{Risks and Discomforts}

There are no known or expected risks from participation in this study. The only known or expected discomfort may be mild muscle soreness in my neck and shoulder muscles with completion of the procedure for testing of neck strength. The principal investigator will be administering the procedure for the testing of neck strength and will terminate the session should I indicate that I am feeling pain or discomfort during testing. I understand that if I feel any pain or discomfort during testing I am to indicate this to the principal investigator by raising my right hand or verbally indicating so and that the testing will be stopped immediately. I will be evaluated and rescheduled to complete the testing at a later date once my pain and discomfort are gone. All of the other evaluations are stationary measurements and therefore, should not cause any discomfort or pain. Should any injury occur, I understand that Deena Dillard, ATC will provide first aid and make any necessary medical referral.

\section{Alternative}

I understand that I do not have to participate in this study and that no negative action will be taken against me by either the coaching staff or the athletic training staff should I choose not to participate.

\section{Benefits}

I understand that this study may not be of direct benefit to me, but the knowledge gained may be of benefit to others with regard to burners or stingers in wrestlers.

\section{Financial Considerations}

I understand that I will not receive monetary compensation for completing this study.

\section{Contact Persons}

For more information about this research, I can contact Deena Dillard, ATC at (304) 293-3309 or at (210) 264-7269 or her faculty advisor, Michelle A. Sandrey, PhD, ATC at (304) 293-3295 Ext. 5220. For information regarding my rights as a research subject, I may contact the Executive Secretary of the Review Board at (304) 293-7073.

11/03/05

Version Date
Page 3 of 4
Initials
Date 


\section{PREDICITVE FACTORS OF BRACHIAL PLEXUS NEUROPATHY IN WRESTLING ATHLETES.}

\section{Confidentiality}

I understand that any information about me that is obtained as a result of my participation in this research will be kept confidential as legally as possible. Identifying information on the informed consent form, demographic information/injury history questionnaire, and data collection sheets will be kept confidential by assigning a code number to each.

I understand that my research records and test results, just like hospital records, may be subpoenaed by court order. In any publications that result from this research, neither my name nor any information from which I may be identified will be published without my consent.

\section{Voluntary Participation}

Participation in this study is voluntary. I understand that I am free to withdraw my consent to participate in this study at any time and that such refusal to participate will not affect my future participation in wrestling, my employee status at West Virginia University, or my class standing, grades, standing with my wrestling coaches, or medical evaluation and treatment. Refusal to participate or withdrawal will involve no penalty to me. I have been given the opportunity to ask questions about the research, and I have received answers concerning areas I did not previously understand. In the event new information becomes available that may affect my willingness to continue to participate in this study, this information will be given to me so I may make an informed decision about my participation.

Upon signing this form I will receive a copy.

I willingly consent to participate in this research.

Signature of Subject Date/Time

Signature of Principal Investigator

Date/Time

$\underline{11 / 03 / 05}$

Version Date

Page 4 of 4
Initials
Date 


\section{Authorization to Use or Disclose Protected Health Information (PHI) West Virginia University}

I hereby voluntarily authorize the use or disclosure of my individually identifiable health information as described below.

Patient Name:

Date of Birth:
ID Number:

IRB Protocol \#:

Persons/organizations providing the protected health information (e.g. hospitals): Ruby Memorial Hospital, Mon General Hospital, and West Virginia University Athletic Training.

Persons/organizations receiving the information (e.g. investigators, clinical coordinators, sponsor, FDA): Deena Dillard, ATC, Kevin Kotsko, MS, ATC, Maggie Miller, and Christian Filer.

The following information will be utilized: Any films or copies of diagnostic testing of any cervical spine injury as well as any medical records pertaining to cervical spine injuries.

The information is being disclosed for the following purposes (Start with the Title of the study and include additional information e.g. screening and recruiting subjects; analyzing research data; or other specified purposes): Predictive Factors of Brachial Plexus Neuropathy in Wrestling Athletes; Pre-Test screening as well as Post-Test screening and Injury records.

I may revoke this authorization at any time by notifying the Principal Investigator in writing at:

Deena Dillard

Graduate Assistant Athletic Trainer

Shell Athletic Training Room

PO Box 0877

Morgantown, WV 26507

If I do revoke my authorization, any information previously disclosed cannot be withdrawn. Once information about me is disclosed in accordance with this authorization, the recipient may redisclose it and the information may no longer be protected by federal privacy regulations.

I may refuse to sign this authorization form. My clinical treatment may not be affected by whether or not I sign this form. I may not be allowed to participate in the research if I do not sign the form.

This authorization will expire on the date that the research study ends.

Expiration Date:

I will be given a copy of this authorization form. 
Signature of subject or subject's legal representative (Form must be completed before signing)

Printed Name of subject or subject's legal representative

Relationship to the subject

Parent

Medical power of attorney/ representative

Legal Guardian

$\square \quad$ Health care surrogate
Date

Initials 
Code \# 16737

Date:

\section{Section 1. Please complete to the best of your ability}

1. Age:

2. Year in school (please circle one)

FR SO JR SR $5^{\mathrm{TH}}$ YEAR $6^{\mathrm{TH}}$ YEAR

3. Number of years of athletic eligibility left (please circle one) $12 \begin{array}{llll}1 & 2 & 3 & 4\end{array}$

4. Current wrestling weight certification (please circle one)

$$
\begin{array}{llllllllll}
125 & 133 & 141 & 149 & 157 & 165 & 174 & 184 & 197 & \text { HWT }
\end{array}
$$

5. State the total number of years that you have been wrestling

6. Please state if you are:

Scholarship: (please specify full, partial, quarter, books, etc.)

Walk-On:

7. What was your win/loss record last season?

8. Are you currently participating in a neck-strengthening program? Yes No

9. With whom and what do you do?

10. Have you ever had a neck injury? Yes No If No, then skip to Question \#14

11. If yes, What happened?

12. How many days were you out of competition/practice?

13. What treatment/medications did you receive?

14. Do you have any neck pathology currently (disc herniation, osteophytes, etc)?

$$
\text { Yes No }
$$

15. If yes, what pathology is it?

16. Have you ever experienced a burner or stinger? Yes No

17. If yes, how many? (please circle one)

$$
\text { 1-3 4-7 } 8 \text { or more }
$$

19. Have you ever had head or neck X-rays?

Yes No


18. If yes, where? When?

19. Have you ever had a MRI on your head or neck? Yes No

20. If yes, where? When?

21. Have you ever had a CT scan on your head or neck? Yes No

22. If yes, where? When?

23. Have you had any other diagnostic evaluation on your head or neck (such as an EMG)?

$$
\text { Yes No }
$$

24. If yes, what procedure?

25. Have you ever had neck surgery? Yes No

\section{Section 2. To be completed by Principal Investigator}

\section{Code \# 16737}

Weight in pounds:

Weight in kilograms:

Head-neck segment:

Head-neck length:

Neck girth:

Neck strength:

Forward Flexion:

Extension:

Left Lateral Flexion:

Right Lateral Flexion: 


\section{Table C4. Neck Muscle Strength Procedure}

1. During the neck muscle strength procedure, the examiner will ask the athlete not to wear a shirt.

2. The subject will be instructed to sit up straight with their back flat against the chair they are seated in.

3. Straps will be crisscrossed across the subject's chest so that compensation with their shoulders does not occur.

4. The athlete will be given one warm-up session of one trial only.

5. A make test will be utilized. The examiner will hold the dynamometer stationary while the athlete applies maximal force against the dynamometer.

6. The subjects will then be instructed to apply maximum force to the Lafayette Manual Muscle Test System for a total of 6 seconds in the direction of forward flexion. The athlete will be asked to gradually build-up to maximal force for a duration of 2 seconds and then hold the maximal effort for a duration of 4 seconds.

7. The athlete will be given 30 seconds of rest.

8. The examiner will read the LCD display and record the results of the test on the appropriate recording sheet, according to pre-test, post-test, or pre-dual match.

9. The subjects will then be instructed to apply maximum force to the Lafayette Manual Muscle Test System for a total of 6 seconds in the direction of extension. The athlete will be asked to gradually build-up to maximal force for a duration of 2 seconds and then hold the maximal effort for a duration of 4 seconds.

10. The athlete will be given 30 seconds of rest.

11. The examiner will read the LCD display and record the results of the test on the appropriate recording sheet, according to pre-test, post-test, or pre-dual match.

12. The subjects will then be instructed to apply maximum force to the Lafayette Manual Muscle Test System for a total of 6 seconds in the direction of right lateral flexion. The athlete will be asked to gradually build-up to maximal force for a duration of 2 seconds and then hold the maximal effort for a duration of 4 seconds.

13. The athlete will be given 30 seconds of rest.

14. The examiner will read the LCD display and record the results of the test on the appropriate recording sheet, according to pre-test, post-test, or pre-dual match.

15. The subjects will then be instructed to apply maximum force to the Lafayette Manual Muscle Test System for a total of 6 seconds in the direction of left lateral flexion. The athlete will be asked to gradually build-up to maximal force for a duration of 2 seconds and then hold the maximal effort for a duration of 4 seconds.

16. The examiner will read the LCD display and record the results of the test on the appropriate recording sheet, according to pre-test, post-test, or pre-dual match. 


\section{Table C5. Head-Neck Segment Procedure}

1. When being weighed, the male athletic training student will be the examiner and will ask the athlete to be nude.

2. The athlete will step onto the scale placing his back toward the scale reading.

3. The athlete will then be asked to place their feet at the exact middle of the scale while placing their hands at their sides.

4. The athlete will be asked to stand still on the scale.

5. The examiner will be on the left side of the athlete reading the scale output.

6. The weight will be recorded on either the Pre-screening Questionnaire or the post-test sheet according to the time in which the measurement is taken.

7. The athlete's weight in pounds will then be converted to kilograms $(\mathrm{kg})$.

8. The weight in kilograms will then be multiplied by the gender specific head-neck segment $($ male $=8.26 \%)$.

9. This number will be recorded on either the Pre-screening Questionnaire or the post-test sheet according to the time in which the measurement is taken. 
1. The athlete will be asked not to wear a shirt.

2. The examiner will utilize a standard measuring tape in centimeters for this procedure.

3. The examiner will hold the tape measure at the level of the center of the spine of the $7^{\text {th }}$ cervical vertebrae.

4. The measurement will be taken from the center tip of the spine of the $7^{\text {th }}$ cervical vertebrae to the top of the head.

5. The measurement will be recorded in centimeters.

6. The measurement will be recorded on either the Pre-Screening Questionnaire or the PostTest sheet according to the time at which the measurement is taken.

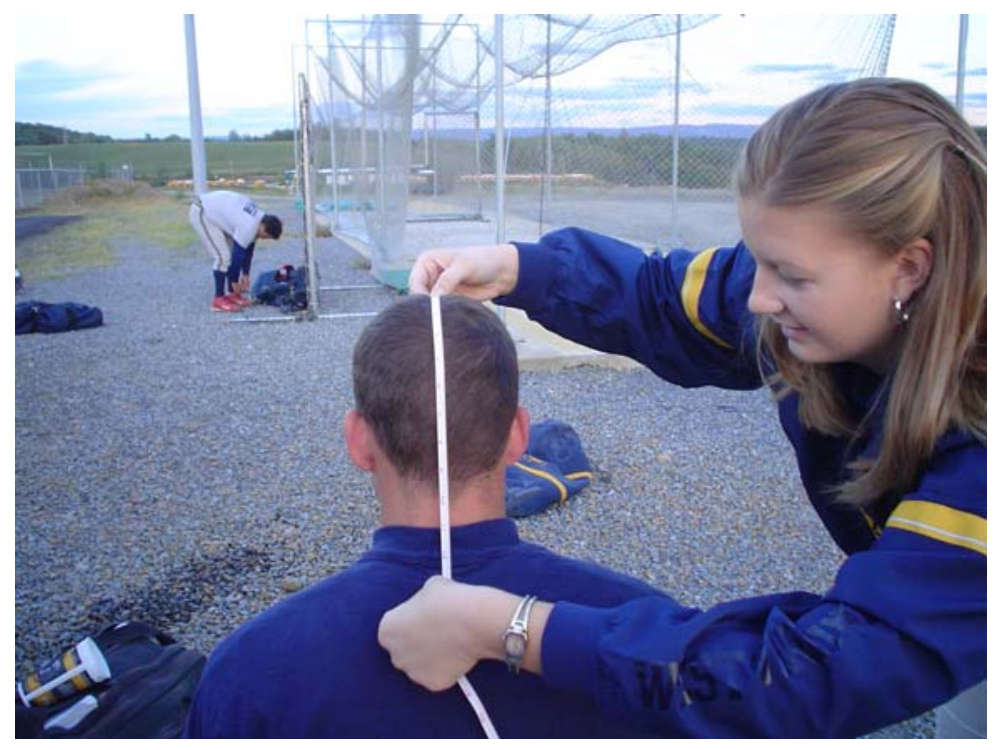


Table C7. Neck Muscle Girth Procedure

1. The examiner will ask the athlete not to wear a shirt during the procedure.

2. A standard measuring tape in centimeters will be utilized for this measurement.

3. The examiner will hold the end of the measuring tape just above the Adam's apple and pull the tape firmly around the circumference of the athlete's neck.

4. The examiner will be careful not to pull the tape unnecessarily tight.

5. The exact measurement in centimeters will be recorded on either the Pre-Screening or the Post-Test sheet according to the time at which the measurement is taken. 
Table C8. Post-Test Recording Sheet

Date:

Code \# 16737

Weight in pounds:

Weight in kilograms:

Head-neck segment:

Head-neck length:

Neck girth:

Neck strength:

Forward Flexion:

Extension:

Left Lateral Flexion:

Right Lateral Flexion: 
Table C9. Pre-Dual Match Neck Muscle Strength Sheet

\section{Code \# 16737}

Match 1

Forward Flexion:

Extension:

Left Lateral Flexion:

Right Lateral Flexion:

Match 2

Forward Flexion:

Extension:

Left Lateral Flexion:

Right Lateral Flexion:

Match 3

Forward Flexion:

Extension:

Left Lateral Flexion:

Right Lateral Flexion:

Match 4

Forward Flexion:

Extension:

Left Lateral Flexion:

Right Lateral Flexion:

Match 5

Forward Flexion:

Extension:

Left Lateral Flexion:

Right Lateral Flexion:

Match 6

Forward Flexion:

Extension:

Left Lateral Flexion:

Right Lateral Flexion: 
Match 7

Forward Flexion:

Extension:

Left Lateral Flexion:

Right Lateral Flexion:

Match 8

Forward Flexion:

Extension:

Left Lateral Flexion:

Right Lateral Flexion:

Match 9

Forward Flexion:

Extension:

Left Lateral Flexion:

Right Lateral Flexion:

Match 10

Forward Flexion:

Extension:

Left Lateral Flexion:

Right Lateral Flexion:

Match 11

Forward Flexion:

Extension:

Left Lateral Flexion:

Right Lateral Flexion:

Match 12

Forward Flexion:

Extension:

Left Lateral Flexion:

Right Lateral Flexion: 
Table C10. Injury Recording Worksheet

Code \# 16737

Injury Record

Date:__ Match or Practice (Please circle one)

Dominant Side (Please circle one): Right Left

History

Mechanism of Injury:

Observation

Atrophy:

Hypertrophy:

Neck Position:

Palpation

Spasm:

Point tenderness:

Range-of-

Motion:

Trigger points:

Myotomes: 
Dermotomes:

Reflexes:

Axial Compression:

Spurling's:

Upper Quadrant Test:

Axial Distraction:

Please record any other findings in the space below. 
Figure C1. Neck Muscle Strength Procedure

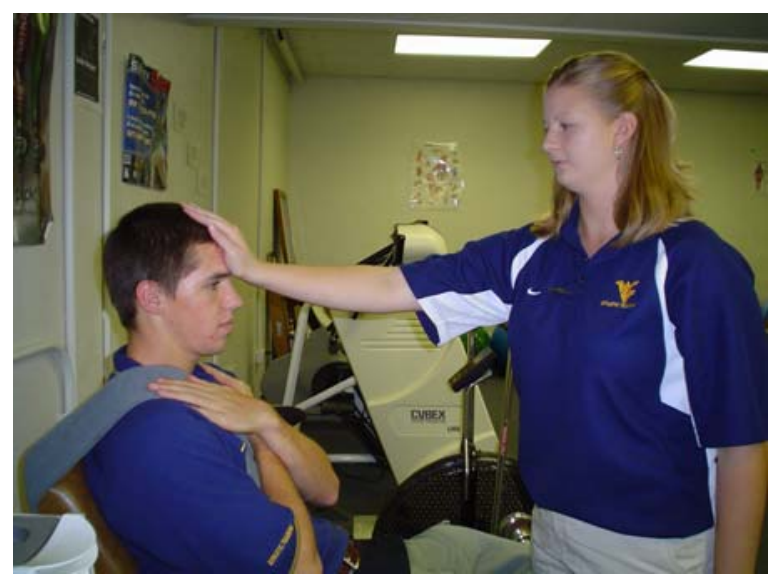

Placement for Forward

Flexion

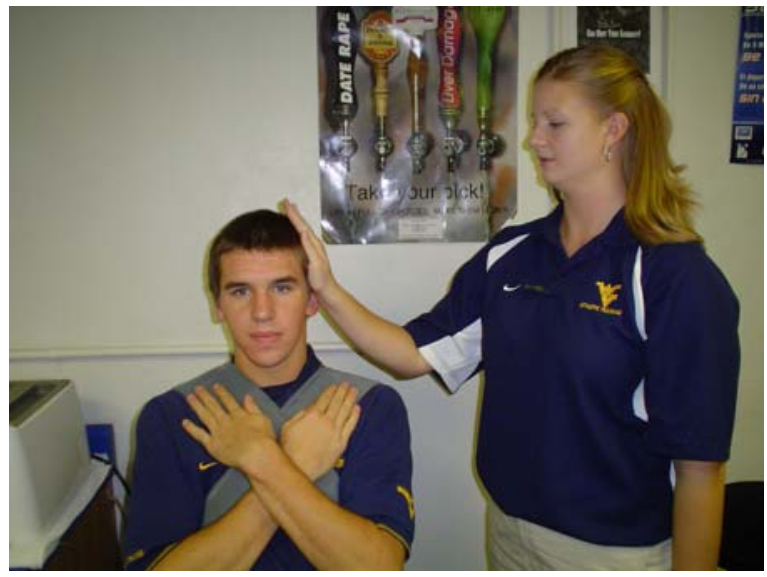

Placement for Left Lateral

Flexion

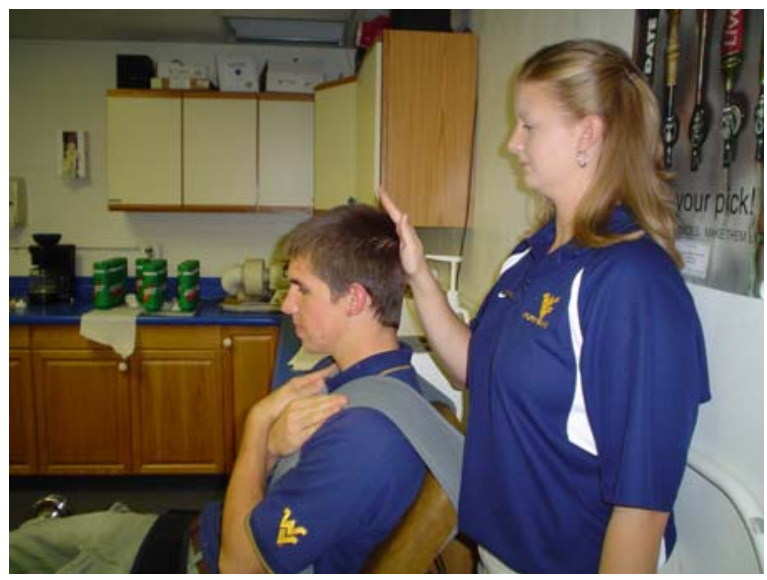

Placement for Extension 
Figure C1. Neck Muscle Strength Procedure, Continued

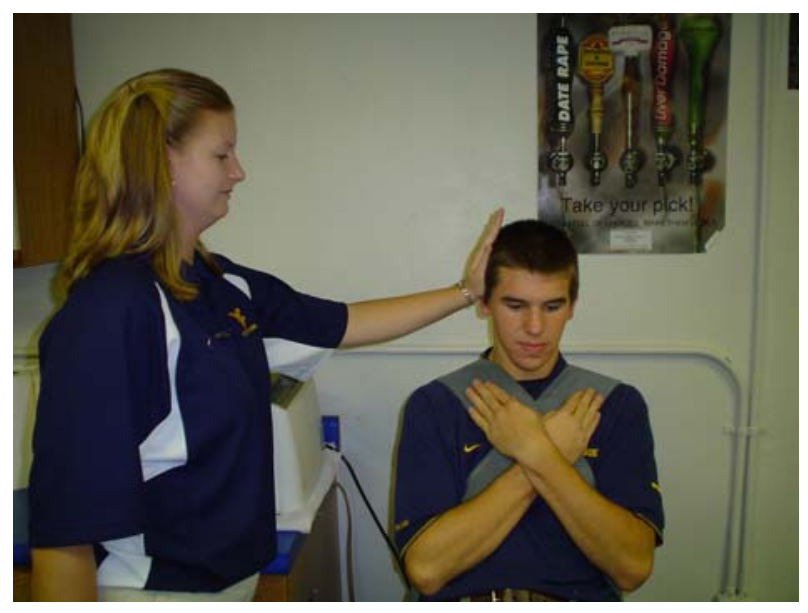

Placement for Right

Lateral Flexion 


\section{APPENDIX D}

\section{ADDITIONAL RESULTS}

Table D1. Subject Demographic Means

\begin{tabular}{lccc}
\hline Variable & Overall $(\mathrm{n}=23)$ & Injured $(\mathrm{n}=6)$ & Non-Injured $(\mathrm{n}=17)$ \\
\hline Age & $19.83+1.62$ & $21.00+1.67$ & $19.41+1.42$ \\
Weight in kg & $74.55+13.28$ & $78.01+9.14$ & $73.33+14.51$ \\
Number of Years Wrestling & $12.93+4.21$ & $15.00+3.03$ & $12.21+4.39$ \\
Number of Burners Experienced & $0.74+0.96$ & $1.17+1.17$ & $0.59+0.87$ \\
\hline
\end{tabular}

Table D2. Hand Dominance Frequencies

\begin{tabular}{cccc}
\hline & & Hand Dominance & Frequency \\
\cline { 2 - 4 } Occurrence & \multirow{2}{*}{ Yes } & Right & 5 \\
of BPN & Left & 1 \\
& \multirow{2}{*}{ No } & Right & 15 \\
& & Left & 2 \\
\hline
\end{tabular}


Table D3. Head-Neck Segment, Head-Neck Length \& Neck Girth Means

\begin{tabular}{|c|c|c|c|c|c|c|c|c|}
\hline \multirow[b]{2}{*}{ Variable } & \multicolumn{2}{|c|}{ Overall $(n=23)$} & \multicolumn{2}{|c|}{ Injured $(n=6)$} & \multicolumn{2}{|c|}{ Non-injured $(n=17)$} & \multirow[b]{2}{*}{ Pre-Test P } & \multirow[b]{2}{*}{ Post-test P } \\
\hline & Pre-Test & Post-Test & Pre-Test & Post-Test & Pre-Test & Post-Test & & \\
\hline Head-Neck Segment (kg) & $6.16 \pm 1.10$ & $6.33 \pm 1.02$ & $6.44 \pm 0.75$ & $6.62 \pm 0.74$ & $6.05 \pm 1.02$ & $6.23 \pm 1.10$ & 0.47 & 0.43 \\
\hline Head-Neck Length $(\mathrm{cm})$ & $31.07 \pm 2.57$ & $30.85 \pm 2.61$ & $31.83 \pm 3.99$ & $31.75 \pm 4.07$ & $30.79 \pm 1.97$ & $30.53 \pm 1.94$ & 0.41 & 0.34 \\
\hline Neck Girth $(\mathrm{cm})$ & $39.59 \pm 2.20$ & $39.67 \pm 2.52$ & $40.42 \pm 2.35$ & $40.33 \pm 3.01$ & $39.29 \pm 2.14$ & $39.44 \pm 2.38$ & 0.29 & 0.47 \\
\hline
\end{tabular}

Table D4. Means Between Injured and Non-Injured Wrestlers

\begin{tabular}{|c|c|c|c|c|}
\hline & \multicolumn{2}{|c|}{ Pre - Test } & \multicolumn{2}{|c|}{ Post Test } \\
\hline & Injured $(n=6)$ & Non-Injured $(\mathrm{n}=17)$ & Injured $(n=6)$ & Non-Injured $(n=17)$ \\
\hline Head-Neck Segment (kg) & $6.44 \pm 0.75$ & $6.05 \pm 1.02$ & $6.62 \pm 0.74$ & $6.23 \pm 1.10$ \\
\hline Head-Neck Length (cm) & $31.83 \pm 3.99$ & $30.79 \pm 1.97$ & $31.75 \pm 4.07$ & $30.53 \pm 1.94$ \\
\hline Neck Girth $(\mathrm{cm})$ & $40.42 \pm 2.35$ & $39.29 \pm 2.14$ & $40.33 \pm 3.01$ & $39.44 \pm 2.38$ \\
\hline Neck Strength - Flexion (kg) & $21.38 \pm 2.05$ & $22.49 \pm 3.29$ & $22.65 \pm 4.43$ & $24.52 \pm 3.16$ \\
\hline Neck Strength - Extension (kg) & $30.70 \pm 5.43$ & $26.88 \pm 6.45$ & $32.65 \pm 7.32$ & $30.64 \pm 5.60$ \\
\hline Neck Strength - Left Lateral Flexion (kg) & $22.63 \pm 2.19$ & $20.83 \pm 3.88$ & $24.92 \pm 3.17$ & $24.92 \pm 2.70$ \\
\hline Neck Strength - Right Lateral Flexion (kg) & $22.07 \pm 3.47$ & $21.47 \pm 4.36$ & $25.35 \pm 4.03$ & $25.14 \pm 3.36$ \\
\hline
\end{tabular}


Table D5. Pre-Test Head-Neck Segment Frequencies (kg)

\begin{tabular}{|c|c|c|c|c|c|c|c|c|}
\hline \multicolumn{3}{|c|}{ Entire Sample $(n=23)$} & \multicolumn{3}{|c|}{ Non-Injured $(n=17)$} & \multicolumn{3}{|c|}{ Injured $(n=6)$} \\
\hline Measurement & Frequency $(\mathrm{n})$ & Percentage & Measurement & Frequency (n) & Percentage & Measurement & Frequency (n) & Percentage \\
\hline 4.81 & 1 & 4.3 & 4.81 & 1 & 5.9 & 5.37 & 1 & 16.7 \\
\hline 4.92 & 1 & 4.3 & 4.92 & 1 & 5.9 & 6.14 & 1 & 16.7 \\
\hline 5.22 & 1 & 4.3 & 5.22 & 1 & 5.9 & 6.22 & 1 & 16.7 \\
\hline 5.23 & 1 & 4.3 & 5.23 & 1 & 5.9 & 6.45 & 1 & 16.7 \\
\hline 5.29 & 1 & 4.3 & 5.29 & 1 & 5.9 & 6.87 & 1 & 16.7 \\
\hline 5.37 & 1 & 4.3 & 5.48 & 1 & 5.9 & 7.61 & 1 & 16.7 \\
\hline 5.48 & 1 & 4.3 & 5.64 & 1 & 5.9 & & & \\
\hline 5.64 & 1 & 4.3 & 5.66 & 1 & 5.9 & & & \\
\hline 5.66 & 1 & 4.3 & 5.86 & 1 & 5.9 & & & \\
\hline 5.86 & 1 & 4.3 & 5.93 & 1 & 5.9 & & & \\
\hline 5.93 & 1 & 4.3 & 6.04 & 1 & 5.9 & & & \\
\hline 6.04 & 1 & 4.3 & 6.08 & 1 & 5.9 & & & \\
\hline 6.08 & 1 & 4.3 & 6.20 & 1 & 5.9 & & & \\
\hline 6.14 & 1 & 4.3 & 6.42 & 1 & 5.9 & & & \\
\hline 6.20 & 1 & 4.3 & 6.65 & 1 & 5.9 & & & \\
\hline 6.22 & 1 & 4.3 & 7.62 & 1 & 5.9 & & & \\
\hline 6.42 & 1 & 4.3 & 9.87 & 1 & 5.9 & & & \\
\hline 6.45 & 1 & 4.3 & & & & & & \\
\hline 6.65 & 1 & 4.3 & & & & & & \\
\hline 6.87 & 1 & 4.3 & & & & & & \\
\hline 7.61 & 1 & 4.3 & & & & & & \\
\hline 7.62 & 1 & 4.3 & & & & & & \\
\hline 9.87 & 1 & 4.3 & & & & & & \\
\hline
\end{tabular}


Table D6. Post-Test Head-Neck Segment Frequencies (kg)

\begin{tabular}{|c|c|c|c|c|c|c|c|c|}
\hline \multicolumn{3}{|c|}{ Entire Sample $(n=23)$} & \multicolumn{3}{|c|}{ Non-Injured $(n=17)$} & \multicolumn{3}{|c|}{ Injured $(n=6)$} \\
\hline Measurement $(\mathrm{kg})$ & Frequency $(\mathrm{n})$ & Percentage & Measurement $(\mathrm{kg})$ & Frequency (n) & Percentage & Measurement (kg) & Frequency $(\mathrm{n})$ & Percentage \\
\hline 4.86 & 1 & 4.3 & 4.86 & 1 & 5.9 & 5.67 & 1 & 16.7 \\
\hline 5.44 & 1 & 4.3 & 5.44 & 1 & 5.9 & 6.20 & 1 & 16.7 \\
\hline 5.48 & 1 & 4.3 & 5.48 & 1 & 5.9 & 6.35 & 1 & 16.7 \\
\hline 5.49 & 1 & 4.3 & 5.49 & 1 & 5.9 & 6.54 & 1 & 16.7 \\
\hline 5.65 & 1 & 4.3 & 5.65 & 1 & 5.9 & 7.21 & 1 & 16.7 \\
\hline 5.67 & 1 & 4.3 & 5.71 & 1 & 5.9 & 7.74 & 1 & 16.7 \\
\hline 5.71 & 1 & 4.3 & 5.73 & 1 & 5.9 & & & \\
\hline 5.73 & 1 & 4.3 & 5.82 & 1 & 5.9 & & & \\
\hline 5.82 & 1 & 4.3 & 5.83 & 1 & 5.9 & & & \\
\hline 5.83 & 1 & 4.3 & 6.13 & 1 & 5.9 & & & \\
\hline 6.13 & 1 & 4.3 & 6.14 & 1 & 5.9 & & & \\
\hline 6.14 & 1 & 4.3 & 6.25 & 1 & 5.9 & & & \\
\hline 6.20 & 1 & 4.3 & 6.31 & 1 & 5.9 & & & \\
\hline 6.25 & 1 & 4.3 & 6.76 & 1 & 5.9 & & & \\
\hline 6.31 & 1 & 4.3 & 6.83 & 1 & 5.9 & & & \\
\hline 6.35 & 1 & 4.3 & 7.88 & 1 & 5.9 & & & \\
\hline 6.54 & 1 & 4.3 & 9.57 & 1 & 5.9 & & & \\
\hline 6.76 & 1 & 4.3 & & & & & & \\
\hline 6.83 & 1 & 4.3 & & & & & & \\
\hline 7.21 & 1 & 4.3 & & & & & & \\
\hline 7.74 & 1 & 4.3 & & & & & & \\
\hline 7.88 & 1 & 4.3 & & & & & & \\
\hline 9.57 & 1 & 4.3 & & & & & & \\
\hline
\end{tabular}


Table D7. Pre-Test Head-Neck Length Frequencies (cm)

\begin{tabular}{|c|c|c|c|c|c|c|c|c|}
\hline \multicolumn{3}{|c|}{ Entire Sample $(n=23)$} & \multicolumn{3}{|c|}{ Non-Injured $(n=17)$} & \multicolumn{3}{|c|}{ Injured $(n=6)$} \\
\hline Measurement $(\mathrm{cm})$ & Frequency $(\mathrm{n})$ & Percentage & Measurement $(\mathrm{cm})$ & Frequency $(\mathrm{n})$ & Percentage & Measurement $(\mathrm{cm})$ & Frequency (n) & Percentage \\
\hline 28.00 & 1 & 4.3 & 28.00 & 1 & 5.9 & 29.00 & 2 & 33.3 \\
\hline 29.00 & 5 & 21.7 & 29.00 & 3 & 17.6 & 20.00 & 1 & 16.7 \\
\hline 29.50 & 1 & 4.3 & 29.50 & 1 & 5.9 & 31.50 & 1 & 16.7 \\
\hline 30.00 & 5 & 21.7 & 30.00 & 4 & 23.5 & 32.00 & 1 & 16.7 \\
\hline 30.50 & 1 & 4.3 & 30.50 & 1 & 5.9 & 39.50 & 1 & 16.7 \\
\hline 31.00 & 2 & 8.7 & 31.00 & 2 & 11.8 & & & \\
\hline 31.50 & 1 & 4.3 & 32.00 & 2 & 11.8 & & & \\
\hline 32.00 & 3 & 13 & 33.00 & 1 & 5.9 & & & \\
\hline 33.00 & 1 & 4.3 & 34.00 & 1 & 5.9 & & & \\
\hline 34.00 & 1 & 4.3 & 35.50 & 1 & 5.9 & & & \\
\hline 35.00 & 1 & 4.3 & & & & & & \\
\hline 39.00 & 1 & 4.3 & & & & & & \\
\hline
\end{tabular}

Table D8. Post-Test Head-Neck Length Frequencies (cm)

\begin{tabular}{|c|c|c|c|c|c|c|c|c|}
\hline \multicolumn{3}{|c|}{ Entire Sample $(n=23)$} & \multicolumn{3}{|c|}{ Non-Injured $(\mathrm{n}=17)$} & \multicolumn{3}{|c|}{ Injured $(n=6)$} \\
\hline Measurement $(\mathrm{cm})$ & Frequency $(\mathrm{n})$ & Percentage & Measurement $(\mathrm{cm})$ & Frequency $(\mathrm{n})$ & Percentage & Measurement $(\mathrm{cm})$ & Frequency (n) & Percentage \\
\hline 28.00 & 3 & 13 & 28.00 & 3 & 17.6 & 29.00 & 2 & 33.3 \\
\hline 29.00 & 4 & 17.4 & 29.00 & 2 & 11.8 & 30.00 & 2 & 33.3 \\
\hline 30.00 & 7 & 30.4 & 30.00 & 5 & 29.4 & 33.00 & 1 & 16.7 \\
\hline 31.00 & 2 & 8.7 & 31.00 & 2 & 11.8 & 39.50 & 1 & 16.7 \\
\hline 32.00 & 2 & 8.7 & 32.00 & 2 & 11.8 & & & \\
\hline 33.00 & 2 & 8.7 & 33.00 & 1 & 5.9 & & & \\
\hline 34.00 & 2 & 8.7 & 34.00 & 2 & 11.8 & & & \\
\hline 39.50 & 1 & 4.3 & & & & & & \\
\hline
\end{tabular}


Table D9. Pre-Test Neck Girth Frequencies (cm)

\begin{tabular}{|c|c|c|c|c|c|c|c|c|}
\hline \multicolumn{3}{|c|}{ Entire Sample $(n=23)$} & \multicolumn{3}{|c|}{ Non-Injured $(\mathrm{n}=17)$} & \multicolumn{3}{|c|}{ Injured $(n=6)$} \\
\hline Measurement $(\mathrm{cm})$ & Frequency $(n)$ & Percentage & Measurement $(\mathrm{cm})$ & Frequency $(n)$ & Percentage & Measurement $(\mathrm{cm})$ & Frequency $(\mathrm{n})$ & Percentage \\
\hline 36.00 & 2 & 8.7 & 36.00 & 2 & 11.8 & 37.50 & 1 & 16.7 \\
\hline 37.00 & 2 & 8.7 & 37.00 & 2 & 11.8 & 38.50 & 1 & 16.7 \\
\hline 37.50 & 2 & 8.7 & 37.50 & 1 & 5.9 & 40.00 & 1 & 16.7 \\
\hline 38.50 & 2 & 8.7 & 38.50 & 1 & 5.9 & 40.50 & 1 & 16.7 \\
\hline 39.00 & 2 & 8.7 & 39.00 & 2 & 11.8 & 42.00 & 1 & 16.7 \\
\hline 39.50 & 2 & 8.7 & 39.50 & 2 & 11.8 & 44.00 & 1 & 16.7 \\
\hline 40.00 & 3 & 13 & 40.00 & 2 & 11.8 & & & \\
\hline 40.50 & 2 & 8.7 & 40.50 & 1 & 5.9 & & & \\
\hline 41.50 & 2 & 8.7 & 41.50 & 2 & 11.8 & & & \\
\hline 42.00 & 2 & 8.7 & 42.00 & 1 & 5.9 & & & \\
\hline 43.50 & 1 & 4.3 & 43.50 & 1 & 5.9 & & & \\
\hline 44.00 & 1 & 4.3 & & & & & & \\
\hline
\end{tabular}

Table D10. Post-Test Neck Girth Frequencies (cm)

\begin{tabular}{|c|c|c|c|c|c|c|c|c|}
\hline \multicolumn{3}{|c|}{ Entire Sample $(n=23)$} & \multicolumn{3}{|c|}{ Non-Injured $(n=17)$} & \multicolumn{3}{|c|}{ Injured $(n=6)$} \\
\hline Measurement $(\mathrm{cm})$ & Frequency (n) & Percentage & Measurement $(\mathrm{cm})$ & Frequency (n) & Percentage & Measurement (cm) & Frequency (n) & Percentage \\
\hline 35.00 & 1 & 4.3 & 35.50 & 1 & 5.9 & 35.00 & 1 & 16.7 \\
\hline 35.50 & 1 & 4.3 & 37.00 & 2 & 11.8 & 39.50 & 1 & 16.7 \\
\hline 37.00 & 2 & 8.7 & 37.50 & 1 & 5.9 & 40.00 & 1 & 16.7 \\
\hline 37.50 & 1 & 4.3 & 38.00 & 2 & 11.8 & 41.50 & 1 & 16.7 \\
\hline 38.00 & 2 & 8.7 & 38.50 & 1 & 5.9 & 42.50 & 1 & 16.7 \\
\hline 38.50 & 1 & 4.3 & 39.00 & 2 & 11.8 & 43.50 & 1 & 16.7 \\
\hline 39.00 & 2 & 8.7 & 40.00 & 4 & 23.5 & & & \\
\hline 39.50 & 1 & 4.3 & 41.00 & 1 & 5.9 & & & \\
\hline 40.00 & 5 & 21.7 & 42.00 & 1 & 5.9 & & & \\
\hline 41.00 & 1 & 4.3 & 43.00 & 1 & 5.9 & & & \\
\hline 41.50 & 1 & 4.3 & 45.00 & 1 & 5.9 & & & \\
\hline 42.00 & 1 & 4.3 & & & & & & \\
\hline 42.50 & 1 & 4.3 & & & & & & \\
\hline 43.00 & 1 & 4.3 & & & & & & \\
\hline 43.50 & 1 & 4.3 & & & & & & \\
\hline 45.00 & 1 & 4.3 & & & & & & \\
\hline
\end{tabular}


Table D11. Neck Strength Means (kg)

\begin{tabular}{|c|c|c|c|c|c|c|}
\hline \multirow[b]{2}{*}{ Variable } & \multicolumn{2}{|c|}{ Overall $(n=23)$} & \multicolumn{2}{|c|}{ Injured $(n=6)$} & \multicolumn{2}{|c|}{ Non-injured $(n=17)$} \\
\hline & Pre-Test & Post-Test & Pre-Test & Post-Test & Pre-Test & Post-Test \\
\hline Forward Flexion & $22.20 \pm 3.01$ & $24.03 \pm 3.53$ & $21.38 \pm 2.05$ & $22.65 \pm 4.43$ & $22.49 \pm 3.29$ & $24.52 \pm 3.16$ \\
\hline Extension & $27.88 \pm 6.32$ & $31.17 \pm 5.98$ & $30.70 \pm 5.43$ & $32.65 \pm 7.32$ & $26.88 \pm 6.45$ & $30.64 \pm 5.60$ \\
\hline Right Lateral Flexion & $21.63 \pm 4.08$ & $25.19 \pm 3.45$ & $22.07 \pm 3.47$ & $25.35 \pm 4.03$ & $21.47 \pm 4.36$ & $25.14 \pm 3.36$ \\
\hline
\end{tabular}

* P-value set at $\mathrm{P}<.05$

Table D12. Pre-Test Neck Strength Frequencies - Forward Flexion (kg)

\begin{tabular}{|c|c|c|c|c|c|c|c|c|}
\hline \multicolumn{3}{|c|}{ Entire Sample $(n=23)$} & \multicolumn{3}{|c|}{ Non-Injured $(n=17)$} & \multicolumn{3}{|c|}{ Injured $(n=6)$} \\
\hline Measurement (kg) & Frequency (n) & Percentage & Measurement (kg) & Frequency (n) & Percentage & Measurement (kg) & Frequency $(\mathrm{n})$ & Percentage \\
\hline 17.30 & 1 & 4.3 & 17.30 & 1 & 5.9 & 18.30 & 1 & 16.7 \\
\hline 17.80 & 1 & 4.3 & 17.80 & 1 & 5.9 & 20.50 & 1 & 16.7 \\
\hline 18.30 & 1 & 4.3 & 20.10 & 1 & 5.9 & 21.70 & 1 & 16.7 \\
\hline 20.10 & 1 & 4.3 & 20.60 & 1 & 5.9 & 23.30 & 1 & 16.7 \\
\hline 20.50 & 1 & 4.3 & 21.10 & 2 & 11.8 & 23.90 & 1 & 16.7 \\
\hline 20.60 & 2 & 8.7 & 21.20 & 1 & 5.9 & & & \\
\hline 21.10 & 2 & 8.7 & 21.30 & 1 & 5.9 & & & \\
\hline 21.20 & 1 & 4.3 & 23.80 & 1 & 5.9 & & & \\
\hline 21.30 & 1 & 4.3 & 24.10 & 1 & 5.9 & & & \\
\hline 21.70 & 1 & 4.3 & 24.70 & 1 & 5.9 & & & \\
\hline 23.30 & 1 & 4.3 & 25.10 & 1 & 5.9 & & & \\
\hline 23.80 & 1 & 4.3 & 25.70 & 1 & 5.9 & & & \\
\hline 23.90 & 1 & 4.3 & 25.80 & 1 & 5.9 & & & \\
\hline 24.10 & 1 & 4.3 & 26.30 & 1 & 5.9 & & & \\
\hline 24.70 & 1 & 4.3 & 28.40 & 1 & 5.9 & & & \\
\hline 25.70 & 1 & 4.3 & & & & & & \\
\hline 25.80 & 1 & 4.3 & & & & & & \\
\hline 26.30 & 1 & 4.3 & & & & & & \\
\hline 28.40 & 1 & 4.3 & & & & & & \\
\hline
\end{tabular}


Table D13. Post-Test Neck Strength Frequencies - Forward Flexion (kg)

\begin{tabular}{|c|c|c|c|c|c|c|c|c|}
\hline \multicolumn{3}{|c|}{ Entire Sample $(n=23)$} & \multicolumn{3}{|c|}{ Non-Injured $(n=17)$} & \multicolumn{3}{|c|}{ Injured $(n=6)$} \\
\hline Measurement (kg) & Frequency (n) & Percentage & Measurement (kg) & Frequency (n) & Percentage & Measurement (kg) & Frequency (n) & Percentage \\
\hline 17.20 & 1 & 4.3 & 20.30 & 1 & 5.9 & 17.20 & 1 & 16.7 \\
\hline 18.40 & 1 & 4.3 & 21.40 & 2 & 11.8 & 18.40 & 1 & 16.7 \\
\hline 20.90 & 1 & 4.3 & 22.30 & 1 & 5.9 & 25.20 & 1 & 16.7 \\
\hline 21.40 & 2 & 8.7 & 22.40 & 1 & 5.9 & 26.30 & 1 & 16.7 \\
\hline 21.90 & 2 & 8.7 & 23.10 & 1 & 5.9 & 27.90 & 1 & 16.7 \\
\hline 22.30 & 1 & 4.3 & 23.60 & 1 & 5.9 & & & \\
\hline 22.40 & 1 & 4.3 & 24.60 & 1 & 5.9 & & & \\
\hline 23.10 & 1 & 4.3 & 24.70 & 1 & 5.9 & & & \\
\hline 23.60 & 1 & 4.3 & 26.00 & 1 & 5.9 & & & \\
\hline 24.60 & 1 & 4.3 & 26.30 & 1 & 5.9 & & & \\
\hline 24.70 & 1 & 4.3 & 28.20 & 1 & 5.9 & & & \\
\hline 25.20 & 1 & 4.3 & 29.10 & 1 & 5.9 & & & \\
\hline 26.00 & 1 & 4.3 & 29.50 & 1 & 5.9 & & & \\
\hline 26.30 & 2 & 8.7 & 30.20 & 1 & 5.9 & & & \\
\hline 27.90 & 1 & 4.3 & & & & & & \\
\hline 29.10 & 1 & 4.3 & & & & & & \\
\hline 29.50 & 1 & 4.3 & & & & & & \\
\hline 30.20 & 1 & 4.3 & & & & & & \\
\hline
\end{tabular}


Table D14. Pre-Test Neck Strength Frequencies - Extension (kg)

\begin{tabular}{|c|c|c|c|c|c|c|c|c|}
\hline \multicolumn{3}{|c|}{ Entire Sample $(n=23)$} & \multicolumn{3}{|c|}{ Non-Injured $(n=17)$} & \multicolumn{3}{|c|}{ Injured $(n=6)$} \\
\hline Measurement (kg) & Frequency (n) & Percentage & Measurement (kg) & Frequency (n) & Percentage & Measurement (kg) & Frequency (n) & Percentage \\
\hline 16.20 & 2 & 8.7 & 16.20 & 2 & 11.8 & 23.00 & 1 & 16.7 \\
\hline 17.00 & 1 & 4.3 & 17.00 & 1 & 5.9 & 24.90 & 1 & 16.7 \\
\hline 23.20 & 1 & 4.3 & 23.40 & 1 & 5.9 & 33.20 & 1 & 16.7 \\
\hline 23.40 & 1 & 4.3 & 23.80 & 1 & 5.9 & 35.50 & 2 & 33.3 \\
\hline 23.80 & 1 & 4.3 & 27.10 & 1 & 5.9 & & & \\
\hline 24.90 & 1 & 4.3 & 27.70 & 1 & 5.9 & & & \\
\hline 27.10 & 1 & 4.3 & 28.10 & 1 & 5.9 & & & \\
\hline 27.70 & 1 & 4.3 & 28.40 & 1 & 5.9 & & & \\
\hline 28.10 & 1 & 4.3 & 28.50 & 1 & 5.9 & & & \\
\hline 28.40 & 1 & 4.3 & 29.10 & 1 & 5.9 & & & \\
\hline 28.50 & 1 & 4.3 & 29.30 & 1 & 5.9 & & & \\
\hline 29.10 & 1 & 4.3 & 31.70 & 1 & 5.9 & & & \\
\hline 29.30 & 1 & 4.3 & 33.10 & 1 & 5.9 & & & \\
\hline 31.70 & 1 & 4.3 & 34.20 & 1 & 5.9 & & & \\
\hline 32.10 & 1 & 4.3 & 40.00 & 1 & 5.9 & & & \\
\hline 33.20 & 1 & 4.3 & & & & & & \\
\hline 34.20 & 1 & 4.3 & & & & & & \\
\hline 35.50 & 2 & 8.7 & & & & & & \\
\hline 40.00 & 1 & 4.3 & & & & & & \\
\hline
\end{tabular}


Table D15. Post-Test Neck Strength Frequencies - Extension (kg)

\begin{tabular}{|c|c|c|c|c|c|c|c|c|}
\hline \multicolumn{3}{|c|}{ Entire Sample $(n=23)$} & \multicolumn{3}{|c|}{ Non-Injured $(n=17)$} & \multicolumn{3}{|c|}{ Injured $(n=6)$} \\
\hline Measurement (kg) & Frequency (n) & Percentage & Measurement (kg) & Frequency (n) & Percentage & Measurement (kg) & Frequency (n) & Percentage \\
\hline 19.80 & 1 & 4.3 & 22.10 & 1 & 5.9 & 19.80 & 1 & 16.7 \\
\hline 22.10 & 1 & 4.3 & 23.60 & 1 & 5.9 & 30.60 & 1 & 16.7 \\
\hline 23.60 & 1 & 4.3 & 24.10 & 1 & 5.9 & 30.80 & 1 & 16.7 \\
\hline 24.10 & 1 & 4.3 & 24.70 & 1 & 5.9 & 37.20 & 1 & 16.7 \\
\hline 24.70 & 1 & 4.3 & 25.80 & 1 & 5.9 & 38.70 & 1 & 16.7 \\
\hline 25.80 & 1 & 4.3 & 29.10 & 1 & 5.9 & 38.80 & 1 & 16.7 \\
\hline 29.10 & 1 & 4.3 & 29.30 & 1 & 5.9 & & & \\
\hline 29.60 & 1 & 4.3 & 30.00 & 1 & 5.9 & & & \\
\hline 30.00 & 1 & 4.3 & 32.30 & 1 & 5.9 & & & \\
\hline 30.60 & 1 & 4.3 & 32.40 & 1 & 5.9 & & & \\
\hline 30.80 & 1 & 4.3 & 32.60 & 1 & 5.9 & & & \\
\hline 32.30 & 1 & 4.3 & 33.40 & 1 & 5.9 & & & \\
\hline 32.40 & 1 & 4.3 & 34.40 & 1 & 5.9 & & & \\
\hline 32.60 & 1 & 4.3 & 35.90 & 1 & 5.9 & & & \\
\hline 33.40 & 1 & 4.3 & 39.00 & 1 & 5.9 & & & \\
\hline 35.90 & 1 & 4.3 & & & & & & \\
\hline 37.20 & 1 & 4.3 & & & & & & \\
\hline 38.70 & 1 & 4.3 & & & & & & \\
\hline 38.80 & 1 & 4.3 & & & & & & \\
\hline 39.00 & 1 & 4.3 & & & & & & \\
\hline 42.60 & 1 & 4.3 & & & & & & \\
\hline
\end{tabular}


Table D16. Pre-Test Neck Strength Frequencies - Left Lateral Flexion (kg)

\begin{tabular}{|c|c|c|c|c|c|c|c|c|}
\hline \multicolumn{3}{|c|}{ Entire Sample $(n=23)$} & \multicolumn{3}{|c|}{ Non-Injured $(n=17)$} & \multicolumn{3}{|c|}{ Injured $(n=6)$} \\
\hline Measurement (kg) & Frequency (n) & Percentage & Measurement $(\mathrm{kg})$ & Frequency (n) & Percentage & Measurement (kg) & Frequency (n) & Percentage \\
\hline 13.20 & 1 & 4.3 & 13.20 & 1 & 5.9 & 19.00 & 1 & 16.7 \\
\hline 13.70 & 1 & 4.3 & 13.70 & 1 & 5.9 & 22.00 & 1 & 16.7 \\
\hline 15.40 & 1 & 4.3 & 15.40 & 1 & 5.9 & 22.40 & 1 & 16.7 \\
\hline 16.70 & 1 & 4.3 & 16.70 & 1 & 5.9 & 22.80 & 1 & 16.7 \\
\hline 19.00 & 1 & 4.3 & 19.40 & 1 & 5.9 & 24.10 & 1 & 16.7 \\
\hline 19.40 & 1 & 4.3 & 19.70 & 1 & 5.9 & 25.50 & 1 & 16.7 \\
\hline 19.70 & 1 & 4.3 & 21.50 & 1 & 5.9 & & & \\
\hline 21.60 & 1 & 4.3 & 21.70 & 1 & 5.9 & & & \\
\hline 21.70 & 1 & 4.3 & 22.70 & 1 & 5.9 & & & \\
\hline 22.00 & 1 & 4.3 & 22.80 & 1 & 5.9 & & & \\
\hline 22.40 & 1 & 4.3 & 23.50 & 1 & 5.9 & & & \\
\hline 22.70 & 1 & 4.3 & 23.90 & 1 & 5.9 & & & \\
\hline 22.80 & 2 & 8.7 & 24.10 & 1 & 5.9 & & & \\
\hline 23.50 & 1 & 4.3 & 24.40 & 1 & 5.9 & & & \\
\hline 23.90 & 1 & 4.3 & 24.60 & 1 & 5.9 & & & \\
\hline 24.40 & 1 & 4.3 & & & & & & \\
\hline 24.60 & 1 & 4.3 & & & & & & \\
\hline 25.20 & 1 & 4.3 & & & & & & \\
\hline 25.50 & 1 & 4.3 & & & & & & \\
\hline
\end{tabular}


Table D17. Post-Test Neck Strength Frequencies - Left Lateral Flexion (kg)

\begin{tabular}{|c|c|c|c|c|c|c|c|c|}
\hline \multicolumn{3}{|c|}{ Entire Sample $(\mathrm{n}=23)$} & \multicolumn{3}{|c|}{ Non-Injured $(\mathrm{n}=17)$} & \multicolumn{3}{|c|}{ Injured $(n=6)$} \\
\hline Measurement (kg) & Frequency $(\mathrm{n})$ & Percentage & Measurement (kg) & Frequency $(\mathrm{n})$ & Percentage & Measurement (kg) & Frequency $(\mathrm{n})$ & Percentage \\
\hline 20.00 & 1 & 4.3 & 20.00 & 1 & 5.9 & 21.90 & 1 & 16.7 \\
\hline 21.40 & 1 & 4.3 & 21.40 & 1 & 5.9 & 22.40 & 1 & 16.7 \\
\hline 21.90 & 1 & 4.3 & 22.40 & 1 & 5.9 & 23.60 & 1 & 16.7 \\
\hline 22.40 & 2 & 8.7 & 22.70 & 1 & 5.9 & 23.80 & 1 & 16.7 \\
\hline 22.70 & 1 & 4.3 & 23.10 & 1 & 5.9 & 28.80 & 1 & 16.7 \\
\hline 23.10 & 1 & 4.3 & 24.30 & 2 & 11.8 & 29.00 & 1 & 16.7 \\
\hline 23.60 & 1 & 4.3 & 24.70 & 2 & 11.8 & & & \\
\hline 24.30 & 2 & 8.7 & 25.70 & 1 & 5.9 & & & \\
\hline 24.70 & 2 & 8.7 & 25.80 & 2 & 11.8 & & & \\
\hline 25.40 & 1 & 4.3 & 26.90 & 1 & 5.9 & & & \\
\hline 25.70 & 1 & 4.3 & 27.10 & 1 & 5.9 & & & \\
\hline 25.80 & 2 & 8.7 & 27.60 & 1 & 5.9 & & & \\
\hline 26.90 & 1 & 4.3 & 31.70 & 1 & 5.9 & & & \\
\hline 27.10 & 1 & 4.3 & & & & & & \\
\hline 27.60 & 1 & 4.3 & & & & & & \\
\hline 29.00 & 1 & 4.3 & & & & & & \\
\hline 31.70 & 1 & 4.3 & & & & & & \\
\hline
\end{tabular}


Table D18. Pre-Test Neck Strength Frequencies - Right Lateral Flexion (kg)

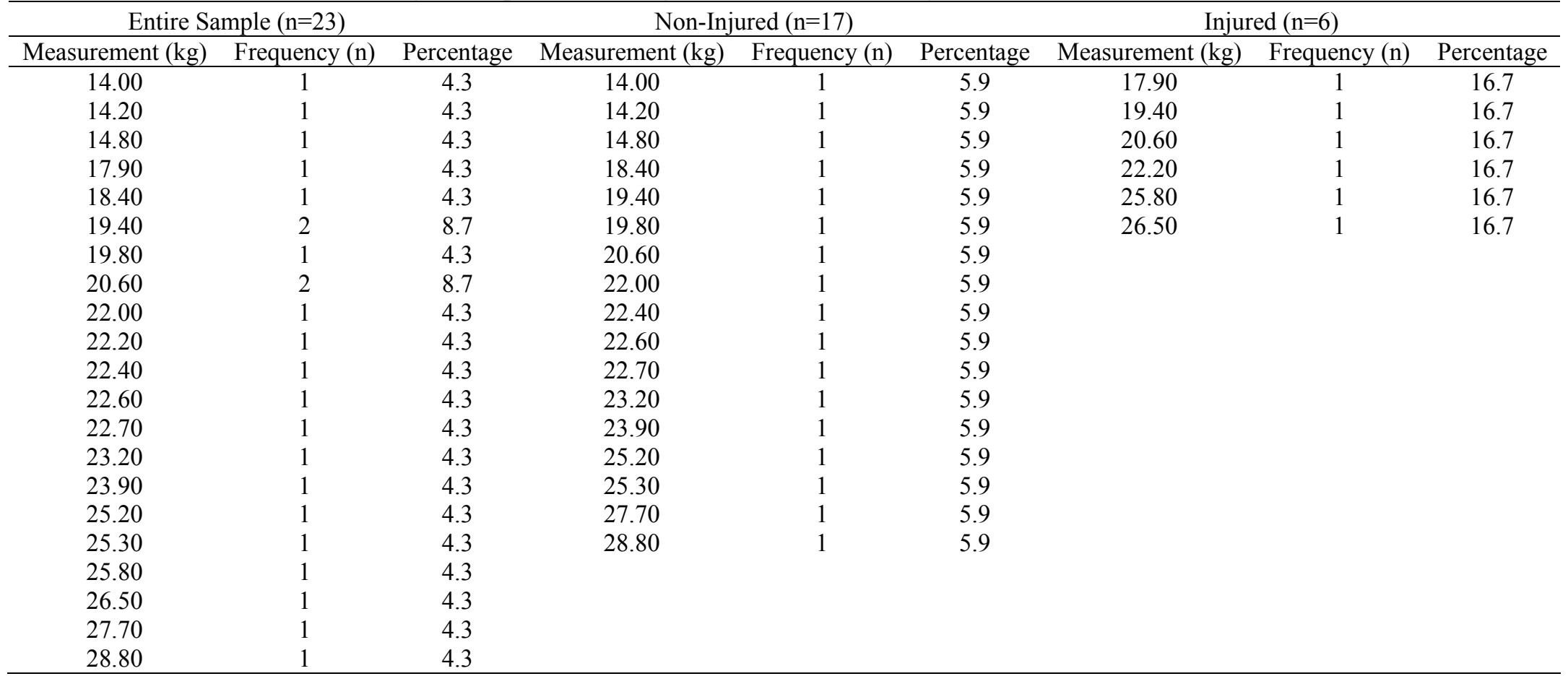


Table D19. Post-Test Neck Strength Frequencies - Right Lateral Flexion (kg)

\begin{tabular}{|c|c|c|c|c|c|c|c|c|}
\hline \multicolumn{3}{|c|}{ Entire Sample $(n=23)$} & \multicolumn{3}{|c|}{ Non-Injured $(n=17)$} & \multicolumn{3}{|c|}{ Injured $(n=6)$} \\
\hline Measurement (kg) & Frequency (n) & Percentage & Measurement (kg) & Frequency (n) & Percentage & Measurement $(\mathrm{kg})$ & Frequency $(\mathrm{n})$ & Percentage \\
\hline 17.80 & 1 & 4.3 & 17.80 & 1 & 5.9 & 19.20 & 1 & 16.7 \\
\hline 19.20 & 1 & 4.3 & 19.50 & 1 & 5.9 & 21.90 & 1 & 16.7 \\
\hline 19.50 & 1 & 4.3 & 22.30 & 1 & 5.9 & 25.70 & 1 & 16.7 \\
\hline 21.90 & 1 & 4.3 & 23.30 & 1 & 5.9 & 27.60 & 1 & 16.7 \\
\hline 22.30 & 1 & 4.3 & 24.10 & 1 & 5.9 & 27.90 & 1 & 16.7 \\
\hline 23.30 & 1 & 4.3 & 24.20 & 1 & 5.9 & 29.80 & 1 & 16.7 \\
\hline 24.10 & 1 & 4.3 & 24.70 & 1 & 5.9 & & & \\
\hline 24.70 & 1 & 4.3 & 25.50 & 2 & 11.8 & & & \\
\hline 25.00 & 1 & 4.3 & 25.90 & 1 & 5.9 & & & \\
\hline 25.50 & 2 & 8.7 & 26.00 & 2 & 11.8 & & & \\
\hline 25.70 & 1 & 4.3 & 27.70 & 1 & 5.9 & & & \\
\hline 25.90 & 1 & 4.3 & 28.50 & 1 & 5.9 & & & \\
\hline 26.00 & 2 & 8.7 & 30.40 & 1 & 5.9 & & & \\
\hline 27.60 & 1 & 4.3 & 30.90 & 1 & 5.9 & & & \\
\hline 27.70 & 1 & 4.3 & & & & & & \\
\hline 28.50 & 1 & 4.3 & & & & & & \\
\hline 29.80 & 1 & 4.3 & & & & & & \\
\hline 30.40 & 1 & 4.3 & & & & & & \\
\hline 30.90 & 1 & 4.3 & & & & & & \\
\hline
\end{tabular}


Table D20. Two-Way Repeated-Measures ANOVA Results for the Entire Sample ( $\mathrm{n}=23$ )

\begin{tabular}{|c|c|c|c|c|c|c|c|c|c|c|c|c|c|c|c|}
\hline & \multicolumn{5}{|c|}{ Time (Pre- and Post-Test) } & \multicolumn{5}{|c|}{ Occurrence of injury (yes or no) } & \multicolumn{5}{|c|}{ Interaction } \\
\hline & df & $F_{(d f)}$ & $\mathrm{P}$ & ES & $\begin{array}{c}\text { Observed } \\
\text { Power }\end{array}$ & df & $F_{(d f)}$ & $\mathrm{P}$ & ES & $\begin{array}{c}\text { Observed } \\
\text { Power }\end{array}$ & df & $F_{(d f)}$ & $\mathrm{P}$ & ES & $\begin{array}{c}\text { Observed } \\
\text { Power }\end{array}$ \\
\hline Forward & & & & & & & & & & & & & & & \\
\hline Flexion & 1 & 4.14 & 0.055 & 0.165 & 0.493 & 1 & 0.224 & 0.641 & 0.011 & 0.074 & 1 & 1.252 & 0.276 & 0.056 & 0.188 \\
\hline $\begin{array}{l}\text { Extension } \\
\text { Left Lateral }\end{array}$ & 1 & 2.377 & 0.138 & 0.102 & 0.313 & 1 & 1.673 & 0.21 & 0.074 & 0.235 & 1 & 0.239 & 0.63 & 0.011 & 0.075 \\
\hline $\begin{array}{l}\text { Flexion } \\
\text { Right Lateral }\end{array}$ & 1 & 13.318 & $0.001^{*}$ & 0.388 & 0.935 & 1 & 0.522 & 0.478 & 0.024 & 0.106 & 1 & 1.069 & 0.313 & 0.048 & 0.167 \\
\hline Flexion & 1 & 12.938 & $0.002^{*}$ & 0.381 & 0.929 & 1 & 0.068 & 0.797 & 0.003 & 0.057 & 1 & 0.039 & 0.845 & 0.002 & 0.054 \\
\hline Neck Girth & 1 & 0.017 & 0.898 & 0.001 & 0.052 & 1 & 0.837 & 0.371 & 0.038 & 0.141 & 1 & 0.219 & 0.645 & 0.01 & 0.073 \\
\hline
\end{tabular}

* A significant main effect was noted at $\mathrm{P}<.05$.

$* * \mathrm{df}=$ degrees of freedom, $\mathrm{P}$-value is significant at $\mathrm{P}<.05, \mathrm{ES}=$ effect size

Table D21. Two-Way Repeated-Measures ANOVA Results For the Starters $(n=9)$

\begin{tabular}{|c|c|c|c|c|c|c|c|c|c|c|c|c|c|c|c|}
\hline & \multicolumn{5}{|c|}{ Time (Pre- and Post-Test) } & \multicolumn{5}{|c|}{ Occurrence of injury (yes or no) } & \multicolumn{5}{|c|}{ Interaction } \\
\hline & df & $F_{(d f)}$ & $\mathrm{P}$ & ES & $\begin{array}{l}\text { Observed } \\
\text { Power }\end{array}$ & $\mathrm{df}$ & $F_{(d f)}$ & $\mathrm{P}$ & ES & $\begin{array}{c}\text { Observed } \\
\text { Power }\end{array}$ & df & $F_{(d f)}$ & $\mathrm{P}$ & ES & $\begin{array}{l}\text { Observed } \\
\text { Power }\end{array}$ \\
\hline Forward & & & & & & & & & & & & & & & \\
\hline $\begin{array}{l}\text { Flexion } \\
\text { Extension } \\
\text { Left Lateral }\end{array}$ & $\begin{array}{l}8 \\
8\end{array}$ & $\begin{array}{l}1.306 \\
1.108\end{array}$ & $\begin{array}{l}0.269 \\
0.378\end{array}$ & $\begin{array}{l}0.207 \\
0.181\end{array}$ & $\begin{array}{r}0.517 \\
0.44\end{array}$ & $\begin{array}{l}1 \\
1\end{array}$ & $\begin{array}{l}4.104 \\
1.555\end{array}$ & $\begin{array}{l}0.099 \\
0.268\end{array}$ & $\begin{array}{l}0.451 \\
0.237\end{array}$ & $\begin{array}{l}0.376 \\
0.175\end{array}$ & $\begin{array}{l}8 \\
8\end{array}$ & $\begin{array}{l}1.273 \\
1.472\end{array}$ & $\begin{array}{l}0.285 \\
0.198\end{array}$ & $\begin{array}{l}0.203 \\
0.227\end{array}$ & $\begin{array}{l}0.504 \\
0.577\end{array}$ \\
\hline $\begin{array}{l}\text { Flexion } \\
\text { Right Lateral }\end{array}$ & 8 & 1.928 & 0.082 & 0.278 & 0.72 & 1 & 2.806 & 0.155 & 0.359 & 0.276 & 8 & 0.992 & 0.457 & 0.165 & 0.394 \\
\hline Flexion & 8 & 2.095 & 0.059 & 0.295 & 0.763 & 1 & 3.013 & 0.143 & 0.376 & 0.293 & 8 & 0.493 & 0.854 & 0.09 & 0.198 \\
\hline
\end{tabular}

** $\mathrm{df}=$ degrees of freedom, $\mathrm{P}$-value is significant at $\mathrm{P}<.05, \mathrm{ES}=$ effect size 
Table D22. Independent t-test Results

\begin{tabular}{llllll}
\hline & \multicolumn{1}{c}{ Injured $(\mathrm{n}=6)$} & \multicolumn{1}{c}{ Non-Injured $(\mathrm{n}=17)$} & & & \\
\cline { 2 - 6 } & \multicolumn{1}{c}{$\mathrm{M} \pm \mathrm{SD}$} & \multicolumn{1}{c}{$\mathrm{M}+\mathrm{SD}$} & $\mathrm{P}$ & $\mathrm{d}$ & $\mathrm{r}$ \\
\hline Number of years wrestling & $15.00 \pm 3.03$ & $12.21 \pm 4.39$ & 0.17 & 0.74 & 0.35 \\
Head-neck segment & $6.44 \pm 0.75$ & $6.05 \pm 1.20$ & 0.47 & 0.39 & 0.19 \\
Head-neck length & $31.83 \pm 3.96$ & $30.79 \pm 1.97$ & 0.41 & 0.33 & 0.16 \\
Neck girth & $40.42 \pm 2.35$ & $39.29 \pm 2.14$ & 0.29 & 0.5 & 0.24 \\
Previous history & $1.17 \pm 1.17$ & $0.59 \pm 0.87$ & 0.21 & 0.56 & 0.27 \\
\hline
\end{tabular}

* P-value $<.05, \mathrm{~d}=$ Cohen's $\mathrm{d}, \mathrm{r}=$ effect size

Table D23. Crosstabulation Results (Previous History * Occurrence)

\begin{tabular}{cccc} 
& & \multicolumn{2}{c}{ Previous History } \\
\cline { 3 - 4 } & & Yes & No \\
\cline { 3 - 4 } Occurrence & Yes & $66.7 \%(\mathrm{n}=4)$ & $33.3 \%(\mathrm{n}=2)$ \\
of BPN & No & $41.2 \%(\mathrm{n}=7)$ & $58.8 \%(\mathrm{n}=10)$ \\
\hline
\end{tabular}

Table D24. Crosstabulation Results (Previous History * Occurrence this season)

\begin{tabular}{cccc} 
& & \multicolumn{2}{c}{ Previous History } \\
\cline { 3 - 4 } & & Yes & No \\
\cline { 3 - 4 } Occurrence & None & $63.6 \%$ & $83.3 \%$ \\
of BPN for & $1-2$ occurrences & $9.1 \%$ & $16.7 \%$ \\
the season & 10 or more occurrences & $27.3 \%$ & $0 \%$ \\
\hline
\end{tabular}


Figure D1. Neck Strength Measurements in the Direction of Forward Flexion Throughout the 2005-2006 Wrestling Season Between Wrestlers Injured by a Brachial Plexus Neuropathy (BPN) and Those Not Injured.

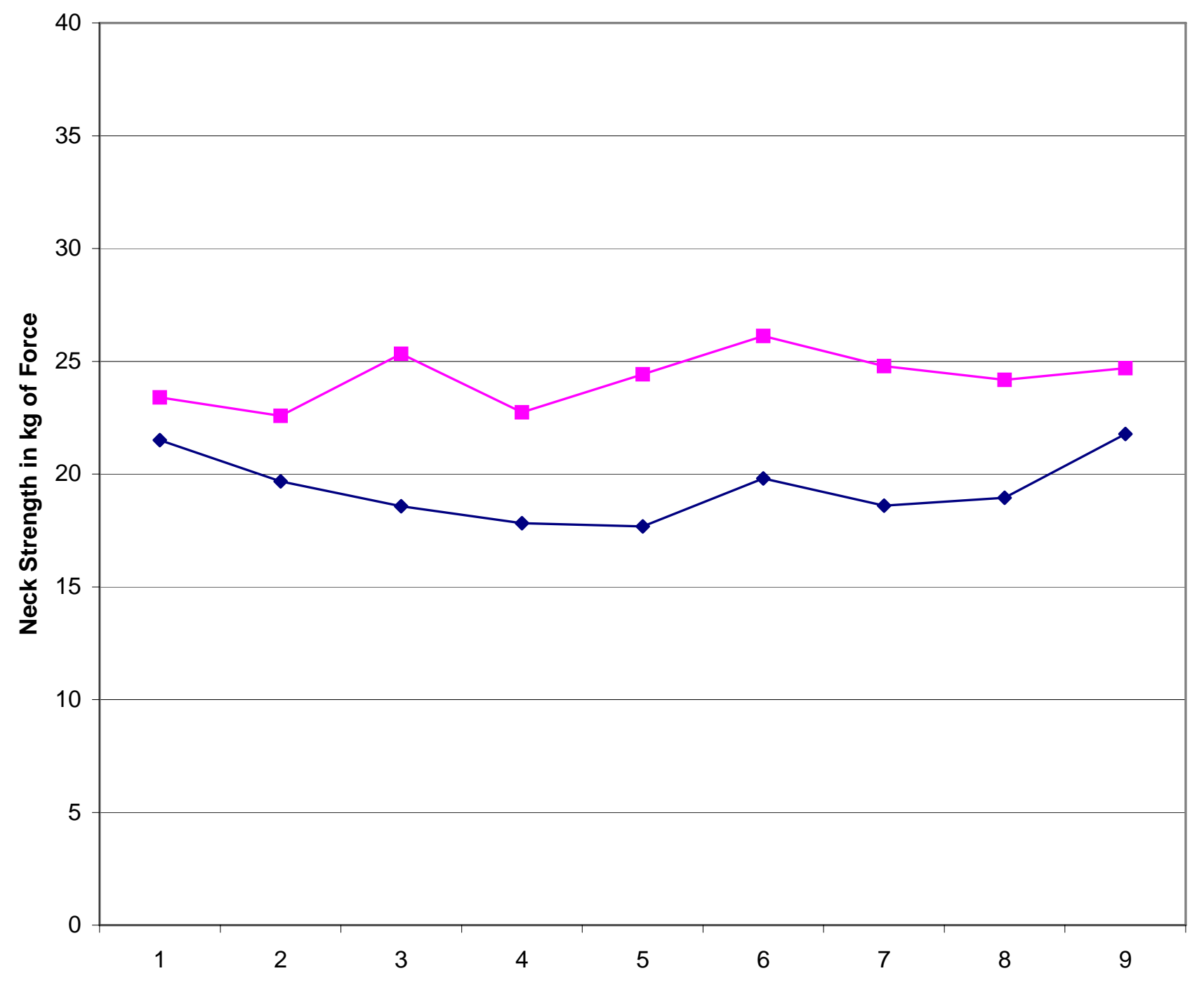
for Non-Injured starters has only 3 rather than 5 subjects due to 2 subjects missing the measurement.

*Time point 1 is pre-test data and time point 9 is post-test data. 
Figure D2. Neck Strength Measurements in the Direction of Extension Throughout the 20052006 Wrestling Season Between Wrestlers Injured by a Brachial Plexus Neuropathy (BPN) and Those Not Injured.

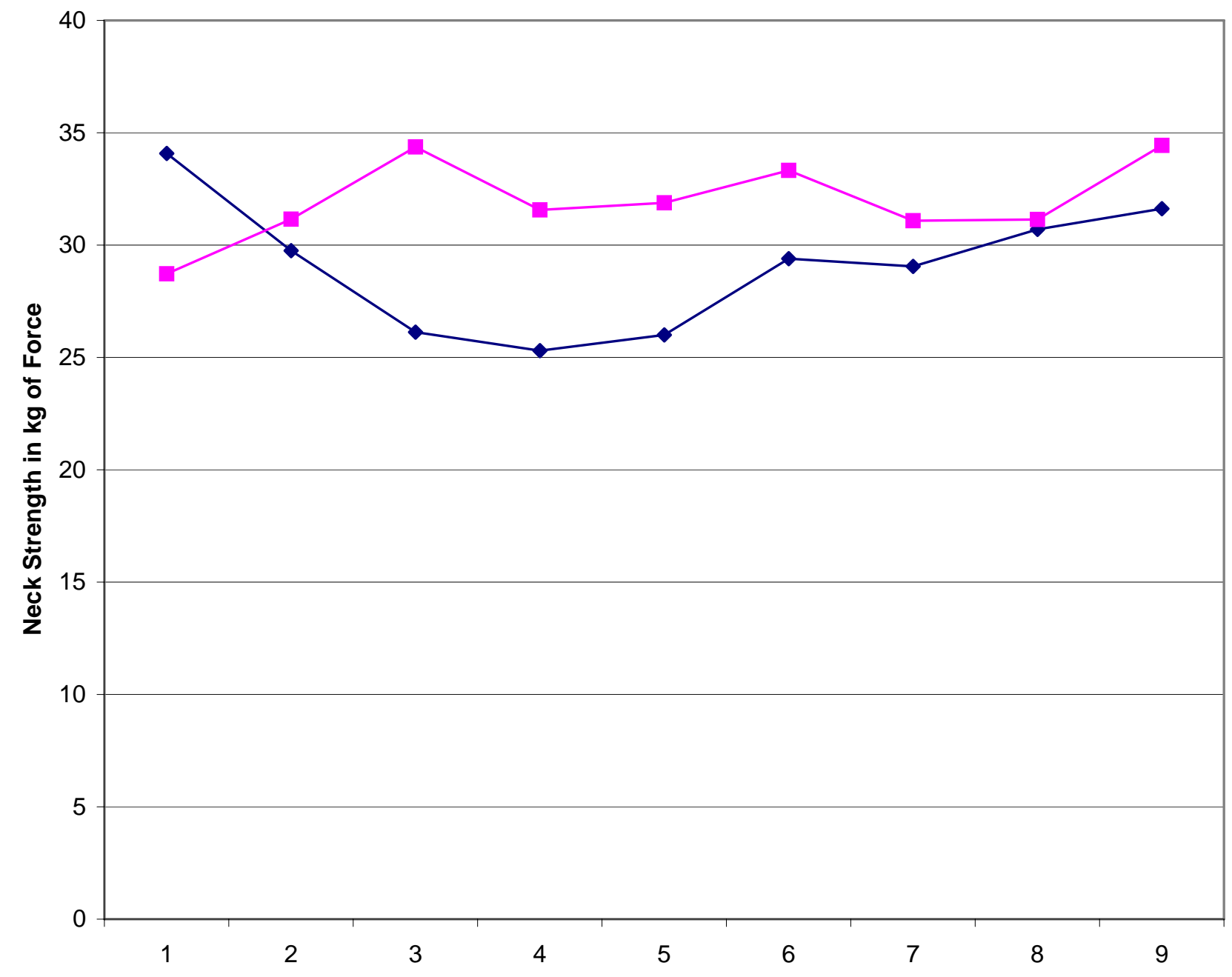

Starters injured by BPN

Starters not injured by BPN

*Measurement point $3 \&$ 7 for Non-Injured starters has only 3 rather than 5 subjects due to 2 subjects missing the measurement.

*Time point 1 is pre-test data and time point 9 is post-test data. 
Figure D3. Neck Strength Measurements in the Direction of Left Lateral Flexion Throughout the 2005-2006 Wrestling Season Between Wrestlers Injured by a Brachial Plexus Neuropathy (BPN) and Those Not Injured.

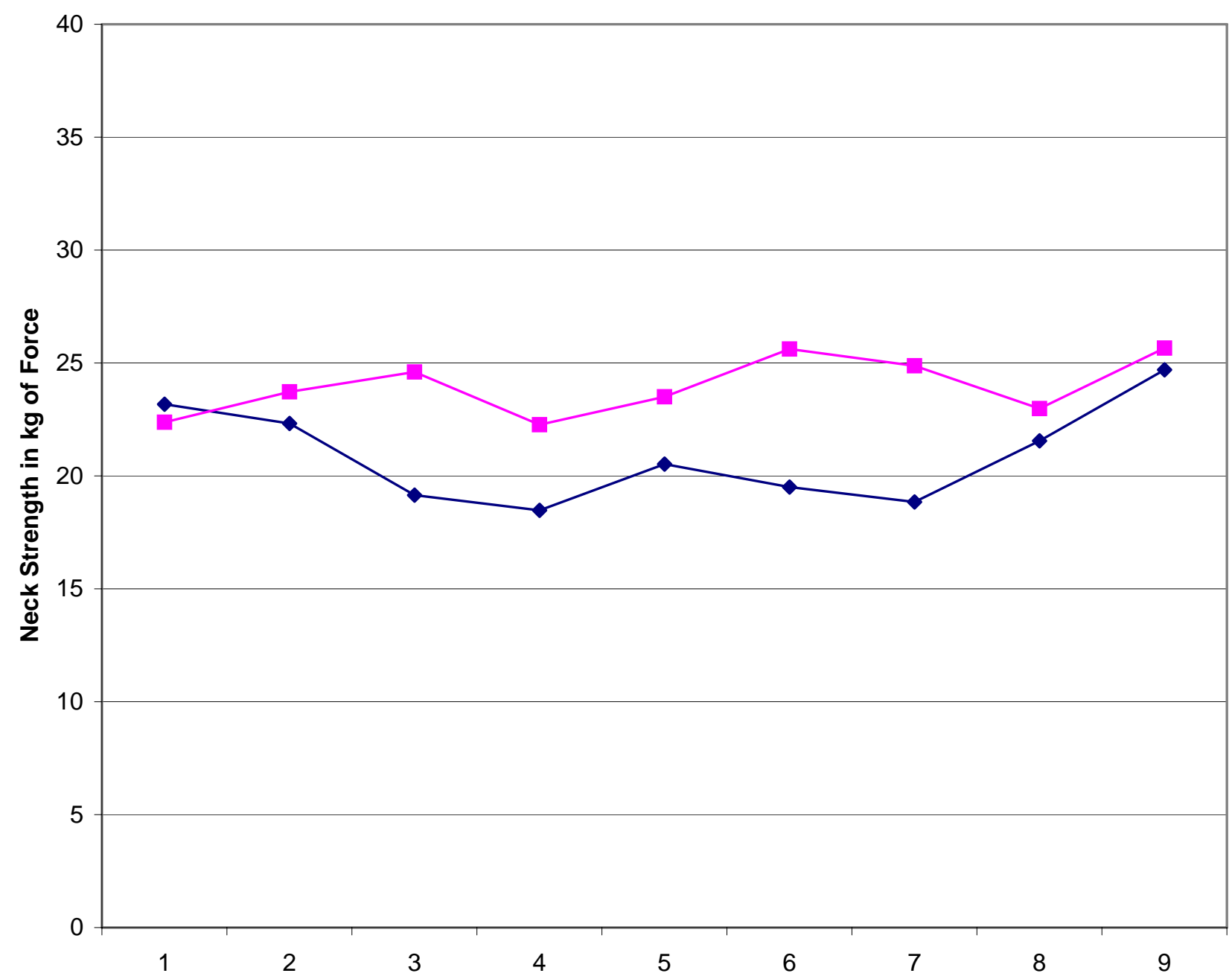

Starters injured by BPN Starters not injured by BPN

*Measurement point $3 \& 7$ for Non-Injured starters has only 3 rather than 5

subjects due to 2 subjects missing the measurement.

*Time point 1 is pre-test data and time point 9 is post-test data. 
Figure D4. Neck Strength Measurements in the Direction of Right Lateral Flexion Throughout the 2005-2006 Wrestling Season

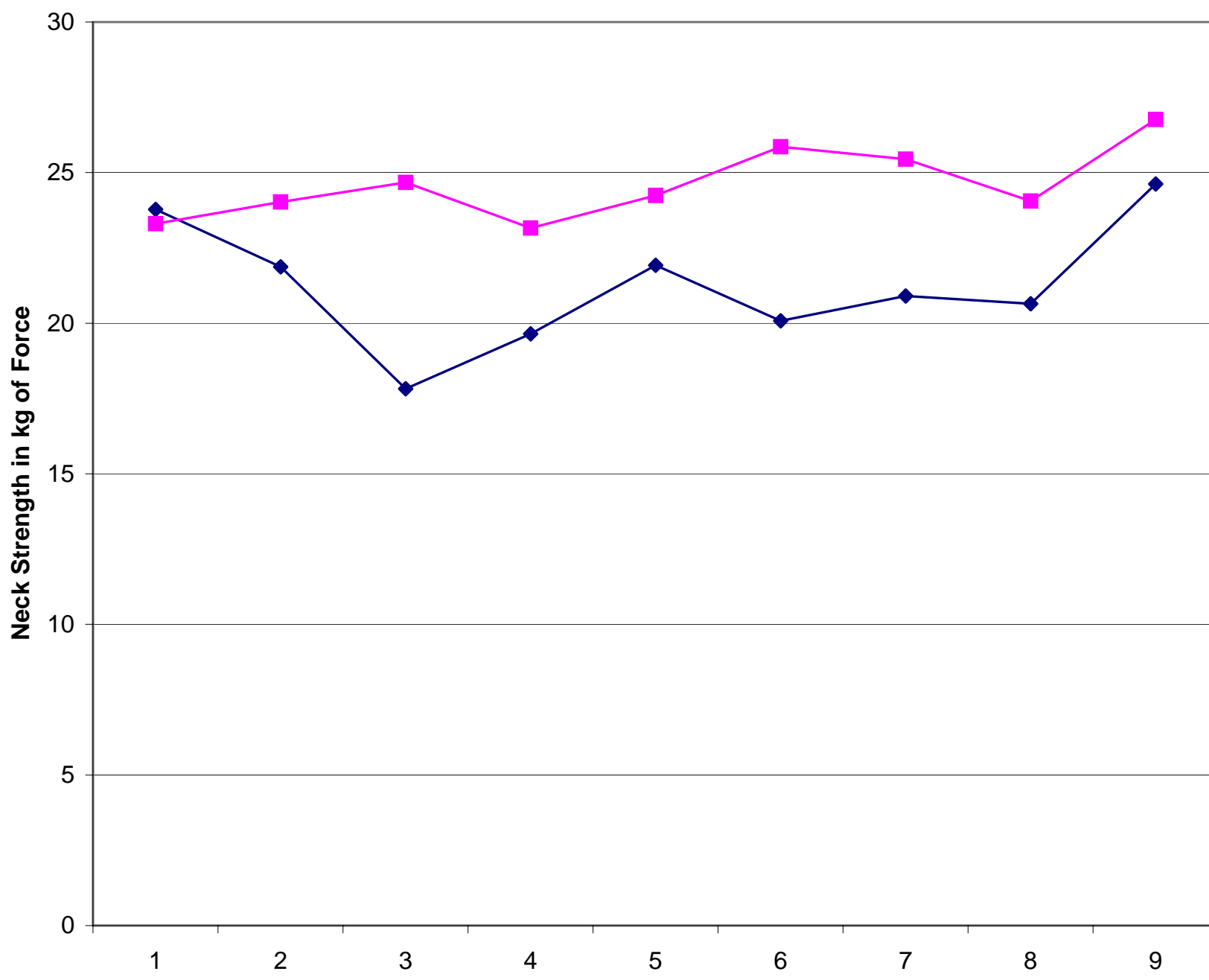

Starters injured by BPN

Starters not injured by BPN

Measurement point $3 \& 7$ for Non-Injured starters has only 3 rather than 5 subjects due to 2 subjects missing the measurement.

*Time point 1 is pre-test data and time point 9 is post-test data. 
Figure D5. Pre-Dual Match Neck Strength Measurements of a Wrestler That Experienced Multiple Incidents of Brachial Plexus Neuropathy Throughout the 2005-2006 Wrestling Season

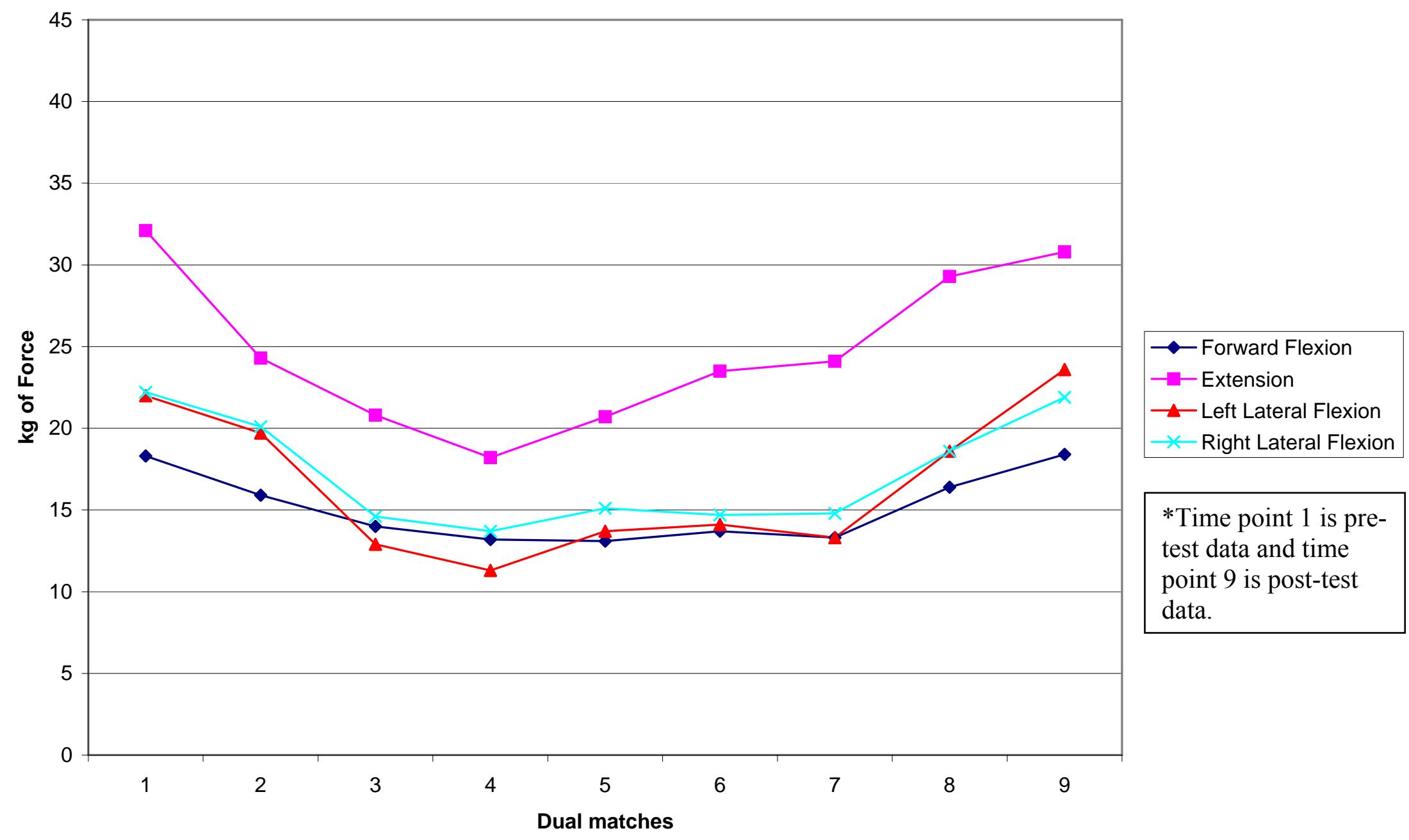


Figure D6. Pre-Dual Match Neck Strength Measurements of a Wrestler that did not Experience any Incidents of Brachial Plexus Neuropathy Throughout the 2005-2006 Wrestling Season

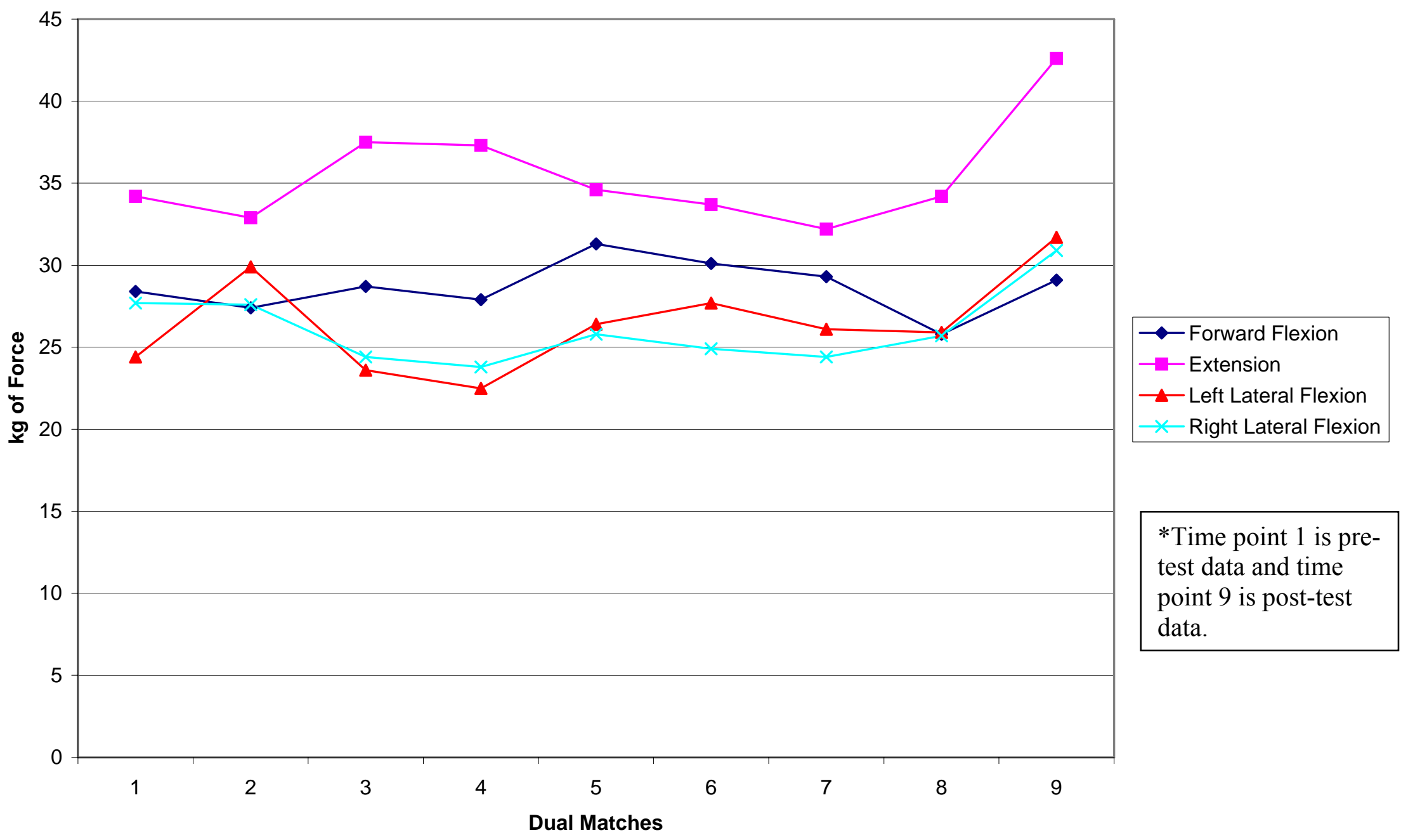




\section{APPENDIX E}

\section{RECOMMENDATIONS FOR FUTURE RESEARCH}

1. Increase the sample size of the subjects. When a Pearson's correlation and/or t-test are performed, a sample size of 23 or greater may be necessary to increase the statistical power of the study. A higher possibility of statistical significance may occur when power is higher.

2. Collect repeated measures data for all subjects rather than just the "Starters." This would have increased the sample size for the repeated-measures ANOVA from nine to twentythree subjects in this study. If combined with other teams, the power may be great enough the see effects and comparisons may be made between subjects for the different subject groups.

3. Athletes from other colleges/universities should be included. Different institutions stress different styles of wrestling that may lead to a different rate of injury. This would also further increase sample size lending to greater power and an increased possibility of seeing effects.

4. Examination between weight classes may provide more clear information about the sample of wrestlers that may be more susceptible to brachial plexus neuropathies.

5. Strength measurements should all be standardized by collecting the measurements at the same time each day to avoid variability in strength measurements as well as eliminating the possibility of fatigue in the subjects.

6. To avoid measurement variability that may arise from utilizing a single examiner when collecting measurements, the subjects should be staggered to eliminate the possibility of fatigue on the part of the examiner.

7. Studying muscle preactivation of the neck musculature may demonstrate the importance of head-neck segment stabilization in prevention of injury. 


\section{ADDITIONAL REFERENCES}

37. Myers BS, Winkelstein BA. Epidemiology, classification, mechanism, and tolerance of human cervical spine injuries. Crit Rev Biomech Engin. 1995;23(5\&6):307-409.

38. Morganti C. Recommendations for return to sports following cervical spine injuries. Sports Med. 2003;33(8):563-73.

39. Levangie PK, Norkin CC. Joint Structure and Function: A Comprehensive Analysis. $3^{\text {rd }}$ Ed.. Philadelphia: F.A. Davis Company, 2001:113-169.

40. Cantu RC. The cervical spinal stenosis controversy. Clin Sports Med. 1998;17(1):121-6.

41. Yoganandan N, Kumasan S, Pintar FA. Biomechanics of the cervical spine Part 2. Cervical spine soft tissue responses and biomechanical modeling. Clin Biomech. 2001;16(1):1-27.

42. Agur A, Lee M. Grant's Atlas of Anatomy. $10^{\text {th }}$ Ed.. Philadelphia: Lippincott Williams \& Wilkins, 1999: 639-702.

43. Ferenz CC. Review of the brachial plexus part I: Acute injuries. Orthopedics. 1988;11(3):479-86.

44. Marieb EN. Human Anatomy \& Physiology: fifth edition. Benjamin Cummings. San Fransisco. 2001; 495-497.

45. Sauerland EK. Grant's Dissector; twelfth edition. Lippincott Williams \& Wilkins. 1999; 194196.

46. Bogduk N, Mercer S. Biomechanics of the cervical spine. I: Normal kinematics. Clin Biomech. 2000;15(9):633-48.

47. White AA, III and Panjabi MM. Clinical Biomechanics of the Spine. 2nd Ed. Philadelphia: JB Lippincott Company, 1990.

48. Veleanu C. Vertebral structural peculiarities with a role in the cervical spine mechanics. Folia Morphologica. 1971;19(4):388-93.

49. Pal GP, Sherk HH. The vertical stability of the cervical spine. Spine. 1988;13(5):447-49.

50. Werne S. Studies in spontaneous atlas dislocation. Acta Orthop. Scand. 1957;S23:1-150.

51. Harris MB, Duval MJ, Davis JA, Jr., Bernini PM. Anatomical and roentgenographic features of atlantooccipital instability. J. Spinal Disord. 1993;6(1):5-10.

52. Dvorak J, Schneider E, Saldinger P, Rahn B. Biomechanics of the craniocervical region: the alar and transverse ligaments. J Orthop. Res. 1988;6(3):452-61. 
53. Fielding JW. Normal and selected abnormal motion of the cervical spine from the second cervical vertebra to the seventh cervical vertebra based on cineroentgenography. J. Bone Joint Surg. 1964;46A(8):1779-81.

54. Crisco JJ, III, Oda T, Panjabi MM, Bueff HU, Dvorak J, Grob D. Transections of the C1-C2 joint capsular ligaments in the cadaveric spine. Spine. 1991;16(10):S474-79.

55. Shannon B, Klimkiewicz JJ. Cervical burners in the athlete. Clin Sports Med. 2002;21(1):2935 , vi.

56. Torg JS. Cervical spinal stenosis with cord neurapraxia and transient quadriplegia. Clin Sports Med. 1990;9(2):279-96.

57. Krivickas LS, Wilbourn AJ. Peripheral nerve injuries in athletes: a case series of over 200 injuries. Semin Neurol. 2000;20(2):225-32.

58. Requa R, Garrick JG. Injuries in interscholastic wrestling. Phys Sportsmed. 1981;9(4):44-49.

59. Wu WQ, Lewis RC. Injuries of the cervical spine in high school wrestling. Surg Neurol. $1985 ; 23(2): 143-7$.

60. Jarrett GJ, Orwin JF, Dick RW. Injuries in collegiate wrestling. Am J Sports Med. 1998;26:674-680.

61. Boden BP, Lin W, Young M, Mueller FO. Catastrophic injuries in wrestlers. Am J Sports Med. 2002;30(6):791-5.

62. Wroble RR, Albright JP. Neck and low back injuries in wrestling. Clin Sports Med. 1986;5(2):295-325.

63. Cantu RC. Cervical spine injuries in the athlete. Semin Neurol. 2000;20(2):173-8.

64. Torg JS, Vegso JJ, O'Neill MJ, Sennett B. The epidemiologic, pathologic, biomechanical, and cinematographic analysis of football-induced cervical spine trauma. Am J Sports Med. 1990;18(1):50-7.

65. Smith MG, Fulcher M, Shanklin J, Tillett ED. The prevalence of congenital cervical spinal stenosis in 262 college and high school football players. J Ky Med Assoc. 1993;91(7):273-5.

66. Boockvar JA, Durham SR, Sun PP. Cervical spinal stenosis and sports-related cervical cord neurapraxia in children. Spine. 2001;26(24):2709-12; discussion 2713.

67. Yue WM, Tan SB, Tan MH, Koh DC, Tan CT. The Torg--Pavlov ratio in cervical spondylotic myelopathy: a comparative study between patients with cervical spondylotic myelopathy and a nonspondylotic, nonmyelopathic population. Spine. 2001;26(16):1760-4. 
68. Pavlov H, Torg JS, Robie B, Jahre C. Cervical spinal stenosis: determination with vertebral body ratio method. Radiology. 1987;164(3):771-5.

69. Odor JM, Watkins RG, Dillin WH, Dennis S, Saberi M. Incidence of cervical spinal stenosis in professional and rookie football players. Am J Sports Med. 1990;18(5):507-9.

70. Herzog RJ, Wiens JJ, Dillingham MF, Sontag MJ. Normal cervical spine morphometry and cervical spinal stenosis in asymptomatic professional football players. Plain film radiography, multiplanar computed tomography, and magnetic resonance imaging. Spine. 1991;16(6 Suppl):S178-86.

71. Chiu TT, Lam TH, Hedley AJ. Maximal isometric muscle strength of the cervical spine in healthy volunteers. Clin Rehabil. 2002;16(7):772-9.

72. Silverman JL, Rodriquez AA, and Agre JC. Quantitative cervical flexor strength in healthy subjects and in subjects with mechanical neck pain. Arch Phys Med Rehabil. 1991; 72: 679681.

73. Seng KY, Lee Peter VS, Lam PM. Neck muscle strength across the sagittal and coronal planes: an isometric study. Clin Biomech. 2002;17(7):545-7. 